\title{
BACTERIAL GROWTH ON METAL AND NON-METAL SURFACES IN A STATIC BIOREACTOR
}

\author{
A Thesis \\ presented to \\ the Faculty of California Polytechnic State University, \\ San Luis Obispo
}

\author{
In Partial Fulfillment \\ of the Requirements for the Degree \\ Master of Science in Biomedical Engineering \\ by \\ Rolan Yuk Loong Liong \\ March 2013
}


(C) 2013

Rolan Yuk Loong Liong

ALL RIGHTS RESERVED 


\section{COMMITTEE MEMBERSHIP}

TITLE:

AUTHOR:

DATE SUBMITTED:

COMMITTEE CHAIR:

COMMITTEE MEMBER:

COMMITTEE MEMBER:
Bacterial Growth on Metal and Non-Metal Surfaces in a

Static Bioreactor

Rolan Yuk Loong Liong

March 2013
Dr. Daniel W. Walsh, Ph.D., Professor

Biomedical and General Engineering Department

California Polytechnic State University, San Luis Obispo

Dr. Lanny Griffin, Ph.D., Department Chair Biomedical and General Engineering Department California Polytechnic State University, San Luis Obispo

Dr. Robert Szlavik, Ph.D., Associate Professor Biomedical and General Engineering Department California Polytechnic State University, San Luis Obispo 


\begin{abstract}
Bacterial Growth on Metal and Non-Metal Surfaces in a Static Bioreactor

By

Rolan Yuk Loong Liong
\end{abstract}

Research was conducted to observe bacterial growth on the surface of metals in a static bioreactor. Metal and non-metal samples were subjected to bacterial exposure (1 day and 9 days). The metal samples were surface treated prior to bacterial exposure. The microstructures of the surface treated samples were analyzed by optical microscopy. After exposure, the microstructures of the samples were analyzed by scanning electron microscopy (SEM). The analysis suggested that microbial attachment on the surface was related to the underlying microstructure of steel. The preferential attachment of microbes could potentially be influenced by cathodic and anodic regions created by the electrolytic cells.

Keywords: bacterial growth, scanning electron microscopy (SEM), static bioreactor, steel, stainless steel, biofilms, microbes, microbial attachments, polystyrene 


\section{ACKNOWLEDGMENTS}

I would like to thank my family for always supporting and encouraging me to pursue higher education. I greatly appreciate all the sacrifices that were made to make this opportunity possible for me. I would also like to thank Moonyeen Emerson for mentorship and inspiration. Without your encouragement, I would not have striven to journey further in my educational path. Dr. Szlavik, thank you for your guidance and support. Without you, I would have missed out on this wonderful opportunity in joining Cal Poly's 4+1 program. Dr. Griffin, thank you for your guidance and ideas. You gave me guidance at times when I am unsure of which direction to take in my research. Most of all, Dr. Daniel W. Walsh, I would like to thank you for giving me this great opportunity to research in this fascinating topic. It is you who made this research possible. I would like to dedicate this thesis to my family and friends, without them I would not be able to pursue my education at Cal Poly. 


\section{TABLE OF CONTENTS}

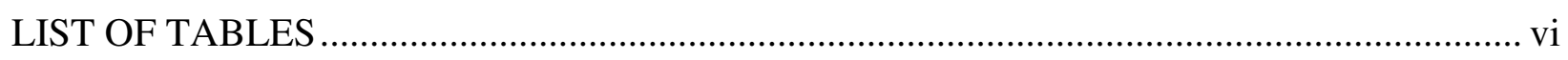

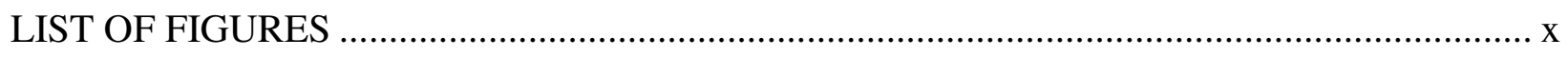

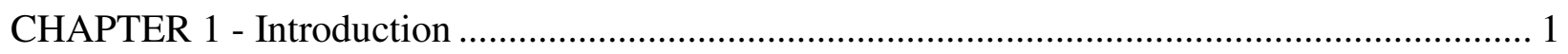

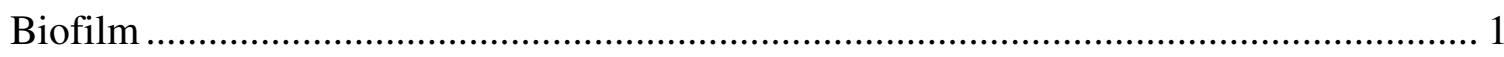

Examples of Biofilm Damage .................................................................................. 4

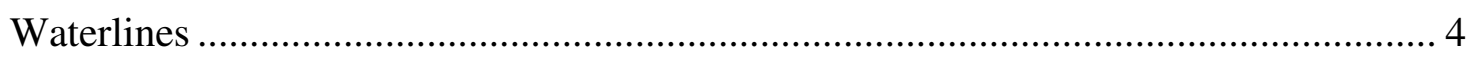

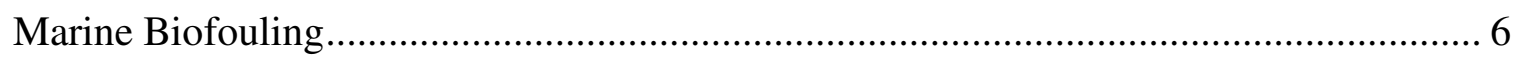

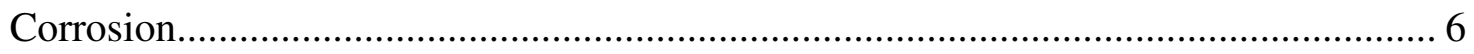

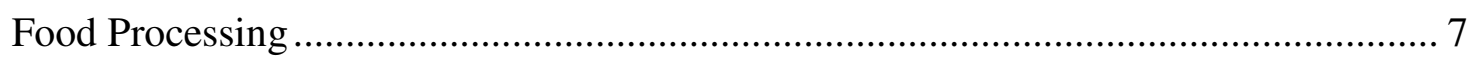

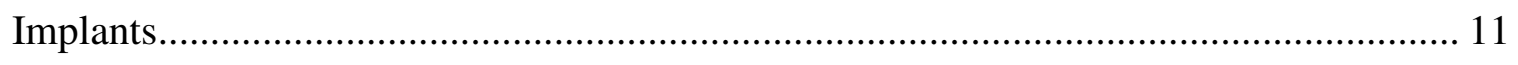

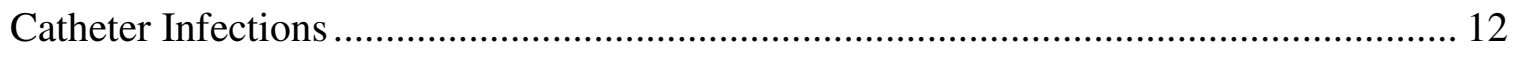

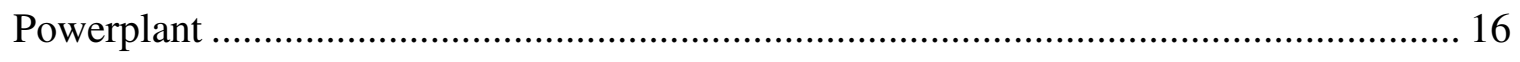

Process of Implant Infecting In the Body …………………..................................... 21

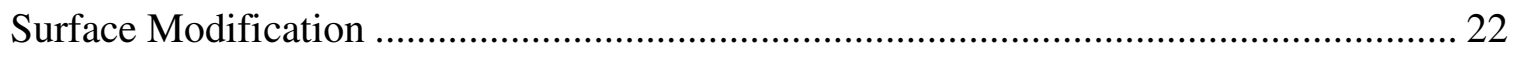

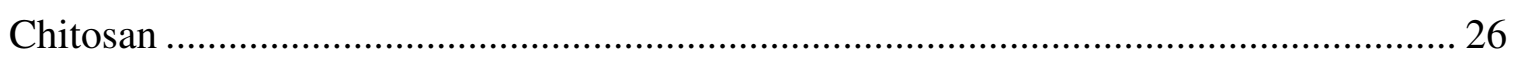

CM-Chitosan Can Potentially Serve As An Antibiofilm Agent ................................... 27

HACC Prevents Biofilm Formation On Titanium Surface .............................................. 30

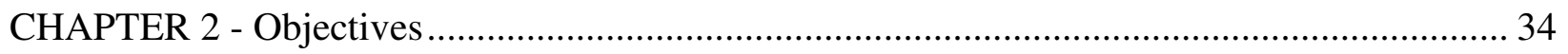

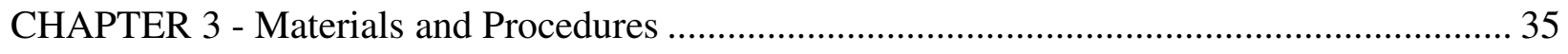

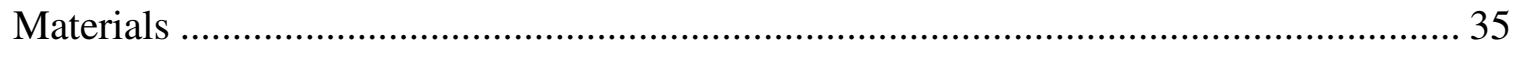

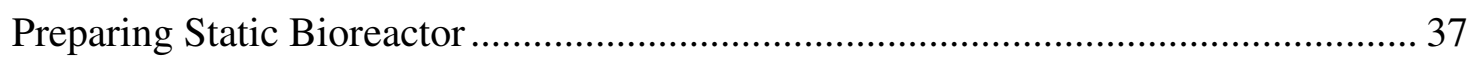


Preparing and Characterizing Sample for Pre-Exposure ....................................... 38

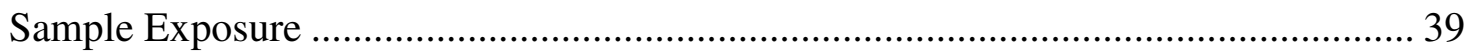

Post Exposure - Sample Characterization \& Imaging ......................................... 39

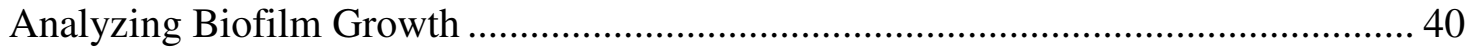

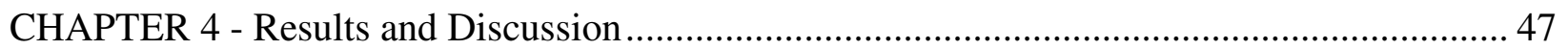

Pre - Exposure Inspection - Optical Light Microscopy...................................... 47

Samples Sanded To 600 Grit ................................................................ 47

Samples Polished From $6 \mu \mathrm{m}$ to $1 \mu \mathrm{m}$..................................................... 50

Post Exposure Inspection - Scanning Electron Microscope (SEM) Examination .... 66

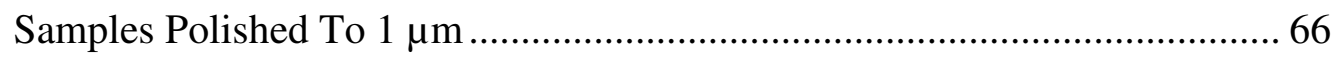

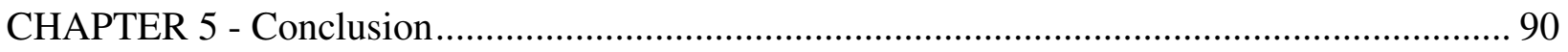

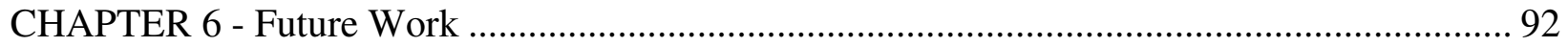

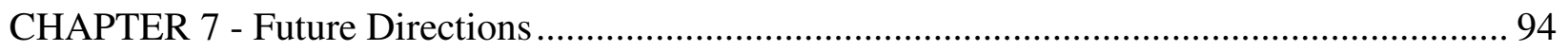

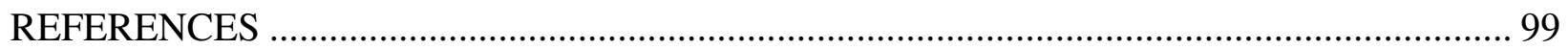

APPENDIX A - List of Materials Used.......................................................................... 106

APPENDIX B - Fixing Microbe Procedure ...................................................................... 107

APPENDIX C - Scanning Electron Microscope (SEM) Procedure ........................................ 109

APPENDIX D - Protocols and Experimental Procedures ................................................ 110

Bakelite Mount Procedure ..................................................................................... 110

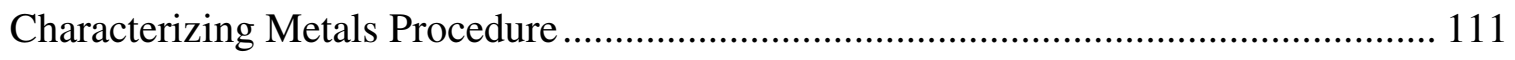

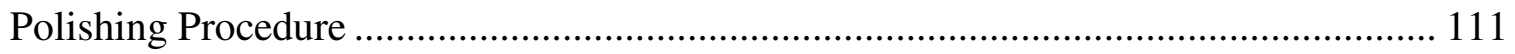

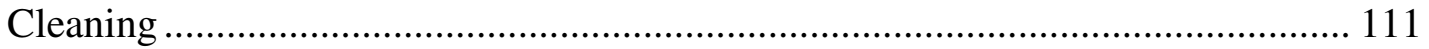


6 Microns Polish ..................................................................................... 112

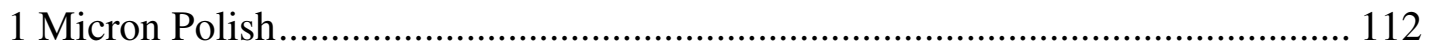

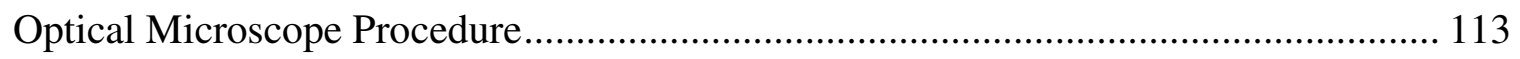

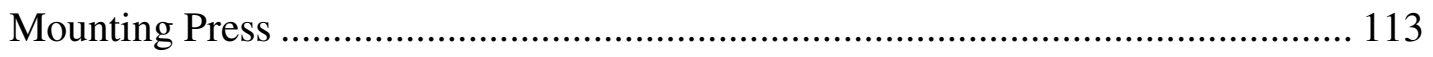

Examining Through Microscope ….......................................................... 113

APPENDIX E - Etching Procedures .............................................................................. 114

Etching Procedure for Stainless Steel ............................................................. 114

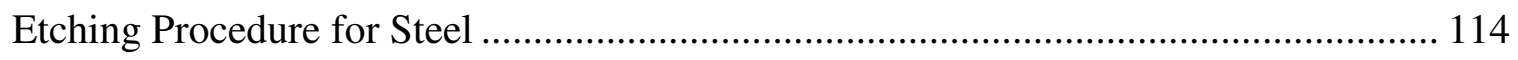

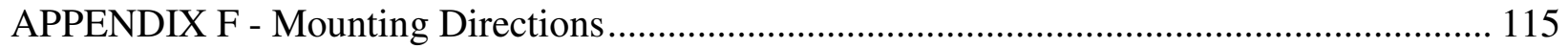




\section{LIST OF TABLES}

Table

Page

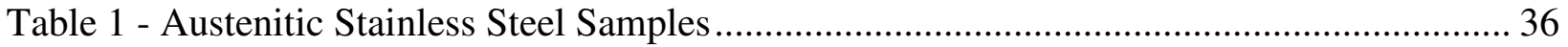

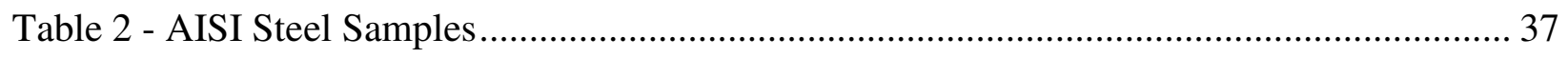

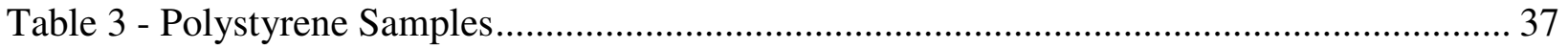

Table 4 - List of Materials Used In This Thesis ..................................................................... 106 


\section{LIST OF FIGURES}

Figure

Page

Figure 1 - Staphylococcus aureus biofilm. ...................................................................... 2

Figure 2 - Model of biofilm development........................................................................... 3

Figure 3 - General model for biofilm formation by motile bacteria ..................................... 9

Figure 4 - Pathogenesis of biofilm formation on urinary catheters ...................................... 14

Figure 5 - Virulence factors of uropathogens. ............................................................. 15

Figure 6 - A flow blockage of tubular heat exchangers...................................................... 19

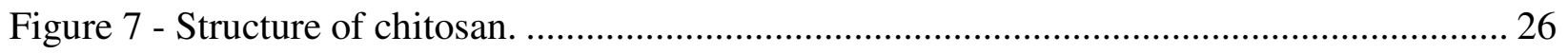

Figure 8 - CLSM images of biofilm formations without (left) or with (right) CM-chitosan........ 28

Figure 9 - CLSM images of biofilm formations without (left) or with (right) CM-chitosan....... 28

Figure 10 - Light microscopy images of the initial adhesion of (A) S. aureus RN6390 or (B)

P. aeruginosa PAO1 attached on the surfaces without (left) or with (right) CM-chitosan ..... 29

Figure 11 - Scanning electron micrographs of biofilms formed by $S$. epidermidis strain ATCC 35984 incubated on a titanium surface for $24 \mathrm{~h}$ with HACC $6 \%$ (a), 18\% (b), or $44 \%$ (c) at the following concentrations: $0 \_\mathrm{g} / \mathrm{ml}, 4 \_\mathrm{g} / \mathrm{ml}(1), 32 \_\mathrm{g} / \mathrm{ml}(2)$, $64 \_\mathrm{g} / \mathrm{ml}$ (3), 128 _g/ml (4), or $256 \_\mathrm{g} / \mathrm{ml}$ (5). Magnification, _3,000. Scale bars, 5 _m..... 31

Figure 12 - Bacteria were stained with green fluorescent SYTO 9 and red fluorescent propidium iodide, resulting in live cells appearing green and dead cells appearing red under CLSM.

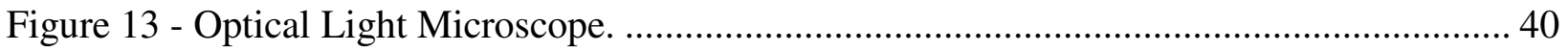

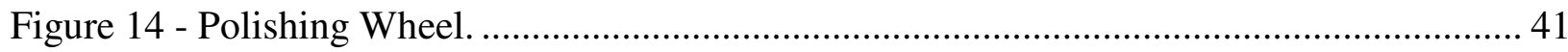

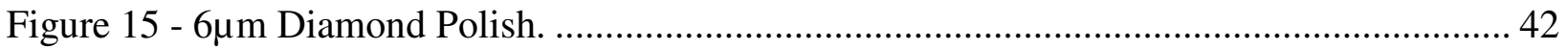


Figure 16 - Forgeng's Solution.

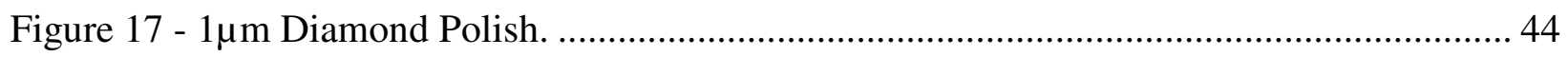

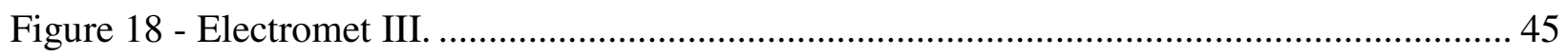

Figure 19 - Static Bioreactor With Submerged Samples................................................... 46

Figure 20 - 303 SS surface after 600 grit sanding (Originally captured at 100X) ................... 47

Figure 21 - Microstructure of 303 SS after 600 grit sanding (Originally captured at 500X) ...... 48

Figure 22 - 304 SS after 600 grit sanding (Originally captured at 500X) .............................. 49

Figure 23 - 303 SS after $1 \mu \mathrm{m}$ diamond polishing (Originally captured at 200X) ...................50

Figure 24 - Microstructure of 304 SS after $1 \mu \mathrm{m}$ diamond polishing (Originally captured

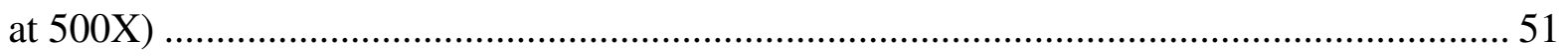

Figure 25 - Microstructure of 304 SS after $1 \mu \mathrm{m}$ diamond polishing (Originally captured

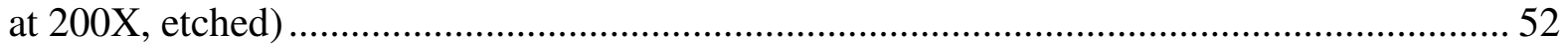

Figure 26 - Microstructure of 303 SS after $1 \mu \mathrm{m}$ diamond polishing (Originally captured

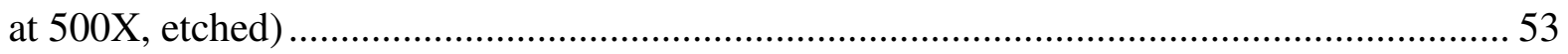

Figure 27 - Microstructure of 303 SS polished through $1 \mu \mathrm{m}$ diamond (Originally captured

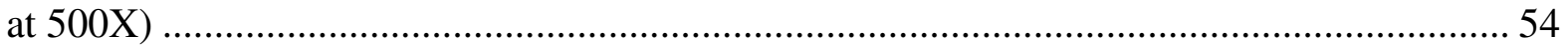

Figure 28 - Microstructure of 304 SS after $1 \mu \mathrm{m}$ diamond polishing (Originally captured

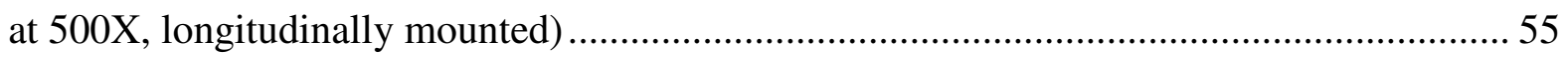

Figure 29 - Microstructure of weld interface region in 304 SS. Polished through $1 \mu \mathrm{m}$ diamond and etched (Originally captured at 200X) .................................................. 57

Figure 30 - Microstructure of 304 SS weldment polished through $1 \mu \mathrm{m}$ diamond and etched

(Originally captured at 200X). 59

Figure 31 - Microstructure of AISI 1018 steel polished through $1 \mu \mathrm{m}$ diamond and etched (Originally captured at 500X and etched)..... 60 
Figure 32 - Cross-section of AISI 1018 steel polished through $1 \mu \mathrm{m}$ diamond and etched (Originally captured at 500X and etched).

Figure 33 - Microstructure of AISI 1075 steel weldment polished through $1 \mu \mathrm{m}$ diamond......... 62

Figure 34 - Microstructure of AISI 1075 steel weldment polished through $1 \mu \mathrm{m}$ diamond (Originally captured at 500X)

Figure 35 - Microstructure of AISI 1075 steel weldment polished through $1 \mu \mathrm{m}$ diamond and etched (Originally captured at 500X, longitudinal, welded and etched)

Figure 36 - Microstructure of steel 304 SS weldment polished through $1 \mu \mathrm{m}$ diamond and etched (10\% oxalic acid electroetch) (Originally captured at 200X, welded pool, etched) ... 65

Figure 37 - 304 SS polished through $1 \mu \mathrm{m}$ diamond and longitudinally mounted (exposed for 24 hrs., originally captured at $3000 \mathrm{X}$ )

Figure 38 - 304 SS polished through $1 \mu \mathrm{m}$ diamond and longitudinally mounted (exposed for $24 \mathrm{hrs}$. and originally captured at $1800 \mathrm{X}$ ) 68

Figure 39 - 304 SS polished through $1 \mu \mathrm{m}$ diamond (exposed for $24 \mathrm{hrs}$. and originally captured at).

Figure 40 - 304 SS polished through $1 \mu \mathrm{m}$ diamond (welded, and exposed for $24 \mathrm{hrs.}$.) 70

Figure 41 - 304 SS polished through $1 \mu \mathrm{m}$ diamond (welded, exposed for $24 \mathrm{hrs}$.) 72

Figure 42 - 304 SS polished through $1 \mu \mathrm{m}$ diamond (welded, exposed for $24 \mathrm{hrs}$.) 74

Figure 43 - AISI 1018 steel polished through $1 \mu \mathrm{m}$ diamond (Originally captured at 1200X, exposed for $24 \mathrm{hrs}$.) 75

Figure 44 - AISI 1075 steel polished through $1 \mu \mathrm{m}$ diamond (Originally captured at 3000X, exposed for $24 \mathrm{hrs}$.) 77

Figure 45 - AISI 1075 steel polished through $1 \mu \mathrm{m}$ diamond (Originally captured at 10,000X, exposed for $24 \mathrm{hrs}$.) 78

Figure 46 - AISI 1075 steel polished through $1 \mu \mathrm{m}$ diamond and longitudinally mounted (Originally captured at 6000X, base metal of weld, exposed for $24 \mathrm{hrs}$.) 80 
Figure 47 - AISI 1075 steel polished through $1 \mu \mathrm{m}$ diamond (Originally captured at 7000X,

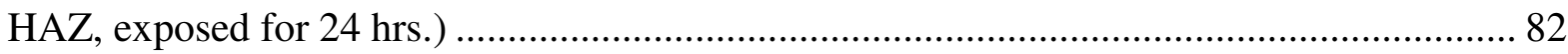

Figure 48 - Polystyrene exposed to bacteria for 9 days (Originally captured at 9000X)............. 83

Figure 49 - Polystyrene exposed to bacteria for 9 days (Originally captured at 3000X) ............. 85

Figure 50 - Polystyrene exposed to bacteria for 9 days (Originally captured at 2000X) ............. 87

Figure 51 - Polystyrene exposed to bacteria for 9 days (Originally captured at 7000X) ............. 88

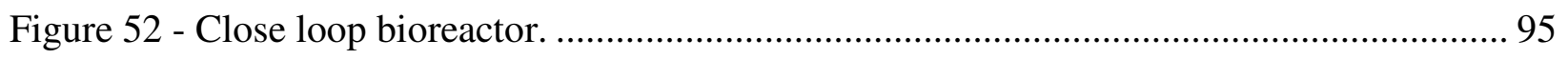

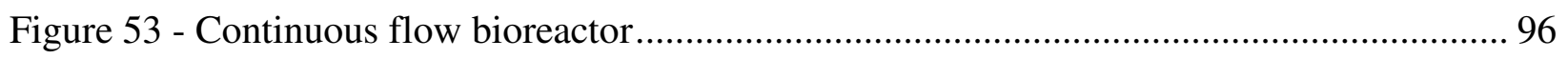

Figure 54 - Diagram of Sample Mounting Directions........................................................... 115 


\section{CHAPTER ONE}

\section{Introduction}

\section{Biofilm}

Biofilms are simply defined as communities of microorganisms attached to a surface (Figure 1) (Costerton, 2007; Dobretsov, 2008; Lewandowski \& Beyenal, 2008; Murthy \& Venkatesan, 2008; Romeo, 2010). Biofilms evolve through a cycle that consists of the stages initiation, maturation, maintenance, and dissolution (Figure 2). The formation of biofilms begins after a group of free floating (planktonic) cells attach to a surface to become sessile bacteria. The cells can either form single or multiple species (consortia) biofilm. In in vivo systems, consortia biofilms are the norm. Bacteria co-exist in a symbiotic relationship in the biofilm. They will flourish only if all species are present to process the organic matter produced in the consortia community (Costerton, 2007; O’Toole, Kaplan, \& Kolter, 2000; Romeo, 2010).

Biofilms go through two stages of development before they mature on a surface. Sessile bacteria are reversible upon attaching to a surface and become irreversible once they mature. In the reversible stage, sessile bacteria are reversibly anchored to the surface. Sessile bacteria rely on electrostatic and Van der Waals forces between the extracellular polymeric substance (EPS), the surface, and bacterial filaments to maintain attachment with the surface that interacts with the bacteria. The forces allow them to move on the surface and "search" for more attractive sites

(O'Toole et al., 2000; Poulsen, 1999). In the irreversible stage, biofilms are able to permanently attach to the surface with dipole - dipole, hydrophobic, ion-dipole, ion - ion, covalent, and hydrogen interaction bonds. 
Planktonic cells come into contact with a free surface. Once on the surface, the bacteria will move to the preferred sites using their flagella. The motion can be random or directed by chemotaxis. Once at a preferred site, bacteria adhere to the surface in a complex mechanism that is driven by Van der Waals forces as mentioned previously (Figure 2) (O'Toole et al., 2000; Romeo, 2010).

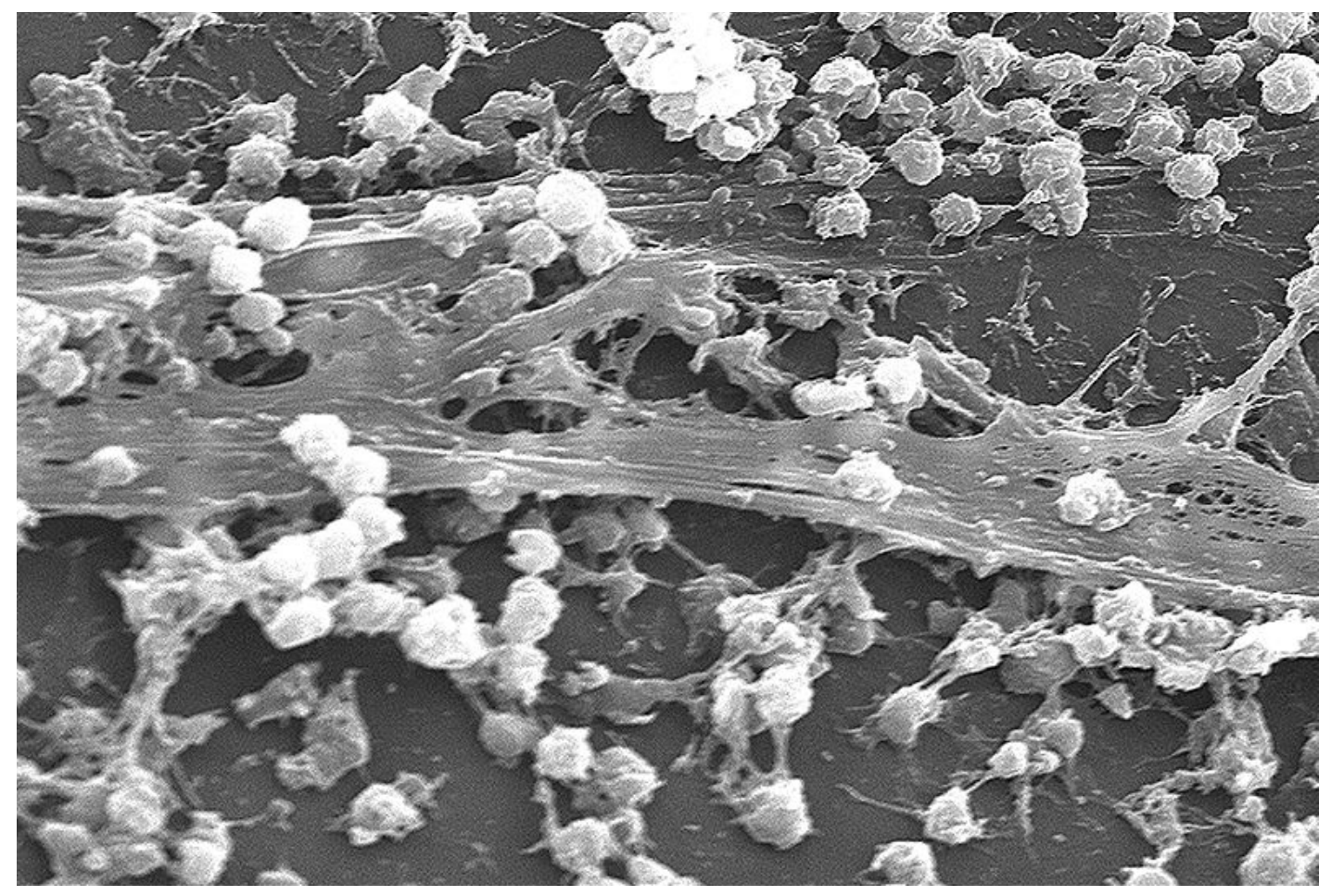

Figure 1 - Staphylococcus aureus biofilm (O’May et al., 2008).

Surfaces provide mechanical stimulations which activate specific genes of the bacteria. Alteration in the genotype accommodates the adaptation of the bacteria to a particular surface. Cell to cell attachment occurs in order to lock bacteria to the surface after the sessile stage (Lewandowski \& Beyenal, 2008; O’Toole et al., 2000). The sessile cells start to form an EPS or 
slime (glucopolysaccharide) layer over the clumps of cells. The EPS acts as a barrier that is resistant to the environment (Figure 2) (O'Toole et al., 2000; Romeo, 2010).

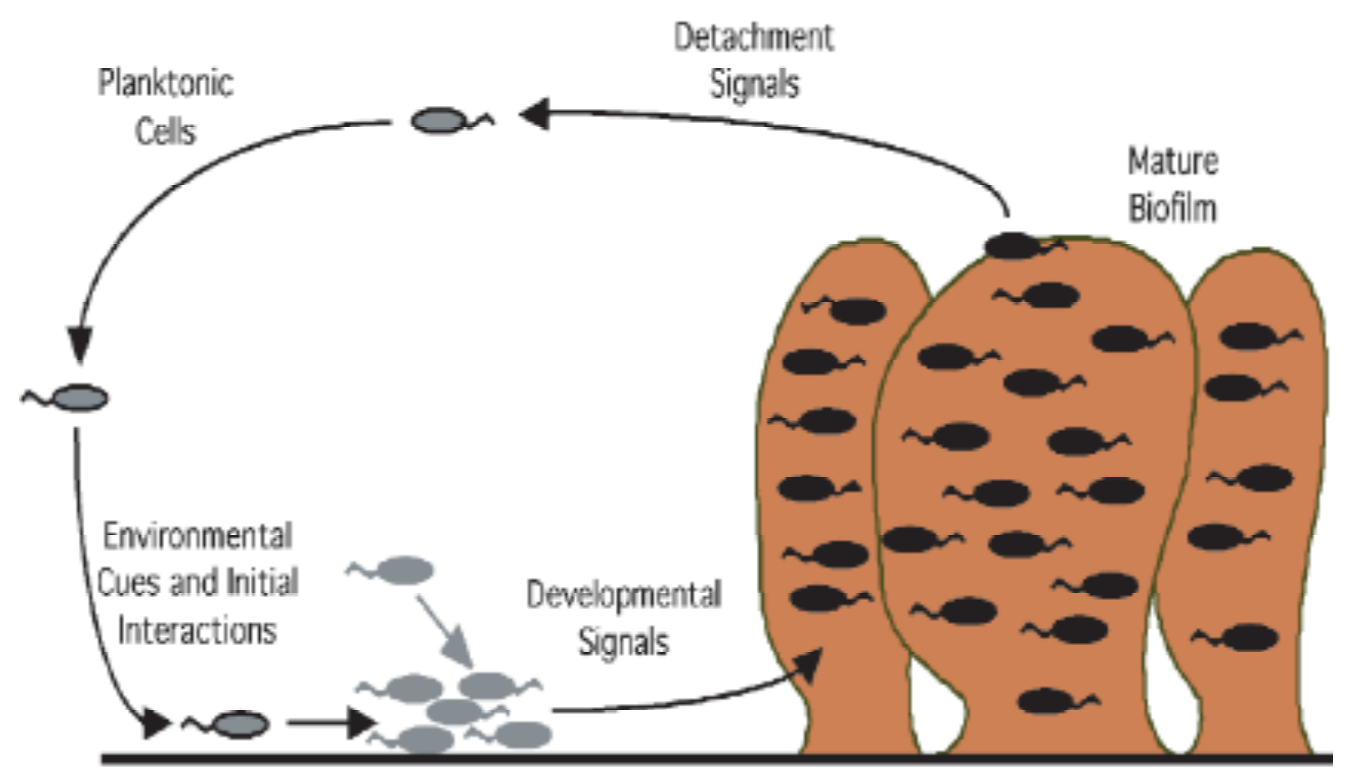

Figure 2 - Model of biofilm development (O'Toole et al., 2000).

After biofilms mature, they are very difficult to remove or reduce in any meaningful way.

Biofilms abate in a given location when depletion of nutrients on the surface occurs. The biofilms will release new planktonic cells to colonize on fresh surfaces in order to restart the film development cycle (O’Toole et al., 2000; Poulsen, 1999; Romeo, 2010). 
It is critical to understand that biofilms which initiate in the microscopic realm can cause problems in macroscopic systems which include infections in organisms, biofouling in distribution systems, and contamination in food delivery systems and processing systems.

\title{
Examples of Biofilm Damage
}

\author{
Waterlines
}

Accumulation of bacteria in pipes causes problems in water distribution systems. Spectrum biocides are not effective in suppressing biofilm growth in a typical aqueous environment for several reasons. First biocides cannot diffuse through nor permeate into the biofilm and second, because of the viscosity of the biofilm (Murthy \& Venkatesan, 2008). Biofilm growth varies due to the physical, chemical, and biological parameters characteristic of different sites in the fluid distribution system in question. Because of the variety of biofilms, the treatment to reduce biofilms has to be tailored specifically for each technical system.

In most systems, there is some level of biofilm tolerance. Once the tolerable amount of biofilm is reached, cleaning is required to rid the surface of the established biofilm communities. Organisms are carried through the pipes by the current of water and eventually adhere to the interior surface of the pipe. Maintaining a clean surface ensures the area is free of organisms because detritus serves as nutrient to the biofilms (Murthy \& Venkatesan, 2008; Venkatesan \& 
Murthy, 2008). By cleaning the surfaces regularly, organisms' attachments are reduced. Although surface cleaning is very important, industries redefined the meaning of cleaning. The word cleaning is redefined to only refer to on biocides to rid the water of biofilms (Murthy \& Venkatesan, 2008).

The efficiency of operating systems would increase if industries could refine their efforts to control biofilm growth. Because each system has its own type of biofilm, and is characterized by a different assemblage of colonizing species, a customized treatment composed of specific biocidal dosages and specific regiments is required. The specific treatment created for each system requires laboratory testing to confirm the type of biofilm existing in their water system (Murthy \& Venkatesan, 2008; Venkatesan \& Murthy, 2008). Specific biocides will effectively reduce the biofilm growth and allow easier maintenance in the industrial systems. Specific treatments are costly, time consuming and require continuous maintenance (Murthy \& Venkatesan, 2008; Venkatesan \& Murthy, 2008). Strong oxidizing biocides are used in cooling systems to control biofouling. Non-oxidizing biocides are attractive alternatives in many cases because non-oxidizing biocides don't endanger the environment. There are many other biofilm controlling techniques that are currently in their developmental stages, these range from enhancing surface smoothness to lowering the surface energy of the contact surfaces (Murthy \& Venkatesan, 2008). Water distribution systems can be threatened by microorganisms, those present as natural flora and fauna, as well as those added intentionally with malevolent intent. Contaminated waters in distributor systems can cause illness or even death (Murthy \& Venkatesan, 2008; Venkatesan \& Murthy, 2008). If proper methods are not employed to keep the microorganisms under control, human survival can be threatened. 


\section{Marine Biofouling}

\section{Corrosion}

For centuries marine biofouling has caused problems for ships. Biofouling decreases the efficiency of ships as they move through the water and compromises their load bearing capacity. Extensive fouling increases drag on ships which decreases their overall hydrodynamic performance (Dobretsov, 2008). With fouling, more fuel is consumed to compensate for the increase in drag as the ship moves through the water. Regularly cleaning ships' hulls is the solution to this challenge, but this approach is costly (Dobretsov, 2008).

Both man-made and natural surfaces in the marine environment are subject to biofouling. Marine biofouling by macroorganisms and microorganisms occurs in three main stages. In the first stage, dissolved organic molecules and planktonic organisms attach onto the submerged surface (Dobretsov, 2008). In the second stage, prokaryotic bacteria and eukaryotes such as algae and their spores colonize on the surface. The absorbed organic molecules serve as nutrients for the growth of the bacteria. In the third stage, biofilms mature, and invertebrate larvae attach to the surface. The bacteria serve as a food supply for the macroorganisms. These stages could either run parallel, overlap, or in series of cycles (Dobretsov, 2008).

Biofilms in the marine environment are populated by different symbiotic species of bacteria. These species produce high molecular weight polysaccharides to form a matrix of EPS around them. The unicellular bacteria in the biofilm make up less than one percent of the biofilm's total weight (Dobretsov, 2008; Romeo, 2010). The development of biofilm depends on the environment and the substrate. The fluid environment and the chemistry at the surface of the substrate cause changes to the previous planktonic cells' phenotype to enhance their survival at 
the surface (Dobretsov, 2008; O'Toole et al., 2000). Thus the development of the biofilm's characteristics hinge upon planktonic cells attaching to a surface, the formation of a slime layer (EPS), the maturation of biofilm, and the release of new planktonic cells and attendant film formation and evolution elsewhere (Dobretsov, 2008; O’Toole et al., 2000).

Metal sheets or coatings (such as paints) that release ions into the water can produce a toxic effect to microorganisms. Such metals, like copper are used to decrease the attachment of biofilms to ships' hulls. Further, it is a common practice to protect the hulls of ships with sheets of Tributyltin (TBT). The metal sheets and paints are added to the bottom of the ships. However, the very mechanism that makes these approaches effective in preventing biofilms makes them damaging to the environment as a whole. Biofouling paint consisting of TBT and other tincontaining substances are banned because they are not environmentally friendly; they are nonspecific (Dobretsov, 2008). Similarly, although metals like copper can reduce the attachment of bacteria, the material isn't environmentally friendly for the same reasons discussed above.

\section{Food Processing}

Biofilms have also caused fouling in pipes used in processing food supplies. This fouling not only contaminates food passing through the pipes but reduces the efficiency of food processing as well. The accumulation of biofilm reduces the flow in pipes, and decreases heat transmission. Furthermore, acid and other metabolic byproducts generated by the biofilms can cause corrosion in the pipes and contaminate the food supply (Poulsen, 1999). The mature biofilms in the corroded pipes can subsequently release planktonic cells that contaminate entire food processing systems. 
Although it is well known that the meat processing industries are threatened by biofouling, the problem persists because cleaning and maintenance in the processing and distribution systems are often neglected (Poulsen, 1999). Because the meat processing industries in particular often have ineffective decontamination processes, the meats passing through these pipes are contaminated which cause a great health risk. Regular news reports attest to this recurrent problem (Andrews, 2012; Bottemiller, 2012; Kovalak, Longton, \& Smithee, 1990; Satran, 2012). To ensure that the meats from the food distribution system are safe to consume, they have to be fully cooked at the correct temperature to kill the bacteria present on the surface of the meat (Poulsen, 1999). Understanding the development of microbial colonization on contact surface of food processing systems is a necessary step to eliminate them and the threats they pose to public health. Once nutrients are present on a surface and bacteria are allowed to form biofilms in one location, the "infection" will spread throughout the processing system (Poulsen, 1999). After biofilms mature, planktonic cells (Figure 3) are released to colonize a new surface, while those (Figure 3) in the biofilms remain stationary on the surface (O'Toole et al., 2000; Poulsen, 1999; Romeo, 2010). As the biofilms in the sessile state mature and form a polysaccharide matrix, they become permanently attached to the surface (Costerton, 2007; O’Toole et al., 2000; Romeo, 2010; Wilson \& Devine, 2003). 


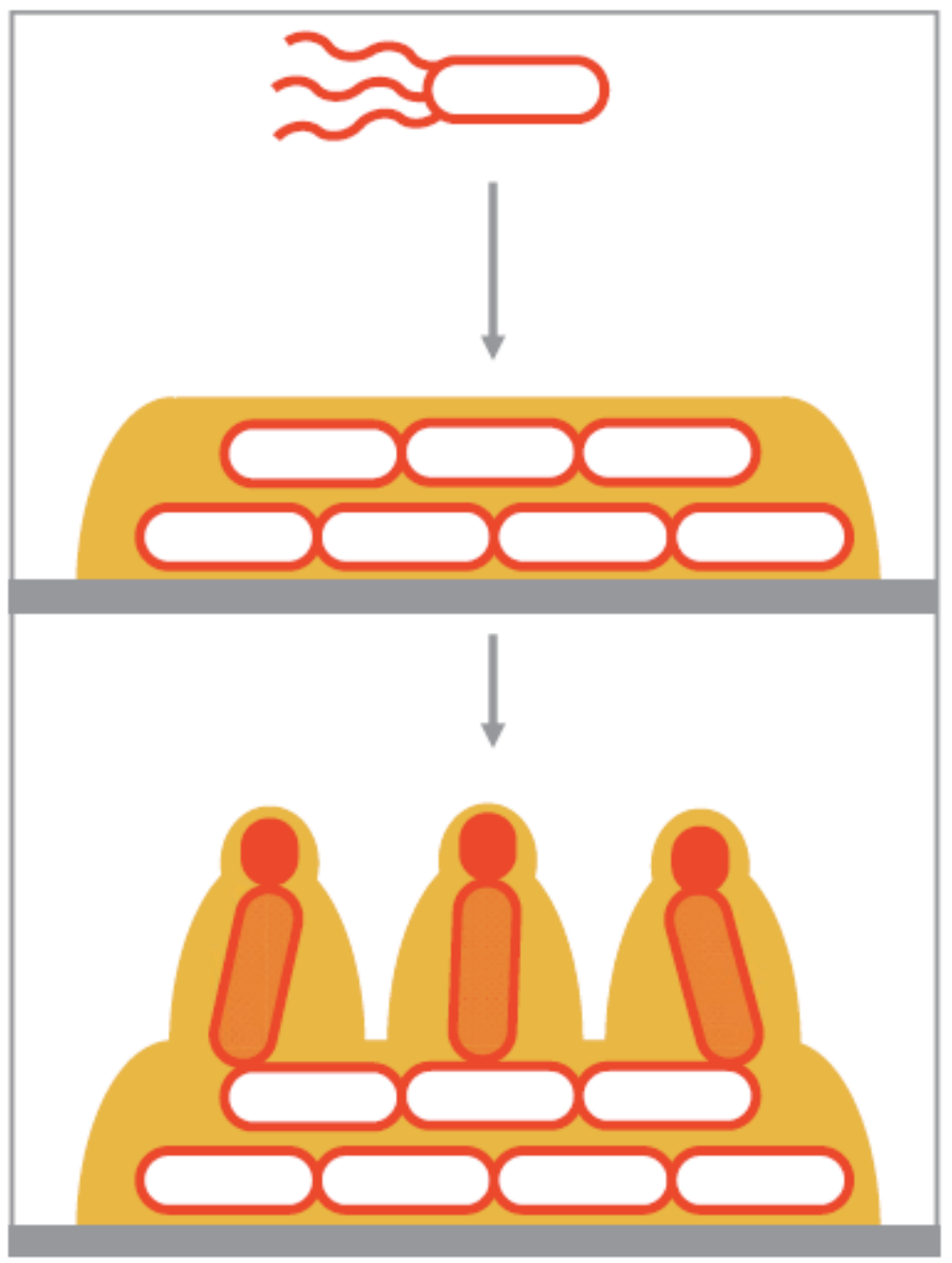

Figure 3 - General model for biofilm formation by motile bacteria (Romeo, 2010).

Bacterial colonies in the biofilm are protected from antibodies and environmental stresses by the EPS matrix. Environmental stresses are caused by shear forces applied to the surface of the pipes (Poulsen, 1999; Romeo, 2010). The EPS matrix of biofilms is formed differently depending if the biofilm is formed by gram negative or gram positive bacteria (O'Toole et al., 2000; Poulsen, 1999). If the food industries maintain a regular cleaning/sterilization routine, it 
will reduce the formation of biofilms before they permanently establish in the food distribution system (Poulsen, 1999).

The liquid flowing in the pipes alters the pipes' surface polarity which then attracts macromolecules. The surface of the pipes becomes negatively charged once immersed in water. The negative charge attracts cations and polar macromolecules from the liquid passing through the pipes. The macromolecules serve as nutrient in the biofilms. In the reversible stage, sessile bacteria hover at the surface of the pipe to consume the organic materials that are flowing through the pipe. The organic materials are concentrated at the pipe's surface relative to concentration in the flowing medium (Poulsen, 1999). Once the nutrient in the liquid flowing through the pipe is depleted, the sessile biofilms will permanently colonize on the surface layer of the pipe. After the sessile bacteria become irreversible, a certain phenotype is expressed and specific genes are activated to enhance their adaptability to the new environment. The irreversible biofilms will capture nutrients in their EPS matrix and the organic materials from the nutrients will be broken down by different sessile species living in the biofilm (O'Toole et al., 2000; Poulsen, 1999). The metabolism of organic materials produces byproducts which can accelerate corrosion in the pipe and lead to the establishment of permanently localized anodic and cathodic regions. At later stages, the paucity of nutrients on the surface will cause the biofilm to reduce in size and release planktonic cells to colonize a new surface with abundant nutrients. As the nutrient becomes abundant again, the reduced biofilm will regrow to its normal size (Poulsen, 1999). The byproducts of corrosion such as hydrogen radical can also serve as nutrients for biofilm growth.

Surface treatment of the pipes can decrease the attachment of micromolecules and biofilms. Industries are currently producing pipes with a smaller R-factor to reduce the 
roughness of the pipes' material. The R-factor is a measure of surface roughness of a material (Moody \& Princeton, 1944; Poulsen, 1999). Biofilms tend to form in spaces produce by cracks, corners, gaskets, joints and crevices in the pipes because organic materials are trapped on the surface of the pipes' layer (Poulsen, 1999). Glass and polished steel are very popular materials to use in the food processing industries because they can produce pipes with a small $\mathrm{R}$ - factor. The dairy industries have set a standard R-factor for all food distribution systems. Decreasing the attachment of biofilm by creating a smoother pipe surface allows an easier cleaning process for the food distribution systems. If biofilms are allowed to grow for a long period of time, the thickness would increase, which decreases the flow rate of the food distribution system (Poulsen, 1999; Venkatesan \& Murthy, 2008). Biofilms not only threaten our food supply through contamination, they can also threaten our health by attachment to medical implants and subsequent interaction of the host.

\section{Implants}

Besides marine biofouling, bacteria also cause inflammation in the human body. Acute systemic infections developed after implant surgery are often caused by the release of planktonic cells from mature biofilms on the implanted materials. There are three possible cases of infections that can develop after a surgical implant. The first type of infection is defined as superficial immediate infection which develops in the skin located near the site of the implant. This type of infection is caused by microorganisms colonizing on the skin of the patient near the site of the implant immediately following the surgical procedure (Temenoff \& Mikos, 2008; Wilson \& Devine, 2003). These skin dwelling bacteria include but are not limited to staphylococcus aureus and staphylococcus epidermidis. The second type of infection is defined 
as deep immediate infection which occurs when the bacteria from the skin is transferred to the site of the implant during the surgical procedure. The bacteria dwell in the skin and proliferate and spread into the site of the implant. The third type of infection is defined as late infection. The cause for late infection is still in question; however, the theory is that the blood borne pathogens derived from another site travel through the blood stream and to the site of the implant (Temenoff \& Mikos, 2008; Wilson \& Devine, 2003). Biofilms not only infect our bodies by traveling through the blood stream; they can also infect catheters during surgical procedures.

\section{Catheter Infections}

Annually there are about one million cases of nosocomial infections and more than forty percent of the time the cases happen in hospital and nursing home settings (Warren, 1997; Stamm, 1991; Stamm \& Hooton, 1993; Tambyah \& Maki, 2000). Eighty percent of the time, nosocomial infections are urinary tract infections (Hartstein et al., 1981). The medical treatments for these infections are costly. Urinary catheter infections associated with bacteria cost about $\$ 2900$ for medical treatment for each episode (Saint, 2000).

Catheter use and hospital settings predispose patients to urinary tract infection. The infection could either be asymptomatic or symptomatic. Asymptomatic means that the patient carries the infection without experiencing any symptoms. Symptomatic means that there are symptoms produced in the infected patient. Urinary tract infections can develop into either mild, chronic or severe, acute infections. Mild infections produce symptoms such as fever, urethritis, and cystitis. Severe infections produce symptoms such as acute pyelonephritis, renal scarring, and calculi formation. 
Urinary tract infections are caused by bacteria introduced by the catheter to the mucous layer. Bacterial attachments to the surface of the catheter are typically caused by surgical and fecal contaminations. During the surgical procedure of inserting the catheter into the bladder, foreign pathogens are introduced from the skin to the periurethral area (Clegg \& Gerlach, 1987; Daifuku \& Stamm, 1986; Leranoz et al., 1997; Old, Adegbola, \& Scott, 1983; Yamamoto, Ariyoshi, \& Amako, 1985). Once the pathogens are introduced into the body, they will replicate and eventually overwhelm the host defense in the mucosal layer. Once the host defense is destroyed, bacteria change phenotype to better attach to the surface of the catheter or periunrethra area. After finding a colonizable surface, the bacteria permanently attach to the surface and become sessile (Figure 5). 


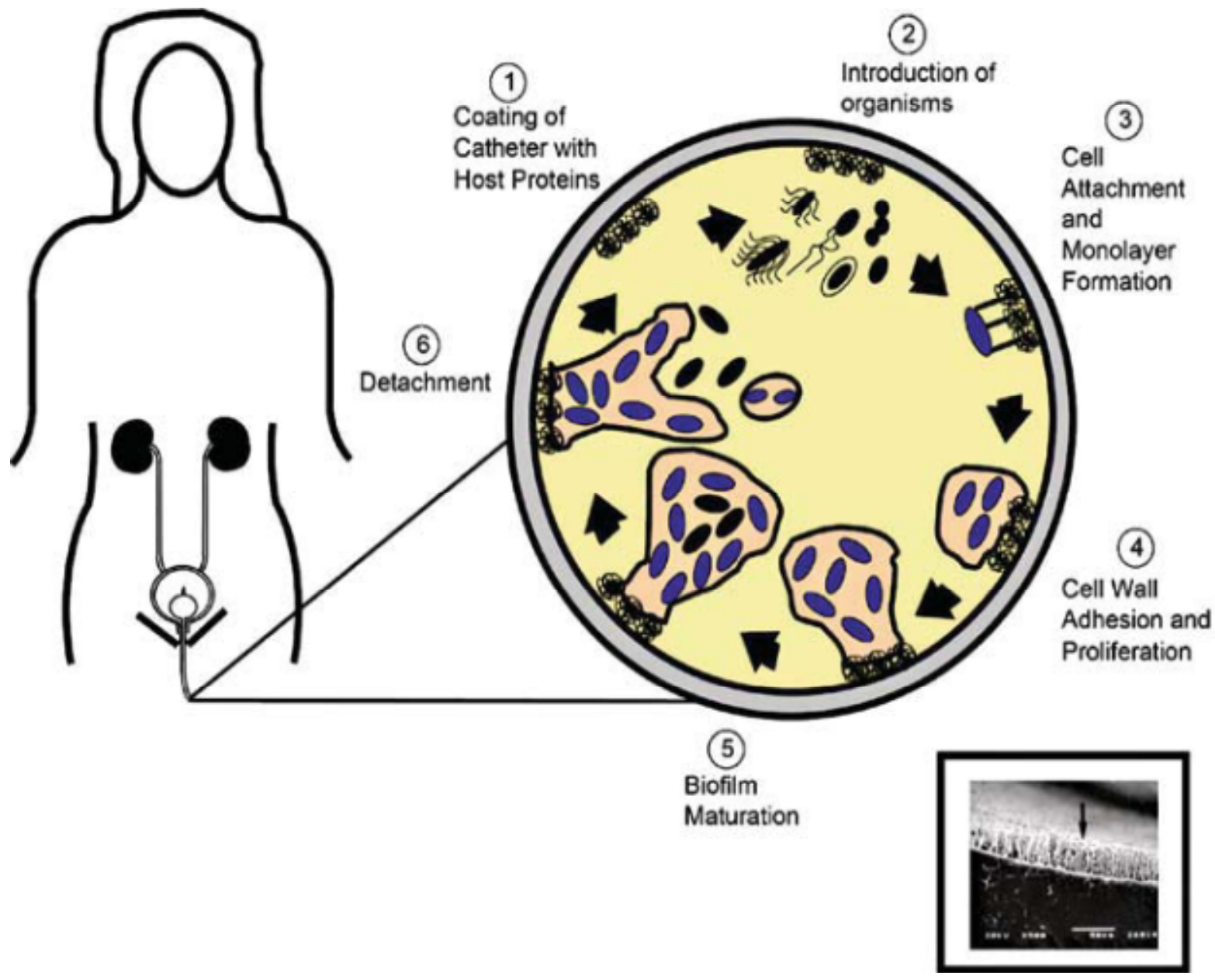

Figure 4 - Pathogenesis of biofilm formation on urinary catheters (Stickler, Morris, Moreno, \& Sabbuba, 1998a; Stickler, Morris, Mclean, \& Fuqua, 1998b). 


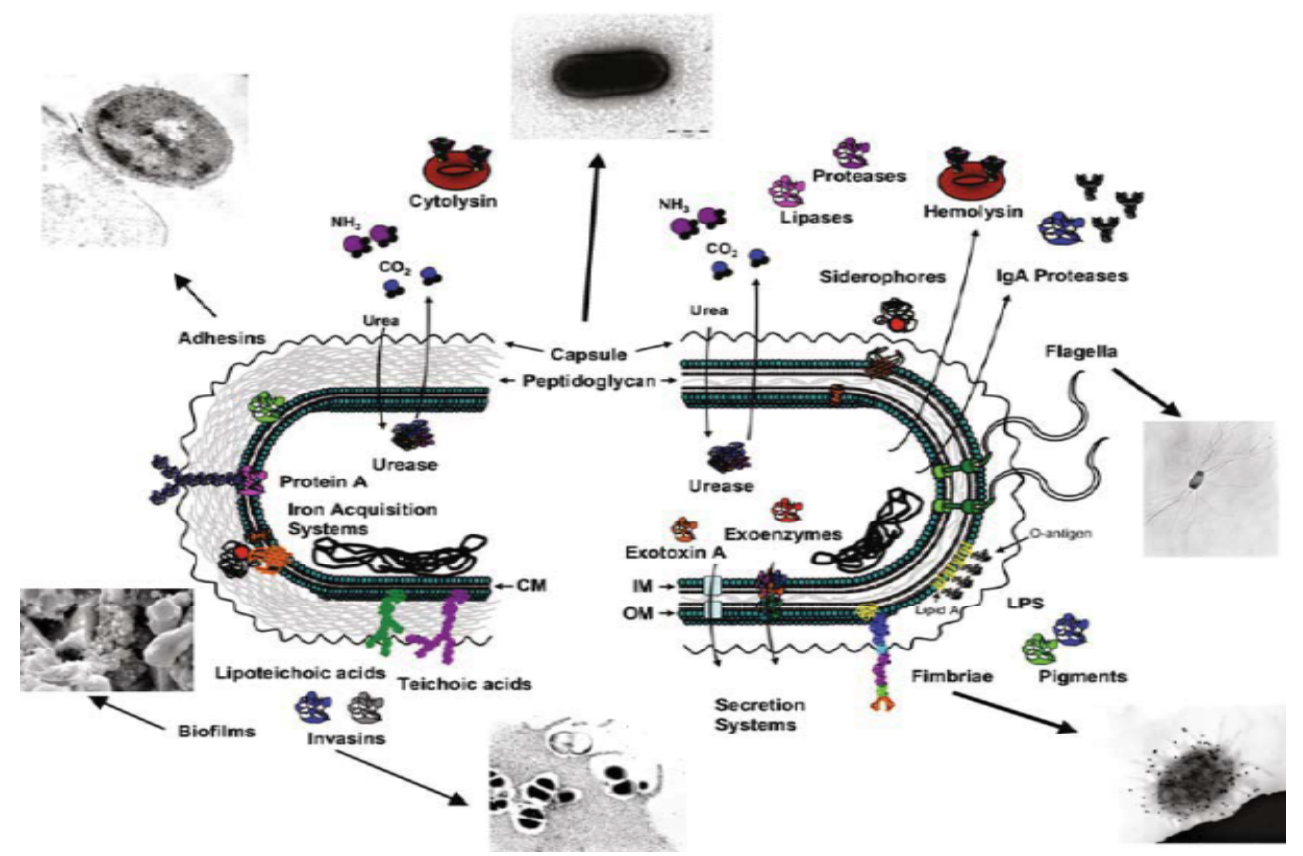

Figure 5 - Virulence factors of uropathogens (Bayles et al., 1998; Jones, Young, Mahenthiralingam, \& Stickler, 2004; Li, Johnson, \& Mobley, 1999; Schembri, Blom, Krogfelt, \& Klemm, 2005).

The uroepithelial mucosal layer protects the urinary tract from infection. The insertion of the catheter damages the uroepithial mucosa layer which exposes the surface of the uroepithelium for bacterial attachment.) The contaminated indwelling urinary catheter contacts the uroepithelium host cell binding receptors. This juxtaposition allows the uropathogens and other bacteria to attach to the surface of the uroepithelium (Figure 5) (Garibaldi et al., 1980). Once the host defense mechanism in the urinary tract is damaged, it will cause the bladder to over extend and incomplete urinary voiding. The overextended bladder will leave residual urine which induces further microbial growth (Figure 4) (Hashmi, Kelly, Rogers, \& Gates, 2003).

Once a catheter introduces bacteria to the urinary track and cause an infection, bacteria will proliferate and develop treatment resistant, irreversible biofilms. If the bacterial infection is not treated before the biofilm matures, the patients' health will continue to degrade. Biofilm growth is dangerous because established bacteria in the biofilm will release degenerative 
enzymes after maturation which causes cell death in the host. A surface treatment can be developed in the future to prevent bacterial attachment to the catheter (O'May et al., 2008).

\section{Powerplant}

Biofouling causes flow degradation and blockage in heat exchangers and coolers of power plants. Not only does biofouling affect the power plant mechanically but also this degradation has a huge financial impact on the power industry, from the standpoint of maintenance and from the standpoint of efficiency. A significant amount of cost is incurred for cleaning and maintaining the cooling system of the power plant to keep the bacterial colonization at an acceptable level. Again, nutrients from the water flowing through the pipes of the cooling system support bacteria colonization on the surface of the pipes. The cooling system acts as a bioreactor which creates a potential habitat for bacteria growth by providing location, nutrients and a suitable temperature. The possibility of exceeding the biofilm tolerance of the system depends on the water quality.

Many species are associated with macro-fouling in seawater systems. However, freshwater only has two living species that cause macrofouling. Asiatic clams and Zebra mussels are the two macrofouling species in the freshwater. Seawater is more susceptible to biofouling because seawater contains about 150 living species known to biofoul. The reduction in water flow caused by initial fouling leads to mechanical damage in the pumps and the condenser pipes which aggravates and accelerates macrofouling in the cooling system. The macrofouling organisms eventually become dead organic matter that adheres to the surface of the pipes which serves to further sustain the biofilms. The bacteria from the water source flow into the pipes of the cooling system and flourish by consuming the dead organic matter in the pipes. 
The abundance of dead organic matter creates the potential for biofilm colonies to form which may cause microfouling. Once the dead organic matter in the pipes deplete in a particular location, mature biofilms will release planktonic cells to colonize on new surfaces (Poulsen, 1999; Venkatesan \& Murthy, 2008). The complex consortium of species in the biofilm is protected from aggressive environments by the EPS.

Commonly, bacteria in the biofilm decrease the $\mathrm{pH}$ in regions of the film. The acid generated from biofilms will cause corrosion in the pipes. In pipes protected by a passivation layer, this can lead to film disruption and localized corrosion (Poulsen, 1999; Venkatesan \& Murthy, 2008). The damaged surface of the pipes will expose the metal to the environment and allow for the formation of electrochemical cells on the surface. The anodic regions will oxidize the metal; meanwhile, reduction will take place at the cathodic regions. The seawater forms a salt bridge that creates current flow (ionic and electron conduction) between the half cells in the electrochemical cells and causes corrosion. The persistence of corrosion in highly localized regions of the pipes will eventually perforate the wall and cause a leak. A leak will result in a significant cost for the power plant, a cost to repair the system, as well as a huge financial loss for plant downtime (Venkatesan \& Murthy, 2008).

Biofouling causes blockage and decreases water flow in tube heat exchangers and plate heat exchangers. Plate heat exchangers are more widely used in nuclear, thermal, and desalination plants. Historically, biofouling was controlled using chemical biocides, introduced into water flowing through the system. If problems persisted, the biocide dosages were simply increased to rid the system of biofilms. This approach met with limited success because generic biocides have a limited ability to diffuse through or perfuse into biofilm EPS matrices (Murthy \& Venkatesan, 2008; Venkatesan \& Murthy, 2008). The new approach in controlling biofouling is 
to control environmental parameters, and maintain their values in a range that limits biofilm growth. The parameters include fluid velocity, temperature, $\mathrm{pH}$ value, nutrient levels, cell concentrations, and surface roughness. Proper control of these variables inhibits the formation and development of biofilms. This approach does not supplant biocide use, but is used in conjunction with it. Biocides are continuously added to inhibit attachment of bacteria to the surface of the pipes. The major goal is to control the surface of the pipes to prevent the attachment of bacteria, thus stopping the problem at its root (Venkatesan \& Murthy, 2008).

Common approaches to maintain the cooling system include adding filtration screens to the intake pipe and the condenser pipe, altering biocide dosages, and thermal shock treatment. Chlorine, a plentiful and inexpensive oxidizing agent, is a commonly used biocide. The amount of biocides used to filter the water depends on the volume of water in the system (Murthy \& Venkatesan, 2008; Poulsen, 1999). The methods employed vary depending on the location of the power plant. Different geographic locations are surrounded by different biomes and are exposed to different species of biofouling organisms. The geographic locations determine the quality of cooling water, the tolerance range for thermal shock treatment, and the tolerance range for biocides to prevent the attachment of macrofouling organisms. Removing macrofouling organisms by filtering decreases the amount of organic matter in the water. Microfouling decreases in the water pipes as soon as macrofouling is under control (Murthy \& Venkatesan, 2008; Poulsen, 1999; Venkatesan \& Murthy, 2008).

The accumulations of larval invertebrates that seep pass the filtration screens and flow into the cooling system cause macrofouling. The larval invertebrates settle into the pipes and metamorphose into their adult stage. In their adult stage, they develop an outer shell. The continuous flow in the cooling system refreshes nutrients, oxygen, and unfiltered wastes which 
underpin the colonization of the surfaces by macrofouling organisms (Murthy \& Venkatesan, 2008; Poulsen, 1999; Venkatesan \& Murthy, 2008).

If the fouling isn't treated the uniform fouling layer would gradually increase in thickness. Kovalak et al. discussed biofouling in "Infestation of power plant water systems by the zebra mussel (Dreissena polymorph)", the study conducted at Monroe Power Plant in western Lake Erie showed that as the thickness of the fouling layer reaches $30 \mathrm{~cm}$ from the walls of the pipes, the velocity of the water would slough the layer off and carry it to the heat exchanger (Kovalak et al., 1990). The heat exchanger would eventually be clogged by clusters of biofilm and this would result in a water blockage (Venkatesan \& Murthy, 2008). The shells from macrofouling organisms caused a blockage of flow to the tube heat exchanger show in Figure 6a. The same situation happened in plate heat exchanger show in Figure $6 b$.
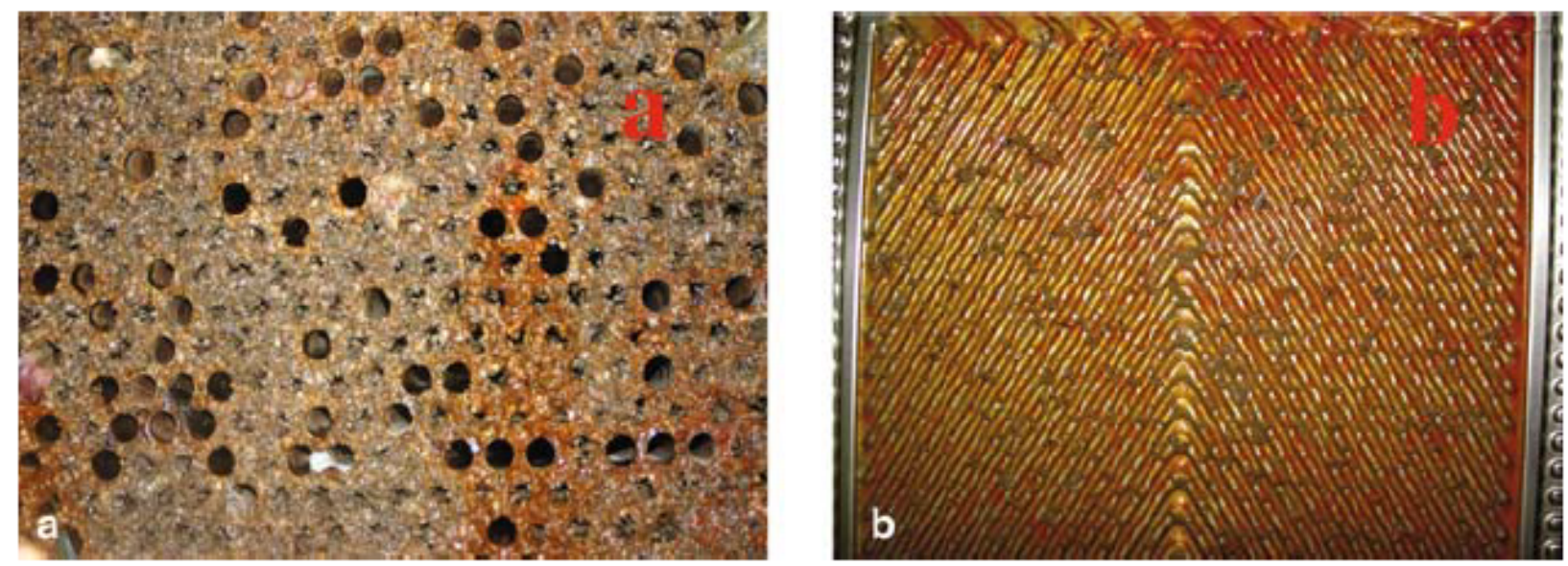

Figure 6 - A flow blockage of tubular heat exchangers (Venkatesan \& Murthy, 2008).

In Figure 6a, many of the tubular heat exchangers were blocked by calcareous shells which decreased the velocity flow in the cooling system. The orange decoration or color near the holes of the tubular heat exchangers in Figure 6a is corrosion byproduct. The bacteria cause a drop in the local $\mathrm{pH}$ by decomposing the dead organic matter. This acidification compromised the 
passive corrosion resistant layer at the surface of the metal pipes. The systems inherent resistance to corrosion depends on the material it was made from as well as its process of manufacture. Titanium metal plates in the tubular heat exchangers appeared to corroded differently due to different manufacturing processes (Venkatesan \& Murthy, 2008). Even though metal plates cover a great amount of surface area, the tiny crevices create a potential habitat for bacteria.

Although plate exchangers are much more efficient than tube or shell exchangers, they are more costly. Seawater potential exposes the plate exchangers to corrosion. The corrosion is caused by the electrochemical cells developed on the plate exchangers. The electrochemical cell contains half cells of an anode and a cathode. The seawater forms a salt bridge between the two half cells which causes current flow (ionic and electron conductions). The cathode receives electrons from the anode. Metal ions will be oxidized at the anode while at the cathode several different reduction reactions take place, depending upon the chemical environment. Mechanical damage caused by the hard calcareous shells increases the energy of the cooling system in order compensate for the damage (Venkatesan \& Murthy, 2008). If biofouling causes pressure drop of only $5 \mathrm{~mm}$ of mercury in the heat exchanger tubes, this consumes an additional three megawatts of energy from the reactor core to produce an equivalent output. The biofouling in the heat exchangers increased the need for additional maintenance and operational cost to increase the heat exchange efficiency and decrease fluid frictional resistance (Venkatesan \& Murthy, 2008).

There were many factors that contribute to the increase of fouling. The two major factors that induced fouling were the material and the surface of the heater exchanger. An experiment was performed on aluminum, copper, and brass plates to test for the growth on Pseudomonas fluorescent. The results of the outcome showed more growth of biofilms on aluminum than the 
other two metals. Copper and brass showed resistance to biofilm growth because they release toxic ions on the surface which prevented aggressive attachment of biofilms onto the surface (Venkatesan \& Murthy, 2008). Past studies have shown that a smooth surface has less biofilm attachment than a rough surface. The theory was proven by comparing a spirally dented tube to a plain tube. There was more biofilm attachment to the spirally dented tube. Rough surfaces provide an environment that shelter biofilms from shear stress. Most of the fouling sites found were followed by corrosion growth. There were more surface properties that can be altered to reduce biofilm attachments and formation. The properties were corrosiveness of the material, the absorption, and the surface charge. By altering these properties the heat exchanger can run more efficiently with less maintenance (Murthy \& Venkatesan, 2008; Poulsen, 1999; Venkatesan \& Murthy, 2008). Besides affecting our lives externally, biofilms also cause problems in the human body.

\section{Process of Implant Infecting In the Body}

Bacteria in the human body are often beneficial for an organism. Typically, they are in the gut (an interior surface) or on the surface of the body. However, bacteria introduced into the body from foreign objects such as implants are a different matter. Implants can introduce bacteria carried on its surface, or it can provide a surface for bacteria from other surfaces to colonize in the body. Once bacteria are introduced in the body, they will attach to the surface of tissues with ECM (extra cellular matrix) damaged by the act of implanting the biomaterial (Temenoff \& Mikos, 2008; Wilson \& Devine, 2003). As a free floating (planktonic) cell, bacteria will search for free surfaces to colonize on. Once a surface is found, planktonic cells 
change phenotype to enhance surface attachment to the surface of the tissue. Once the planktonic cells attach to the surface, cell - cell interaction is enhanced for bacterial growth. The cell - cell interaction allows the bacteria to form a slime layer (ECM). This slime layer creates a chemical and physical barrier that frustrates the normal foreign body response found with implants. The phagocytes released by the immune system are overwhelmed by engulfing a foreign material. The immune system also produces a large quantity of granulocytes to attack the foreign material and the body eventually is exhausted from fighting an endless chemical battle (Adams, Jr. et al., 2008; Temenoff \& Mikos, 2008). Consequently, the body's immune system is weakened because the response is never resolved (Temenoff \& Mikos, 2008; Wilson \& Devine, 2003).

\section{Surface Modification}

Currently there are three common approaches to control biofouling. The three types of approaches consist of mechanically detaching biofoulers, inactivating biofouling organisms using chemical treatments, and modifying the surface of the substrate material to reduce the attachment of bacteria. These three types of treatments can alter many features at the surface, to include the surface's chemical composition, morphology, topography, roughness, hydrophilic balance, hydrophobic balance, surface energy and polarity. Although chemical treatments are commonly used, the most effective antifouling coatings were banned because they contained environmentally unfriendly toxic biocides (Brady, 2003; Vladkova, 2008). Further research is needed to develop alternative chemical treatments that are environmentally friendly. 
Materials in the marine environment are predisposed to biofouling. Industries are currently modifying the surface of materials to reduce biofouling without the use of toxic biocides. For example, the surface modification can alter the material's surface to become hydrophobic and low energy. Hydrophobic surfaces, and low energy surfaces are less susceptible to biofilm formation in aquatic environments. They also reduce interaction with living organisms which help control biofouling in marine environments (Abarzua \& Jakubowski, 1995; Vladkova, 2008).

In the marine environment biofouling is caused by the attachment of microorganisms and macroorganisms on surfaces. Before biofilm formation, bacteria attach onto the surface of the substrate that is submerged in water. As discussed previously, the bacteria will proliferate and become permanently attached forming biofilms, leading to microfouling. Larger marine organisms will attach on the surface that is colonized by microorganisms. Larger marine organisms consume polysaccharides and glycoproteins that the biofilm produces. In order to prevent biofouling, Industries are currently producing new material surfaces that will reduce bacterial attachment and minimize macrofouling. Surface treated synthetic materials have shown resistance to bacterial attachments. Although surface treated synthetic material can potentially reduce bacterial attachments, it is still not clear that synthetic material is highly effective in preventing bacterial absorption (Callow \& Fletcher, 1994). More studies on synthetic materials are needed to determine if they can be a potential solution to reduce biofouling.

Surface roughness and topography are significant factors that influence macroorganism adhesion. Macroorganisms secrete liquid cements to increase adhesion to the material's surface. The mechanism of attachment is complex because even smooth surfaces are rough at molecular scale (Baier, Shafrin, \& Zisman, 1968; Vladkova, 2008). Whether or not the adhesive fills all 
the small crevices at the surface depends on the viscosity of the liquid produced by the organism. If the viscosity is low, the crevices are filled; conversely, if the viscosity is high, not all the crevices will be filled (Baier, Shafrin, \& Zisman, 1968; Vladkova, 2008). When the biological adhesive sets, it causes stress concentrations at particular locations or geometric singularities on the surface. At these singularities, the applied force is multiplied several times and can rise to levels large enough to fracture the film or film to surface bond (Vladkova, 2008). If the fractures are close together, it allows the crack to elongate more.

In addition to these mechanical effects, the extent of surface roughness can be altered. Recent work showed that as roughness increases, the receding angle decreases and the advancing angle increases. During research under the static conditions, it was noticed that as the surface roughness increases, its causes the contact angle to increase (An \& Friedman, 1998; Morra \& Cassinelli, 1997). This finding doesn't factor into consideration the size, shape, and the exact location of the droplet placed to determine the contact angle; however, the researchers did show that roughness affects the spreading of adhesive liquid (An \& Friedman, 1998; Morra \& Cassinelli, 1997; Vladkova, 2008). Although many researchers have focused on the cellular response to the topographical cues, there are many other researchers who argue that cellular response is less significant in the initial attachment stage than intrinsic thermodynamic factors (An \& Friedman, 1998; vanLoosdrecht, Norde, Lyklema, \& Zehnder, 1990; Morra \& Cassinelli, 1997; Vladkova, 2008).

The attachment of microfouling and macrofouling species differs depending on the topography of the surface. Macrofouling species in the marine environment consist of barnacles (Berntsson, 2001; Berntsson \& Jonsson, 2003; Berntsson, Jonsson, Lejhall, \& Gatenholm, 2000), algae (Callow et al., 2002; Hoipkemeier-Wilson et al., 2004), and invertebrates with shells (Bers 
\& Wahl, 2004; Scardino et al., 2003). Recent work employing wettability testing has shown that roughness does alter surface attachment. Attachment of swimming zoospores depends on the characteristics of the surface (Callow, Callow, Pickett-Heaps, \& Wetherbee, 1997; Callow et al., 2002; Nedved \& Hadfield, 2009). Wettability models are limited because the scale of droplets is larger than the significant topographical features. The large liquid droplets neglect the line tension effects while small droplets include the line tension effects. From the study of Blecua et al., line tension effects are defined as "On a homogeneous substrate, the line tension leads to a discontinuous unbinding of the droplet if its volume is decreased below a critical value." (Blecua, Lipowsky, \& Kierfeld, 2006). More research is needed to create a more precise method of predicting an energy driven model of bioadhension (Bers \& Wahl, 2004; Bohringer, 2003; Brennan et al., 2005; Carman et al., 2006; Gerbig, Phani, \& Haefke, 2005; Griesser et al., 2002; Hoipkemeier-Wilson., 2004).

Although smooth surfaces seem to be the current solution in preventing biofilm attachment, there are other alternative engineering methods that have the potential for future improvements. The alternative methods consist of engineering local surface with hydrodynamic property and altering the surface topography. The coatings used currently to prevent fouling and attachment only decreases the amount of attachment rather than absolutely preventing biofilm formation. Modifying surface morphology and surface composition can affect biofouling. One potentially promising venue for biofilm control is the use of specific molecular complexes to inhibit film formation. Studies concentrating on biomimetic materials and on the process their adsorption at surfaces to create a biofouling free surface are very promising (Brennan et al., 2005; Vladkova, 2008). Recently a biological polymer called chitosan was found to have the properties of reducing the attachment of bacteria on surfaces. 


\section{Chitosan}

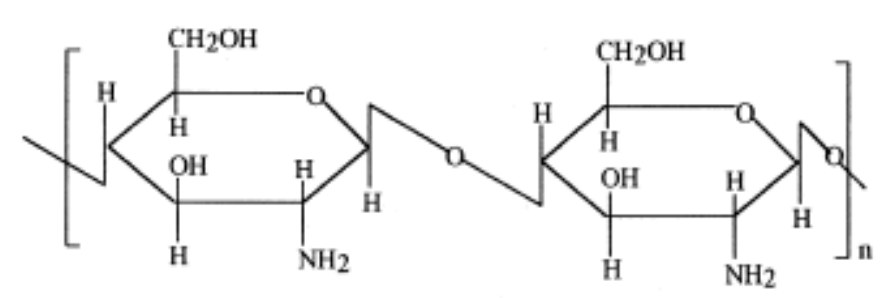

Figure 7 - Structure of chitosan (Kumar, 2000).

Chitosan (Figure 7) is a natural linear polysaccharide that is highly tunable for specific biomedical applications. Chitosan is produced by deacetylation of chitin which is derived from exoskeletons of crustaceans and cell walls of fungi. For medical use, it is usually chemically treated to enhance the antimicrobial activity. The amino acid side groups, molecular weights, and degree of deacetylation all affect key properties of chitosan. Currently, the two most studied properties of chemically treated chitosan are biodegradability and toxicity. Both of these properties are very dependent on molecular weight and degree of deacetylation. If the properties mentioned above are tailored to a lower molecular weight and lower degree of deacetylation, the biodegrading rate will increase while the toxicity level decreases. Although chitosan is biocompatible and has a minimal toxicity in the body, it is highly toxic to bacteria, fungi and parasites (Kean \& Thanou, 2010; Orgaz, Lobete, Puga, \& Jose, 2011).

The FDA has approved chitosan to be a GRAS (generally recognized as safe) material. At this time, chitosan can only be used as a food additive. Although many derivatives of chitosan are produced, the chemical versatility and variety of formulations are still in question. 
Past studies of chitosan formulations lack a clear documentation of chitosan derivative structure and any systemic study on biodistribution. The systemic study on biodistribution in past studies does not clearly state the molecular weight and degree of deacylation used to test the toxicity during in vivo and in vitro tests. For future approval for specific use by the FDA, a common precursor is needed for the testing procedure to ensure that the amount of chitosan used to reduce bacterial attachments is non-toxic to the body (Kean \& Thanou, 2010).

\section{CM-Chitosan Can Potentially Serve As An Antibiofilm Agent}

In a recent study, high concentrations of carboxymethyl chitosan (CM chitosan) have been proven to reduce the proliferation of both gram-positive and gram-negative bacteria. CMchitosan was tested on staphaloccocus aureus RN6390 and pseudomonas aerugnosa PAO1. Figure 8 shows the result when a $2.5 \mathrm{mg} / \mathrm{ml}$ concentration of CM-chitosan was applied to an assay plate of staphylococcus aureus RN6390. The high concentration of CM-chitosan reduced gram - positive bacteria to $0.71 \pm 0.03) \times 10^{8}(\mathrm{CFU} / \mathrm{ml})$ of viable cells which is about one-fourth the original. The control and the CM-chitosan treated surfaces were contrasted by fluorescence staining and microscopy. There were about $(1.30 \pm 0.12) \times 10^{8}(\mathrm{CFU} / \mathrm{ml})$ of viable bacterial cells present on the surface after treatment with CM-chitosan which showed a significant reduction of bacterial cells compared to the control (Martinez et al., 2009; Orgaz, Lobete, Puga, \& Jose, 2011; Tan, Han, Ma, \& Yu, 2011). 


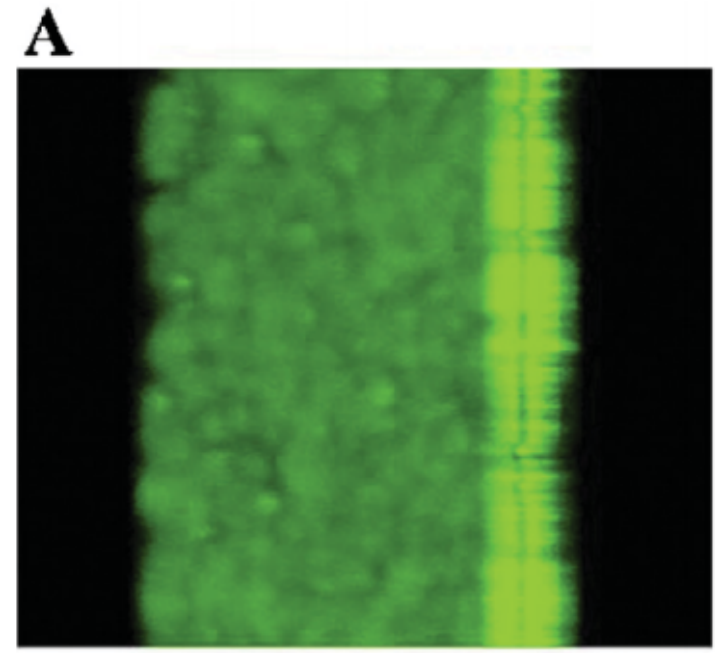

Control

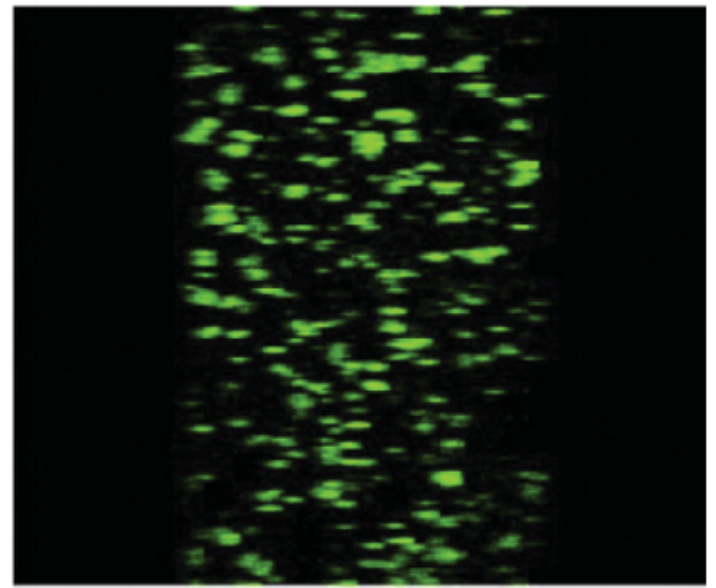

Treated with CMCS

Figure 8 - CLSM images of biofilm formations without (left) or with (right) CM-chitosan (Tan, Han, Ma, \& Yu, 2011) .

\section{B}

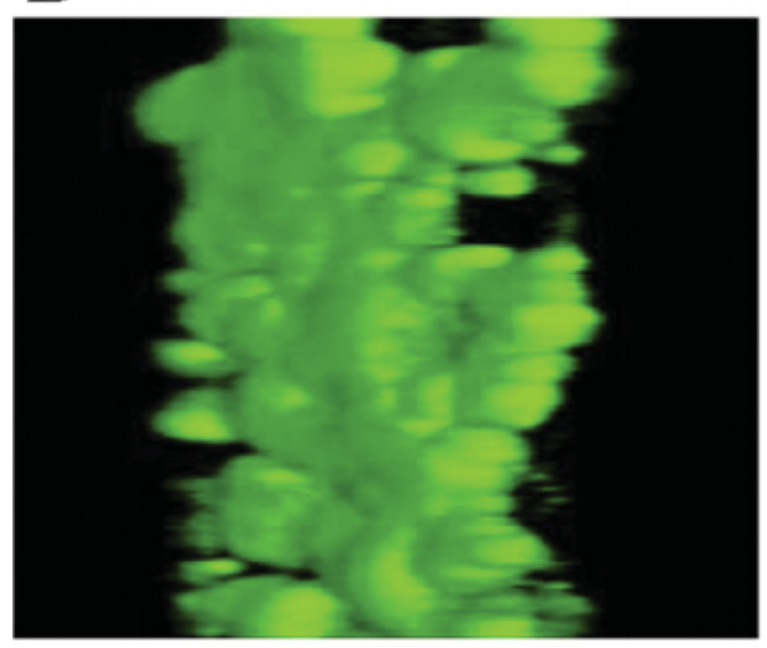

Control

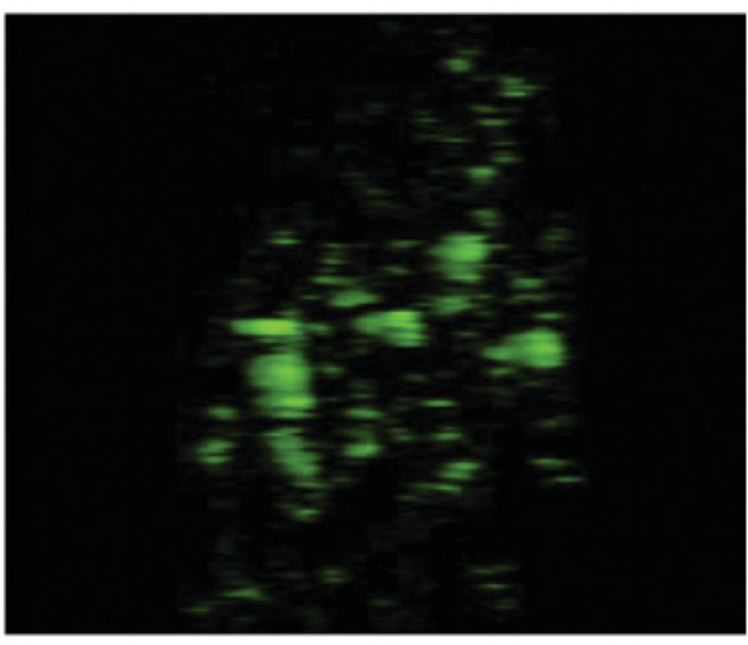

Treated with CMCS

Figure 9 - CLSM images of biofilm formations without (left) or with (right) CM-chitosan (Tan, Han, Ma, \& Yu, 2011). 
In Figure 9, the biofilm treated with CM-chitosan shows a 90\% reduction of cell attachment in both gram-positive and gram - negative bacteria compared to the control (Martinez et al., 2009; Orgaz, Lobete, Puga, \& Jose, 2011; Tan, Han, Ma, \& Yu, 2011).

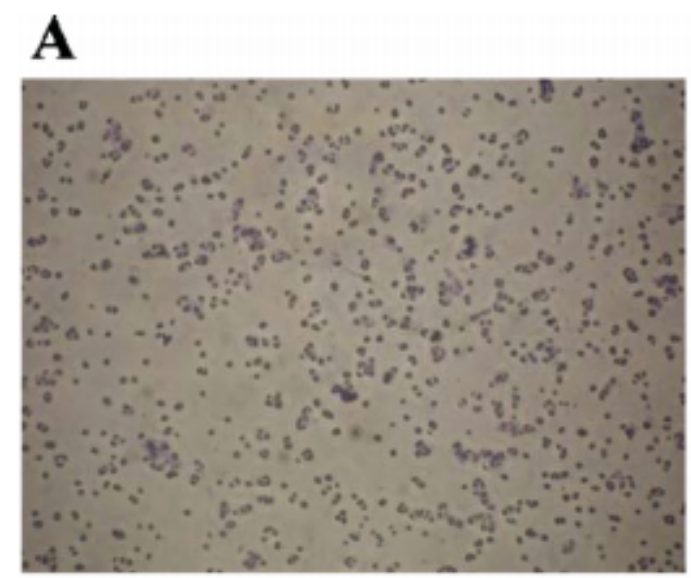

Control

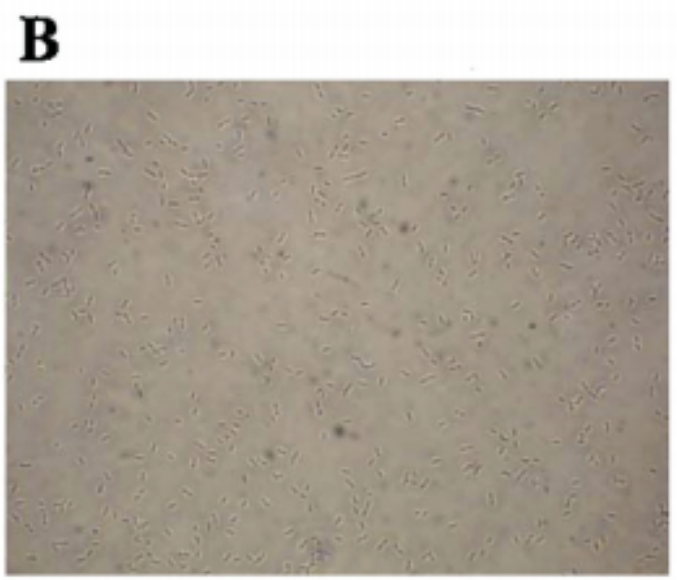

Control

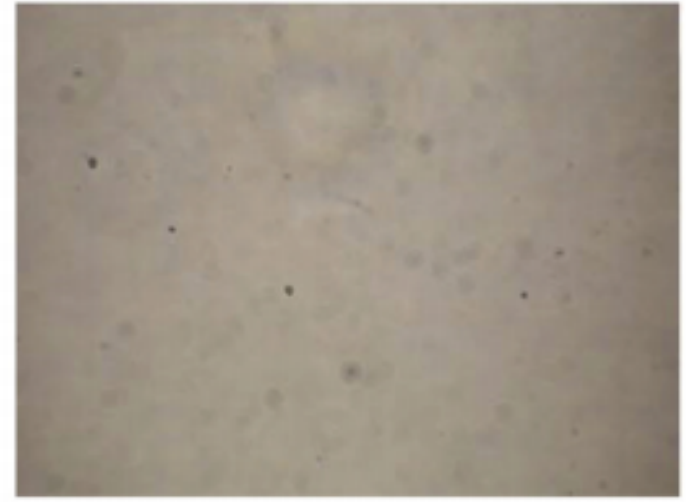

Treated with CMCS

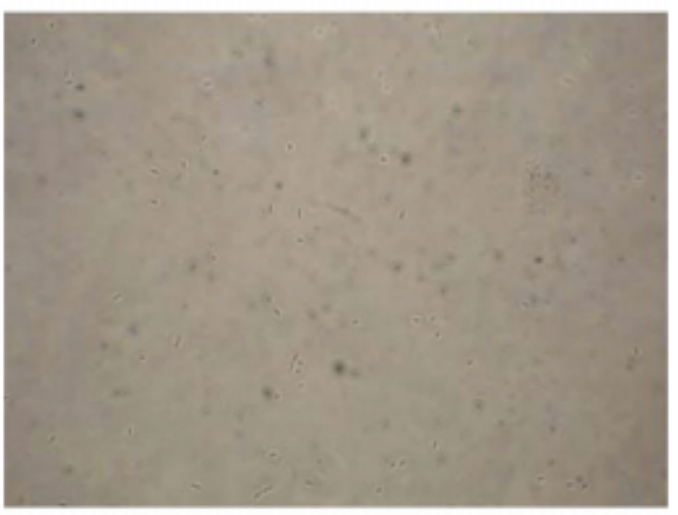

\section{Treated with CMCS}

Figure 10 - Light microscopy images of the initial adhesion of (A) S. aureus RN6390 or (B) P. aeruginosa PAO1 attached on the surfaces without (left) or with (right) CM-chitosan (Tan, Han, Ma, \& Yu, 2011). 
Chitosan was also investigated for its ability to reduce biofilm formation. Researchers added a range of concentrations of $\mathrm{CM}$-chitosan containing solutions at different stages of bacterial biofilm development. The bacteria with $\mathrm{CM}$ - chitosan was incubated at 37 Celsius, rinsed and stained. The result shows that more than $90 \%$ of the cells in both bacteria were prevented from adhering to the surfaces (Figure 10). From these results, the researchers deduced that CMchitosan inhibits the adhesion of bacteria to the surface which reduced the formation of biofilm (Martinez et al., 2009; Orgaz, Lobete, Puga, \& Jose, 2011; Tan, Han, Ma, \& Yu, 2011; Tang et al., 2010).

\section{HACC Prevents Biofilm Formation On Titanium Surface}

In this study, hydroxypropyltrimethyl ammonium chloride chitosan (HACC) was used to reduce biofilm growth on the surface of titanium. HACC was tested with different degrees of substitution and also at different concentrations. The two biofilms grown on titanium disk surfaces are staphylococcus aureus and staphylococcus epidermis. In this experiment the tissue cultured plate method was used to quantify the biomass of the biofilms (Peng et al., 2011).

In Figure 11, the result of a5, b5, c5 shows that there are fewer clumps of biofilm formed when high concentrations of HACC are present on the infected site regardless of the degree of substitution (Peng et al., 2011). 


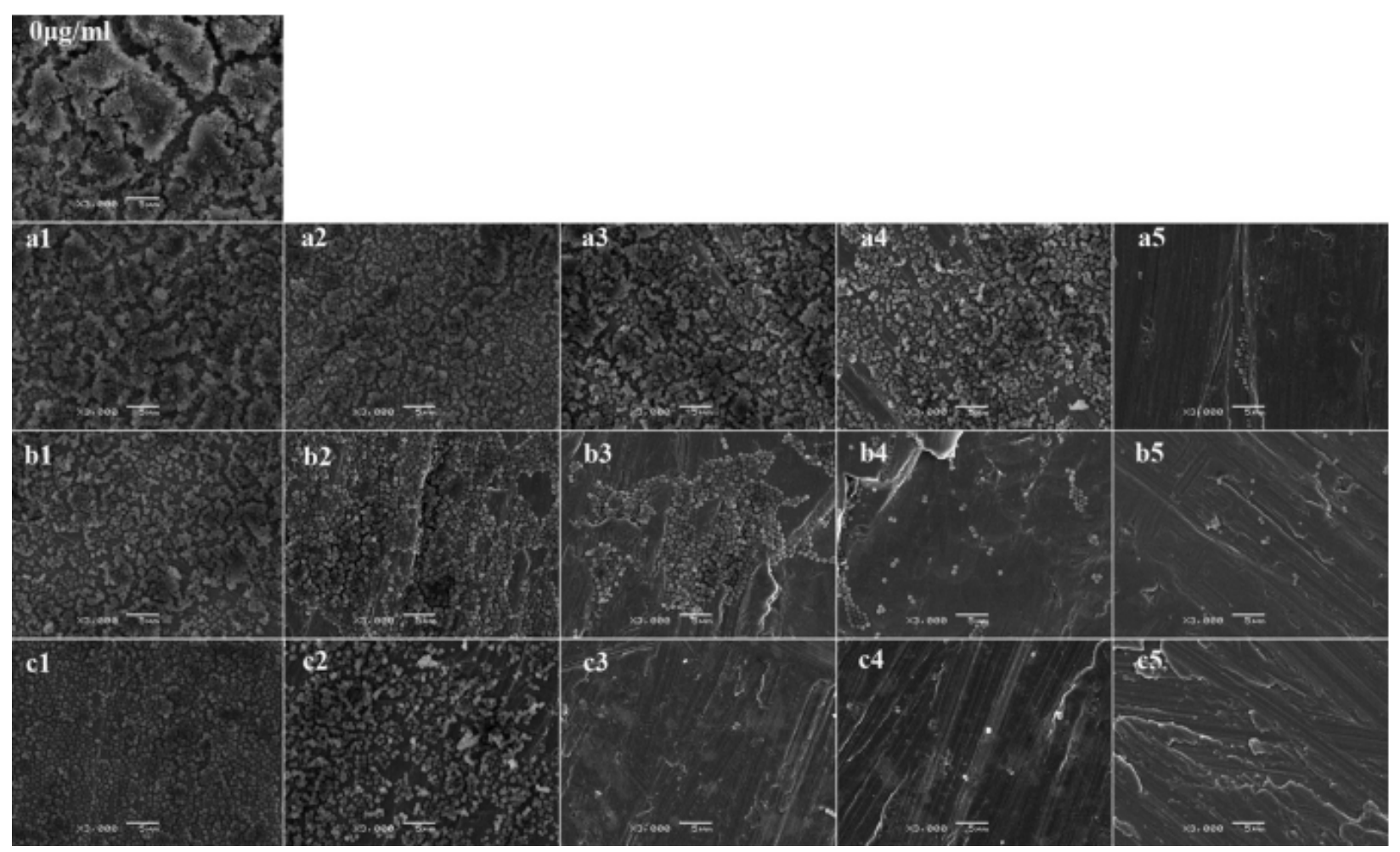

Concentration

Figure 11 - Scanning electron micrographs of biofilms formed by S. epidermidis strain ATCC 35984 incubated on a titanium surface for $24 \mathrm{~h}$ with HACC $6 \%$ (a), $18 \%$ (b), or $44 \%$ (c) at the following concentrations: $0 \_\mathrm{g} / \mathrm{ml}, 4 \_\mathrm{g} / \mathrm{ml}(1), 32 \_\mathrm{g} / \mathrm{ml}(2), 64 \_\mathrm{g} / \mathrm{ml}$ (3), $128 \_\mathrm{g} / \mathrm{ml}$ (4), or 256 _g/ml (5). Magnification, _3,000. Scale bars, 5 _m (Peng et al., 2011).

In Figure 12, fluorescent staining was added to the biofilms in the images a5, b5 and c5.

The red stains shown cell apoptosis which were expressed greatly in the images a5, b5 and c5 (Peng et al., 2011). 

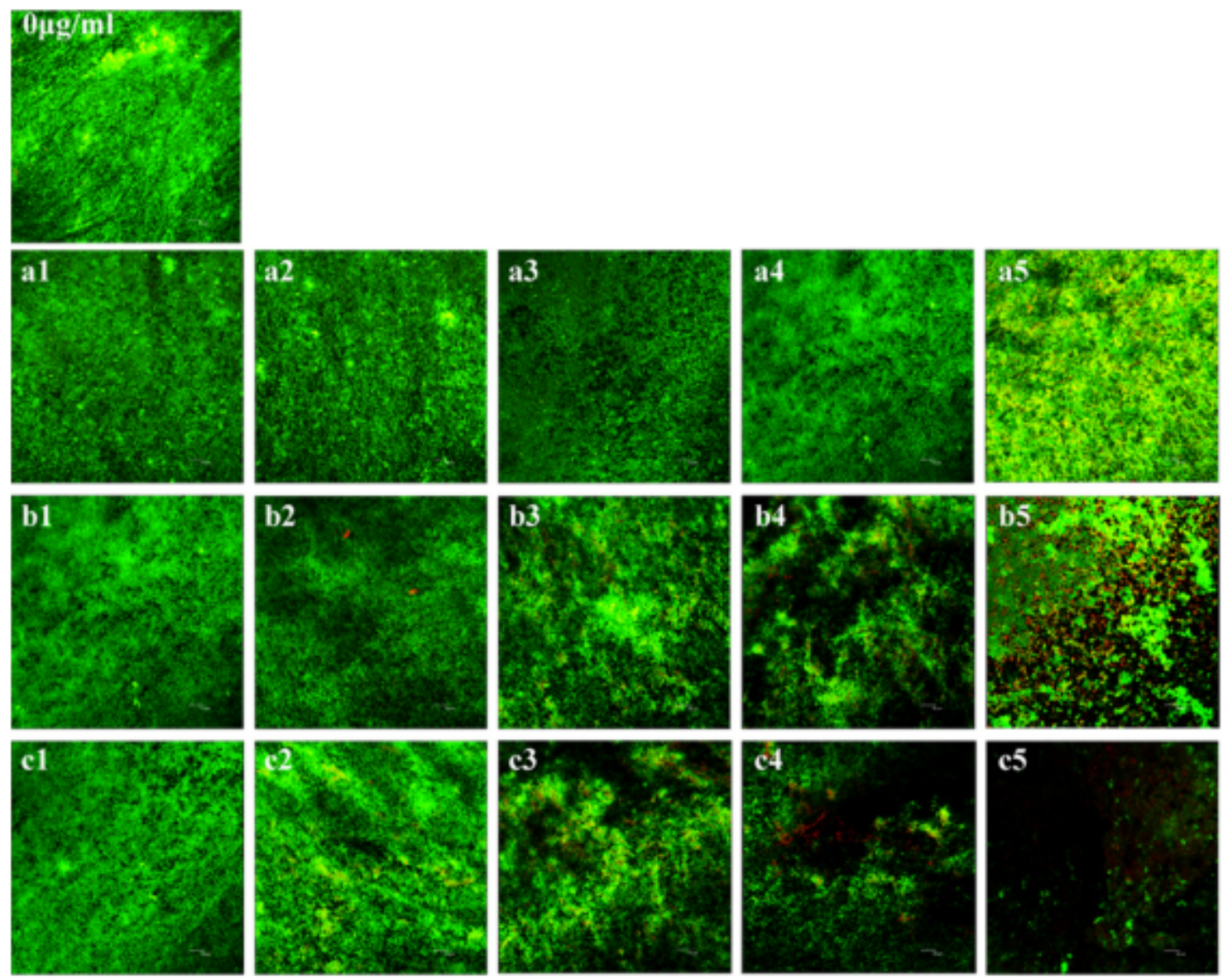

Figure 12 - Bacteria were stained with green fluorescent SYTO 9 and red fluorescent propidium iodide, resulting in live cells appearing green and dead cells appearing red under CLSM (Peng et al., 2011).

The data from this research has shown that even at concentrations lower than minimum inhibitory concentration assay, HACC can still significantly inhibit biofilm formation. Through this study, HACC has shown that increasing degrees of substitution and concentrations can effectively reduce previous biofilm growth and prevent new biofilm growth (Adams, Jr. et al., 2008; Peng et al., 2011). Although biofilm formation is significantly reduced at $18 \%$ and $44 \%$ degrees of substitution, $44 \%$ is toxic to living cells (cytotoxic). HACC at $18 \%$ is a better choice for degree of substitution because it is non-cytotoxic to L-929 cells and highly compatible with osteogenic cells (Peng et al., 2011). 
From the results of the two experiments mentioned above, chitosan has the potential to cause apoptosis to bacterial cells. Chitosan appears to be a potential solution in reducing bacterial growth and attachment. In the future more experiments can be conducted to fully examine chitosan's properties in reducing bacterial growth and its potential to become a biomaterial. 


\section{CHAPTER TWO}

\section{Objectives}

The goals of my thesis:

1) To observe bacterial growth on metal surfaces in a static bioreactor.

2) To demonstrate that the approach may also be used to study non- metallic material.

3) To demonstrate that the approach may also be used to study the effect of treatments on the surface. 


\section{CHAPTER THREE}

\section{Materials and Procedures}

A protocol was developed to satisfy the objectives listed in Chapter 2. Five different materials including four different metals and one polymer were exposed to a bioactive environment. Two of the metals were tested in two different conditions, as received and welded. All metal samples were tested at the same level of the mechanical surface preparation, polished through $1 \mu \mathrm{m}$ diamond. The polymeric material was tested in the as-received condition.

\section{$\underline{\text { Materials }}$}

The following are groups of metals and polymers used in this experiment:

I. A group of eight Austenitic Stainless Steels (303 and 304) 
Table 1 - Austenitic Stainless Steel Samples

\begin{tabular}{|c|c|c|c|c|}
\hline Materials & Surface & TMT & Direction & Comments \\
\hline 303SS & 600 grit & Unwelded & Longitudinal & $\begin{array}{l}\text { Demonstrate use for surface } \\
\text { altered metallic materials }\end{array}$ \\
\hline $304 \mathrm{SS}$ & 600 grit & Unwelded & Longitudinal & $\begin{array}{l}\text { Demonstrate use for surface } \\
\text { altered metallic materials }\end{array}$ \\
\hline $303 \mathrm{SS}$ & $1 \mu \mathrm{m}$ & Unwelded & Longitudinal & $\begin{array}{l}\text { Demonstrate use for surface } \\
\text { altered metallic materials }\end{array}$ \\
\hline 304SS & $1 \mu \mathrm{m}$ & Unwelded & Longitudinal & $\begin{array}{l}\text { Demonstrate use for surface } \\
\text { altered metallic materials }\end{array}$ \\
\hline $303 \mathrm{SS}$ & $1 \mu \mathrm{m}$ & Unwelded & CrossSection & $\begin{array}{l}\text { Demonstrate use for surface } \\
\text { altered metallic materials }\end{array}$ \\
\hline $304 \mathrm{SS}$ & $1 \mu \mathrm{m}$ & Unwelded & CrossSection & $\begin{array}{l}\text { Demonstrate use for surface } \\
\text { altered metallic materials }\end{array}$ \\
\hline 304SS & $1 \mu \mathrm{m}$ & Welded & Longitudinal & $\begin{array}{c}\text { Demonstrate use for metallic } \\
\text { materials }\end{array}$ \\
\hline 304SS & $1 \mu \mathrm{m}$ & Welded & CrossSection & $\begin{array}{l}\text { Demonstrate use for metallic } \\
\text { materials }\end{array}$ \\
\hline
\end{tabular}


II. A group of three AISI Steels (1018 and 1075)

Table 2 - AISI Steel Samples

\begin{tabular}{|c|c|c|c|c|}
\hline Materials & Surface & TMT & Direction & Comments \\
\hline Steel 1018 & $1 \mu \mathrm{m}$ & Unwelded & Longitudinal & $\begin{array}{c}\text { Demonstrate use for surface } \\
\text { altered metallic materials }\end{array}$ \\
\hline Steel 1018 & $1 \mu \mathrm{m}$ & Unwelded & CrossSection & $\begin{array}{c}\text { Demonstrate use for surface } \\
\text { altered metallic materials }\end{array}$ \\
\hline Steel 1075 & $1 \mu \mathrm{m}$ & Welded & Longitudinal & $\begin{array}{c}\text { Demonstrate use for } \\
\text { metallic materials }\end{array}$ \\
\hline
\end{tabular}

III. Polystyrene

Table 3 - Polystyrene Samples

\begin{tabular}{|c|c|c|c|c|}
\hline Materials & Surface & TMT & Direction & Comments \\
\hline Polystyrene & AR & AR & AR & $\begin{array}{c}\text { Demonstrate use for } \\
\text { non-metallic materials }\end{array}$ \\
\hline
\end{tabular}

\section{Preparing Static Bioreactor}

A glass container was used as a static bioreactor. The components of the bioreactor (Figure 19) were disinfected by methanol to sanitize the system. The system was sprayed with methanol and dried with paper towels.

The appropriate materials were laid out to ensure that they fit into the proper places before the assembly of the bioreactor system (Figure 19). This includes preparing tongs, placing glassware lid, readying fixing chemical, applying masking tape, and placing cotton balls. 


\section{Preparing and Characterizing Sample for Pre-Exposure}

The samples were sized to $1 \mathrm{~cm}$ by $2 \mathrm{~cm}$ by a chop saw. The samples were Bakelite mounted in the Buehler SimpliMet 2 Mounting Press. The detailed protocol of Mounting Procedure can be found in Appendix D. The samples were sanded with 240, 400 and 600 grit sand papers to remove major scratches or inclusions from the surface. The sanded samples were imaged to characterize the surface roughness (see Appendix D).

The samples were diamond polished from $6 \mu \mathrm{m}$ to $1 \mu \mathrm{m}$ (Figure 15, 17) with the polishing wheels (Figure 14). The appropriate Forgeng's Solution (Figure 16) was added as a lubricant (see Appendix D). In order to create samples with different surface properties, some samples were only polished with the coarsened wheel (6 um), while others were polished all the way to the finishing wheel (1 um).

The polished stainless steel samples were Electrochemically Etched with the Buehler Electromet III (Figure 18, 10\% folic acid) at 4 volts and 2 amps for approximately 15 to 20 seconds to prepare for imaging. The polished steel samples were etched with Nital (2ml $\mathrm{NHO}_{3}$ and $98 \mathrm{ml}$ methanol) for approximately 3 to 5 seconds to prepare for imaging (see Appendix E).

The samples were imaged by the optical light microscope (Figure 13) to identify the microstructure of the surface. For the non-welded samples, the images were focused on the bulk material for surface properties and inclusions. The images of the welded samples were focused on the welded region, the HAZ and the bulk material. Each sample has multiple images taken for a more precise characterization of the surface.

After imaging, the samples were re-polished to remove corrosion and pitting caused by the etching procedure before exposure. The samples were cleaned and sanitized by methanol 
to remove bacteria from the surface. This ensures that the biofilm development was from the natural water in the bioreactor.

\section{Sample Exposure}

Natural water collected from Brizzolara Creek was used as the media for the bioreactor. The media was added into the static bioreactor until the samples were completely submerged. The samples were spaced out on the bottom of the reactor. The mounted portion was exposed to the natural water. The smaller (non-Bakelite mounted) samples were suspended in the natural water while attached to nylon monofilament (fishing line). The glass container was sealed off with a glass lid in order to maintain a static environment. The metal samples were submerged in the static bioreactor for 24 hours. The non-metal samples were submerged in the static bioreactor for 9 days.

Immediately after removal the samples were submerged, sequentially, in Glutaraldehyde, pure Ethanol, and pure Feon (trichlorotrifluoroethane). The samples were submerged in each liquid for three minutes. The solutions fix and dehydrate the attached microbes on the surface of the samples. For a detailed protocol, please refer to Appendix B.

\section{IV. $\quad$ Post Exposure - Sample Characterization \& Imaging}

The samples were imaged in the Hitachi TM-1000. Because the Hitachi TM-1000 is an Environmental SEM, additional coating wasn't needed. Conventional SEM requires the sample to be sputter coated with carbon or gold in order to produce images. For each sample, several images were taken at different locations of the exposed surface. The recorded images of the 
exposured surface were used to analyze the microbial activity and the biofilm growth on the substratum.

\section{Analyzing Biofilm Growth}

Microbial attachments observed on the surface of metallic materials and non-metallic materials with the Scanning Electron Microscope were characterized for shape and distribution. These were correlated to the underlying structures observed with optical microscopy and with scanning electron microscopy prior to exposure.

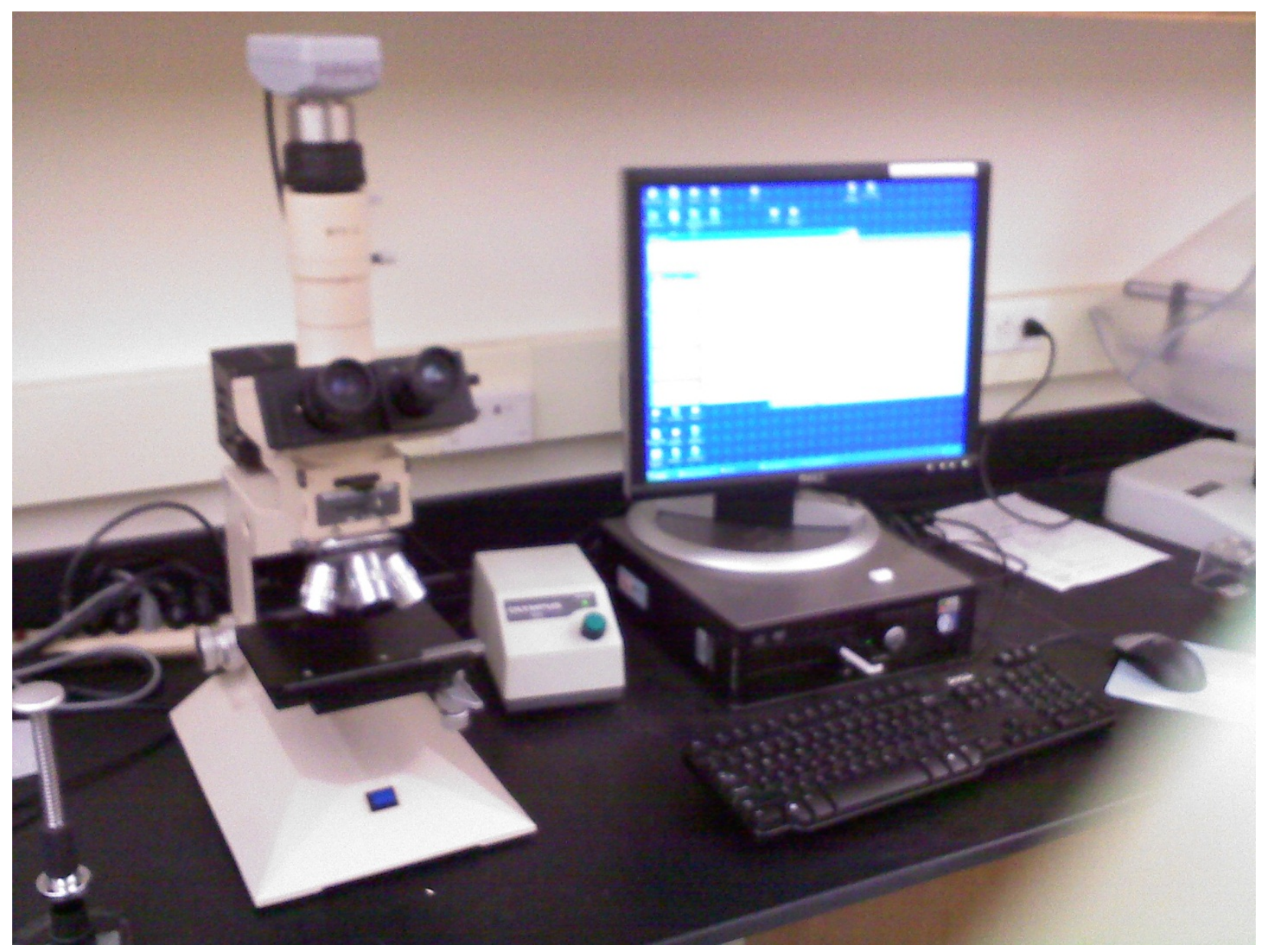

Figure 13 - Optical Light Microscope. 


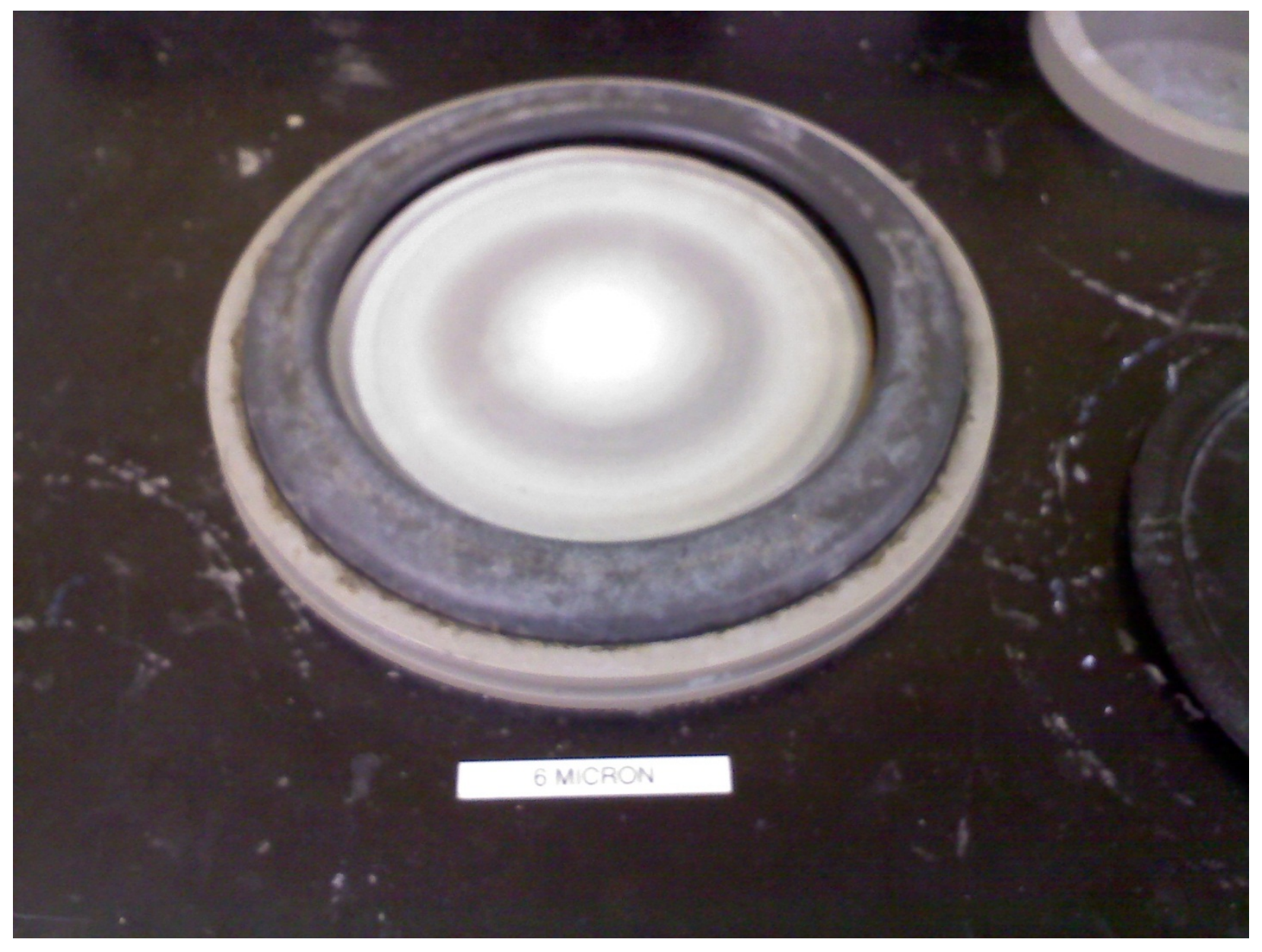

Figure 14 - Polishing Wheel. 


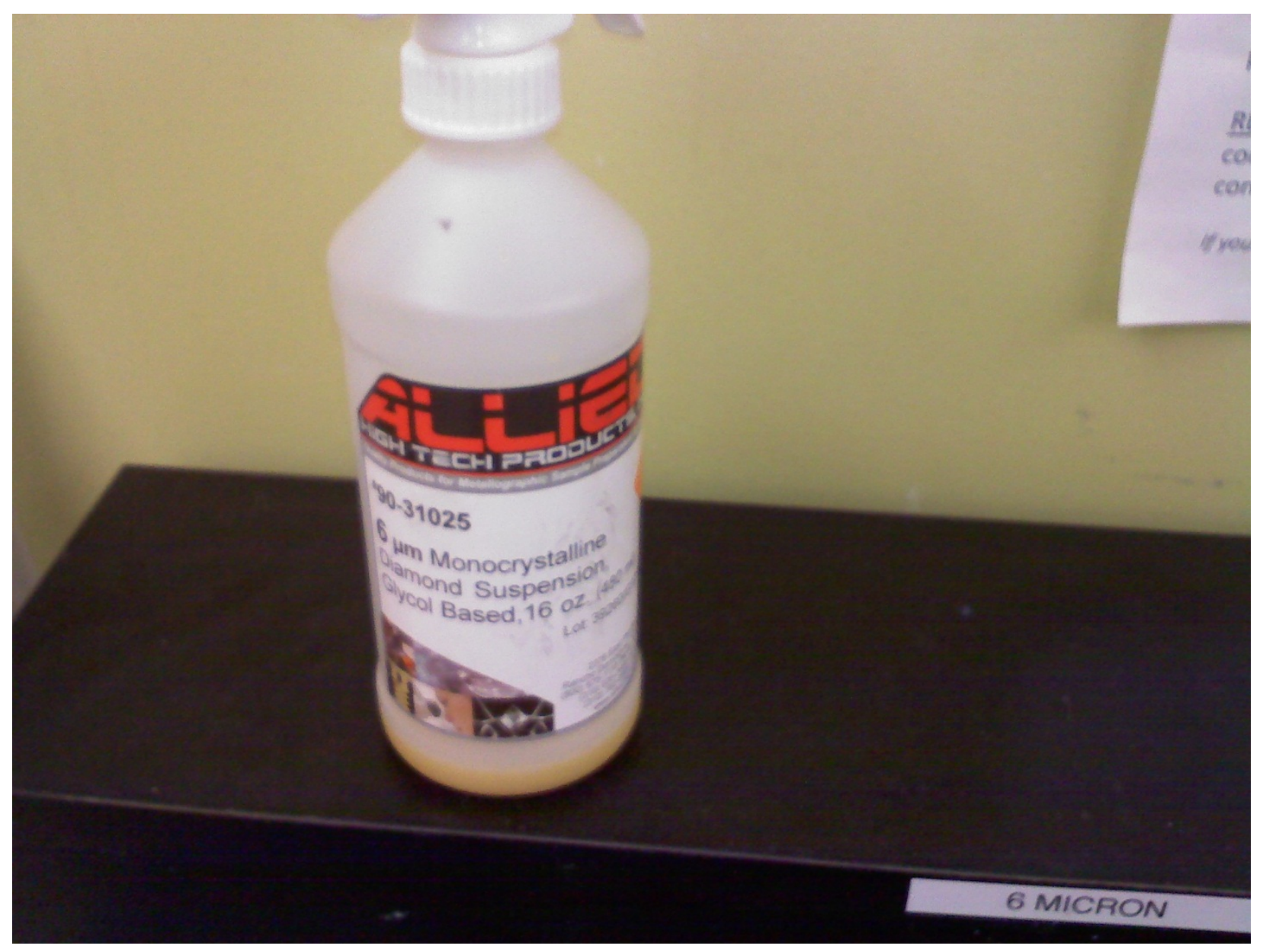

Figure 15 - $6 \mu \mathrm{m}$ Diamond Polish. 


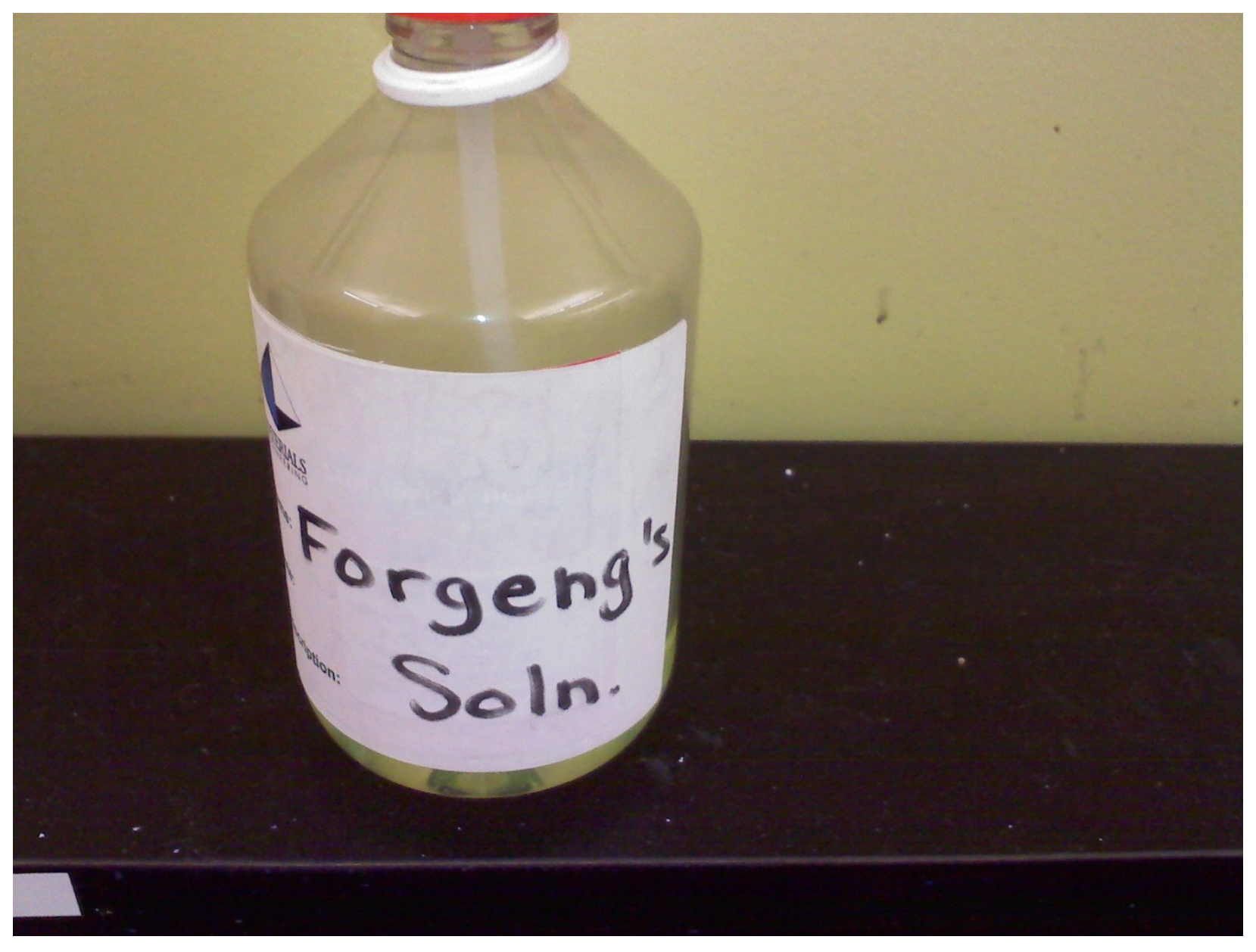

Figure 16 - Forgeng's Solution. 


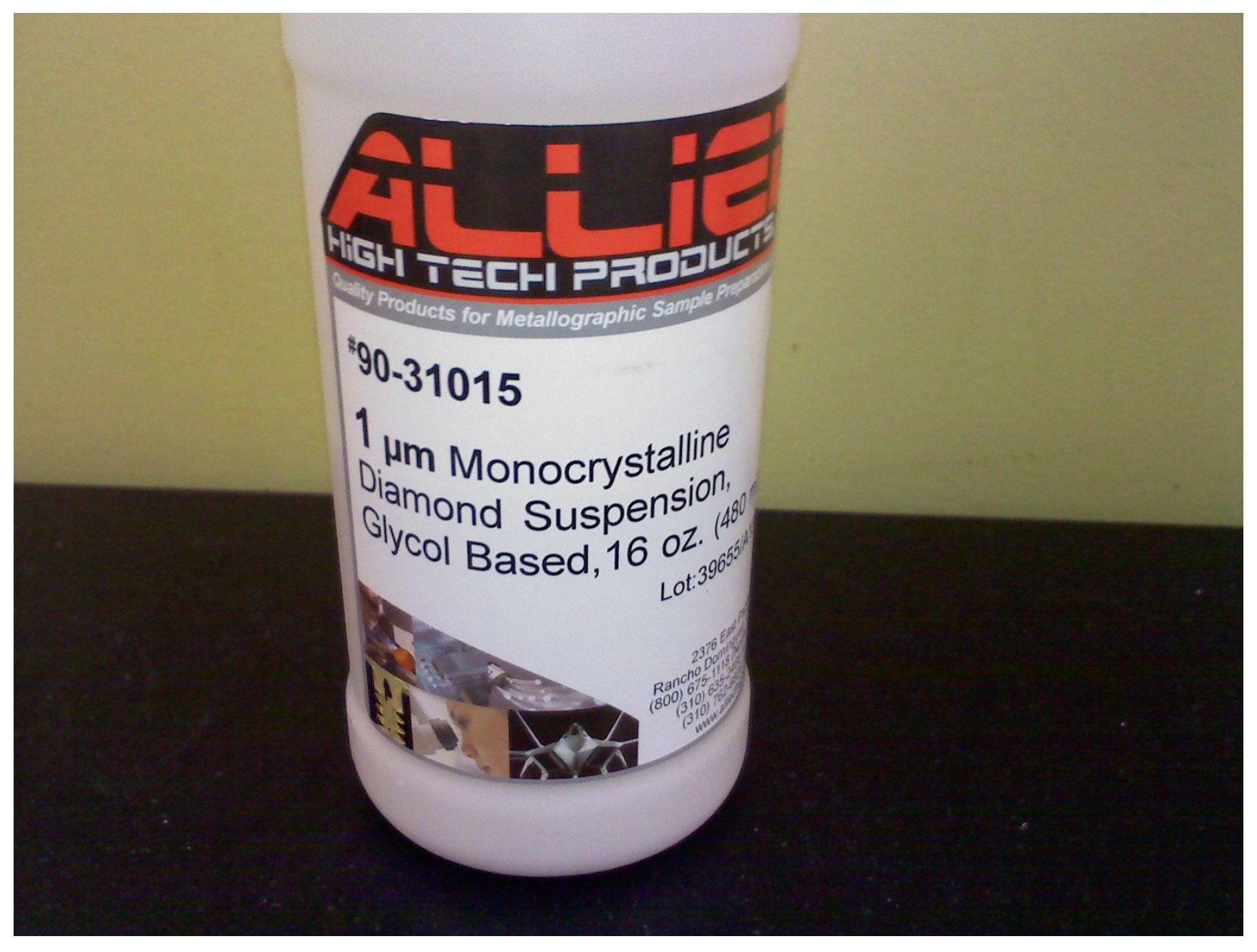

Figure 17 - 1 $\mu \mathrm{m}$ Diamond Polish. 


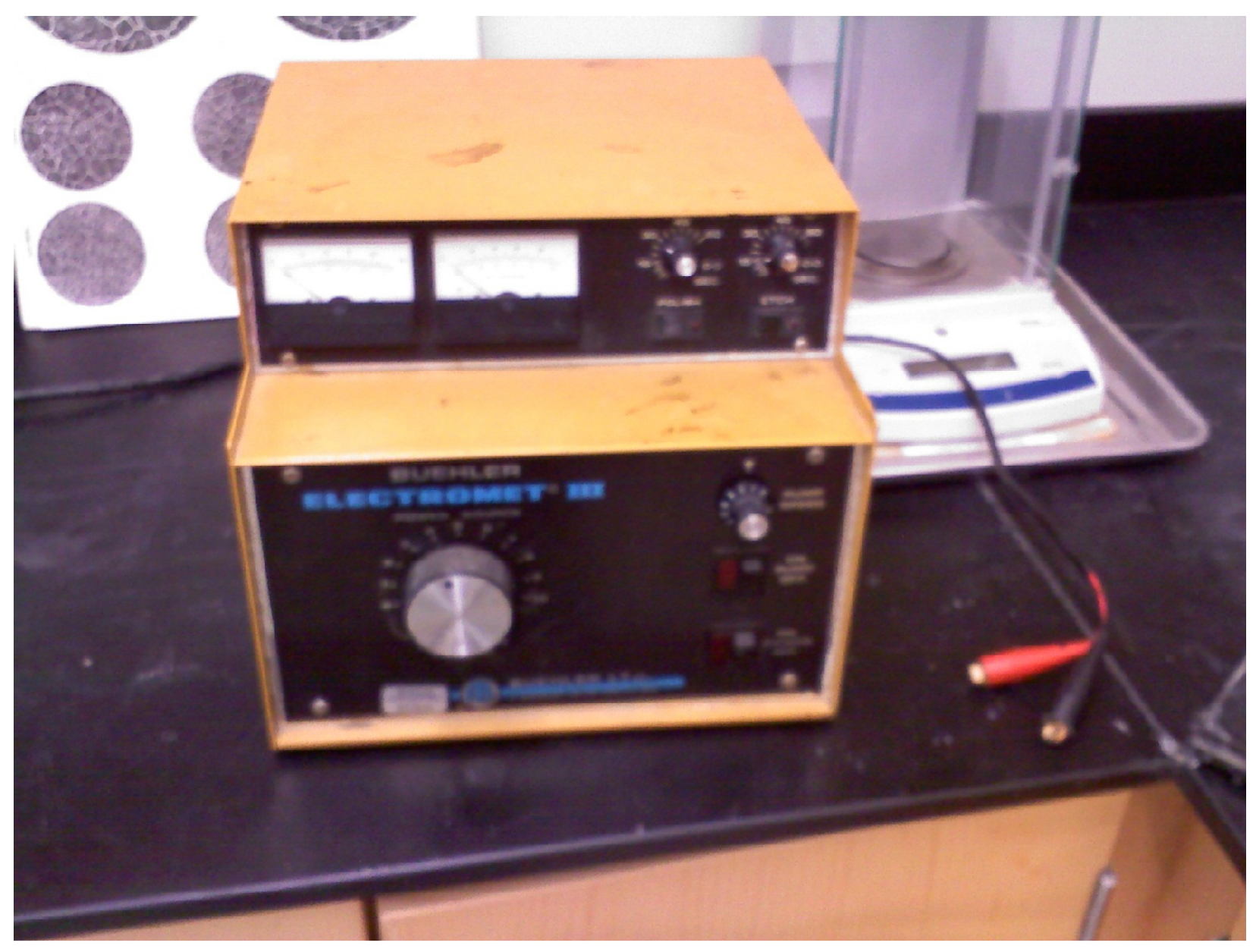

Figure 18 - Electromet III. 


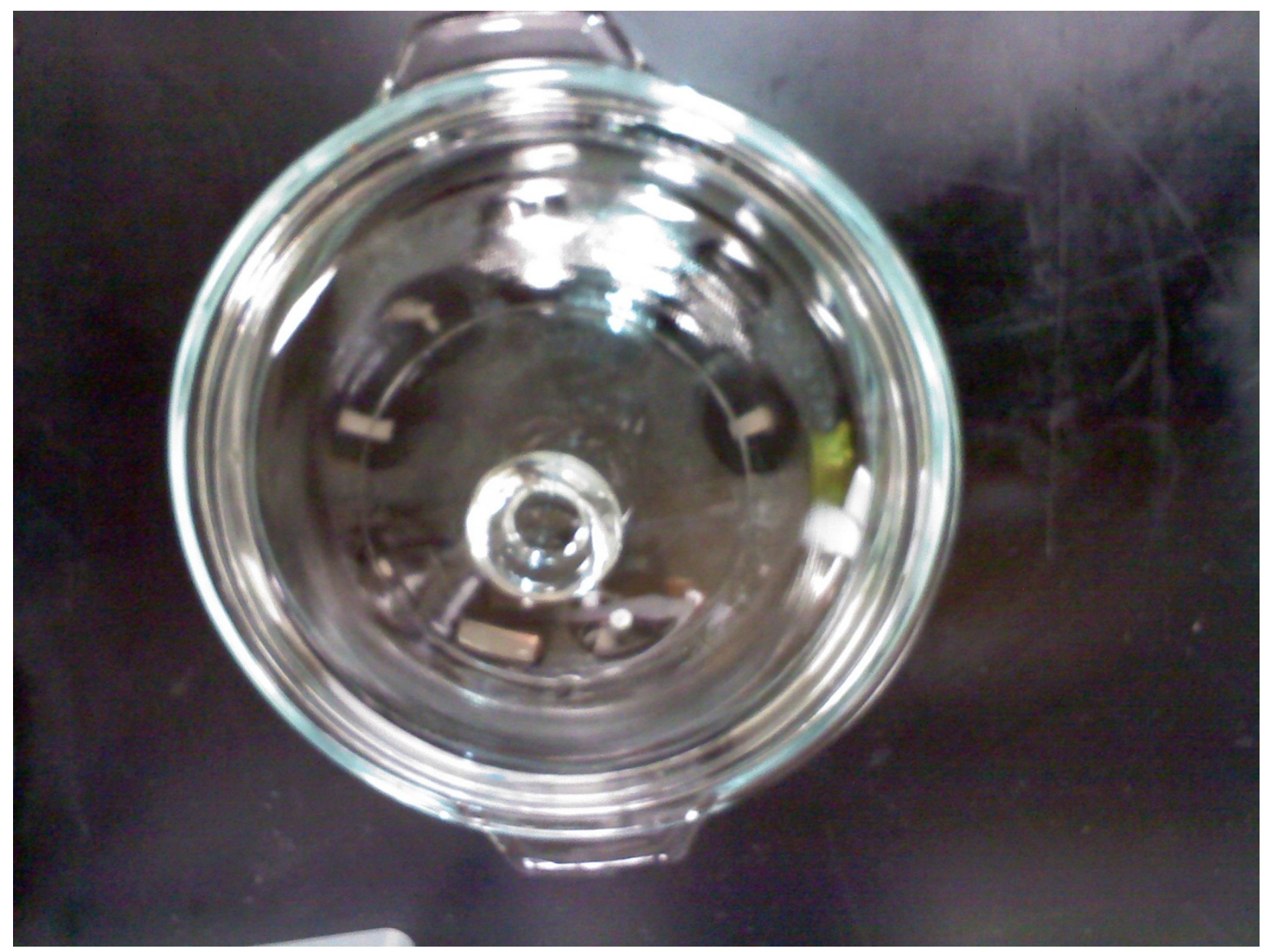

Figure 19 - Static Bioreactor With Submerged Samples. 


\section{CHAPTER FOUR}

\section{Results and Discussion}

I. Pre - Exposure Inspection - Optical Light Microscopy

1. Samples Sanded To 600 Grit:

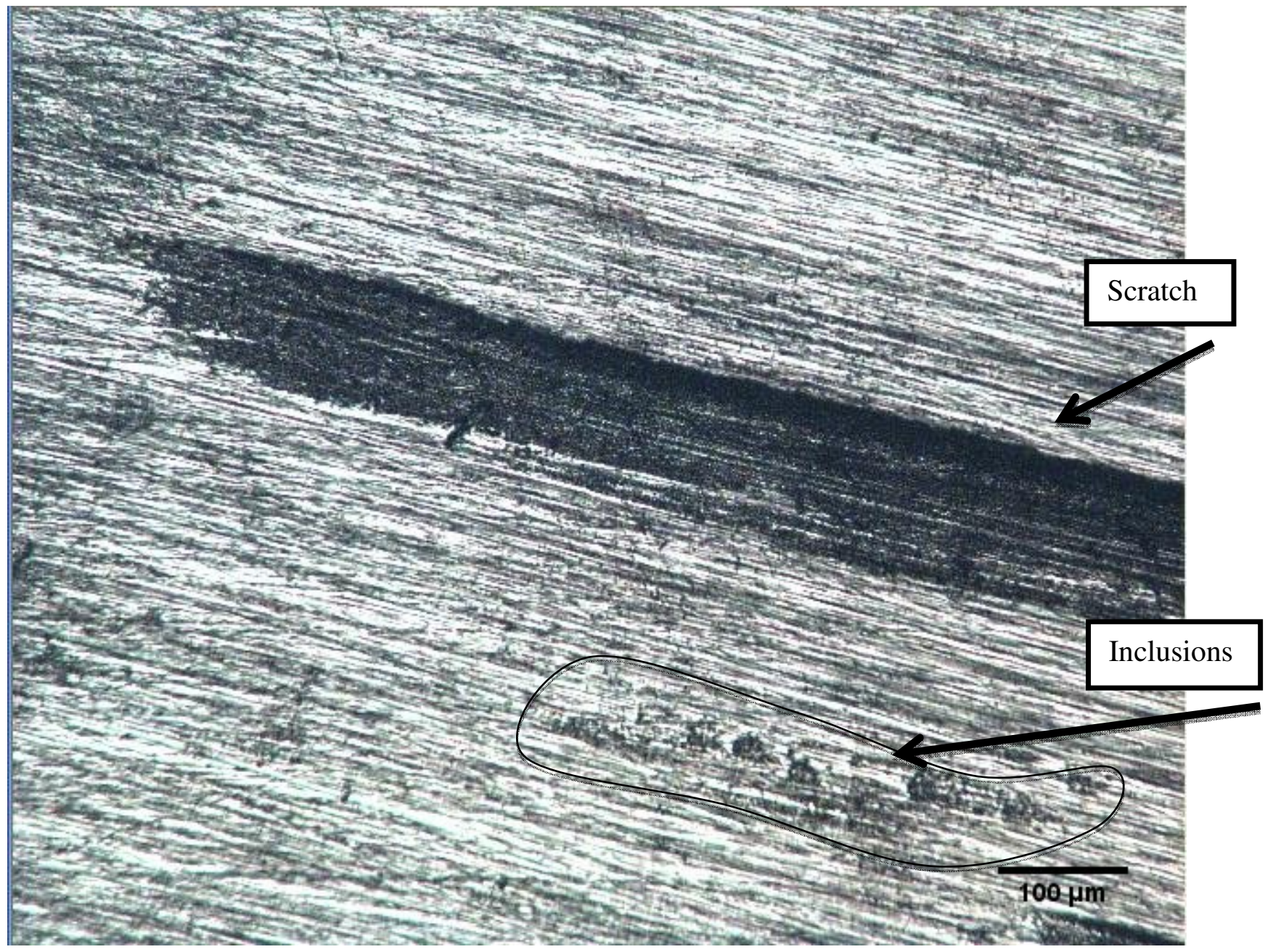

Figure 20 - 303 SS surface after 600 grit sanding (Originally captured at 100X). Note the deep scratch on the surface. 
Figure 20 shows the surface of a sample of 303 SS ground through 600 grit sanding paper. The dark line that travels through the middle of the image was a deep scratch left on the surface of the metal during the cutting process. The smaller lines traveling down the image were scratches left from sanding. As the sand paper becomes finer, the scratches become narrower. The small shapes at the lower right of the image are nonmetallic inclusions.

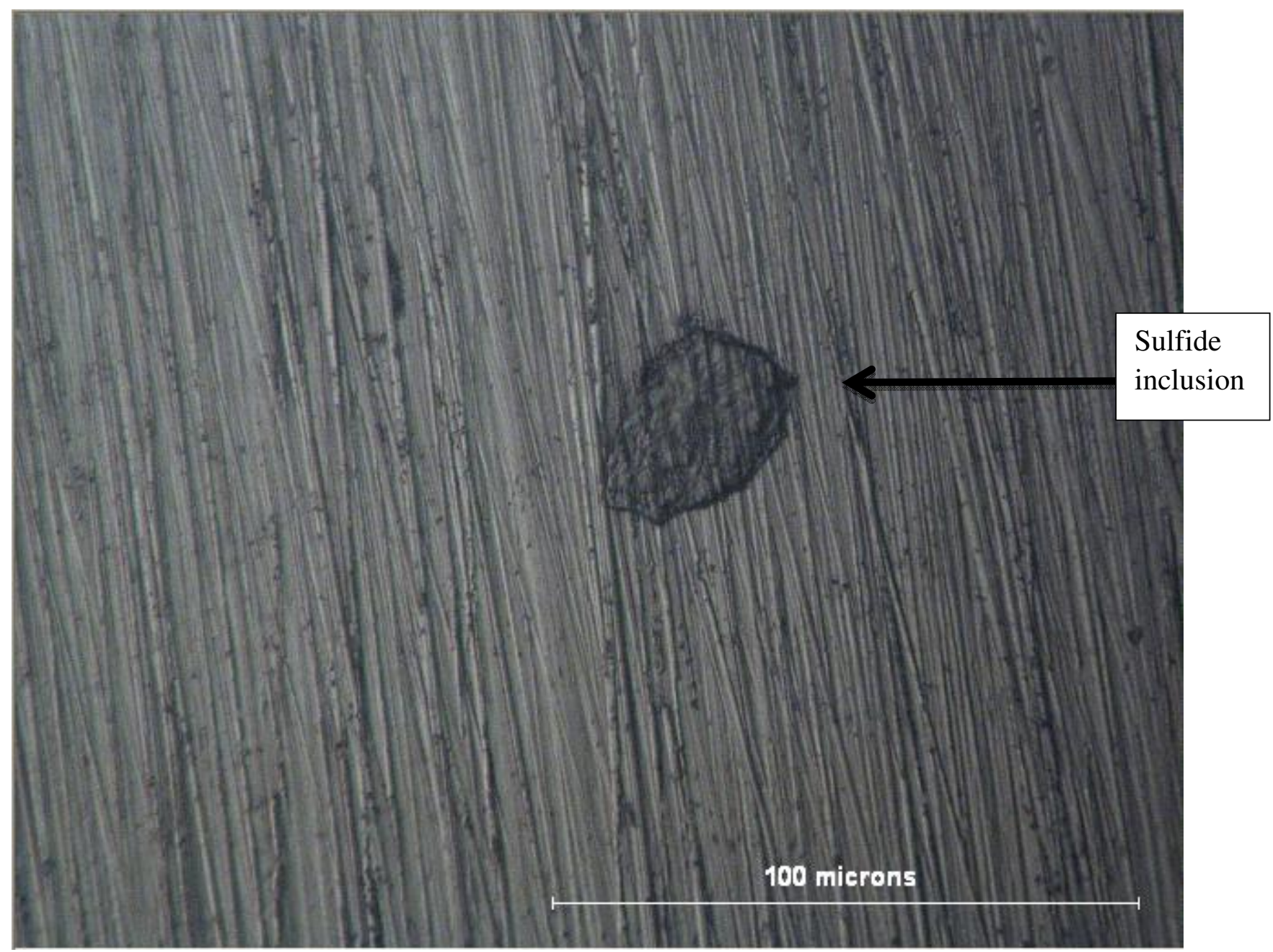

Figure 21 - Microstructure of 303 SS after 600 grit sanding (Originally captured at 500X). Note the large sulfide inclusion. 
Figure 21 shows the surface of a sample of 303 SS ground through 600 grit sanding paper.

The scratches seen are remnants from sanding the surface to 600 grit. The large shape on the surface is a sulfide inclusion; some sanding remnants are seen on that surface as well. The 303 is a re-sulfurized stainless steel, the sulfur additions are meant to improve machinability. In some cases the added sulfur diminishes the corrosion resistance of the material.

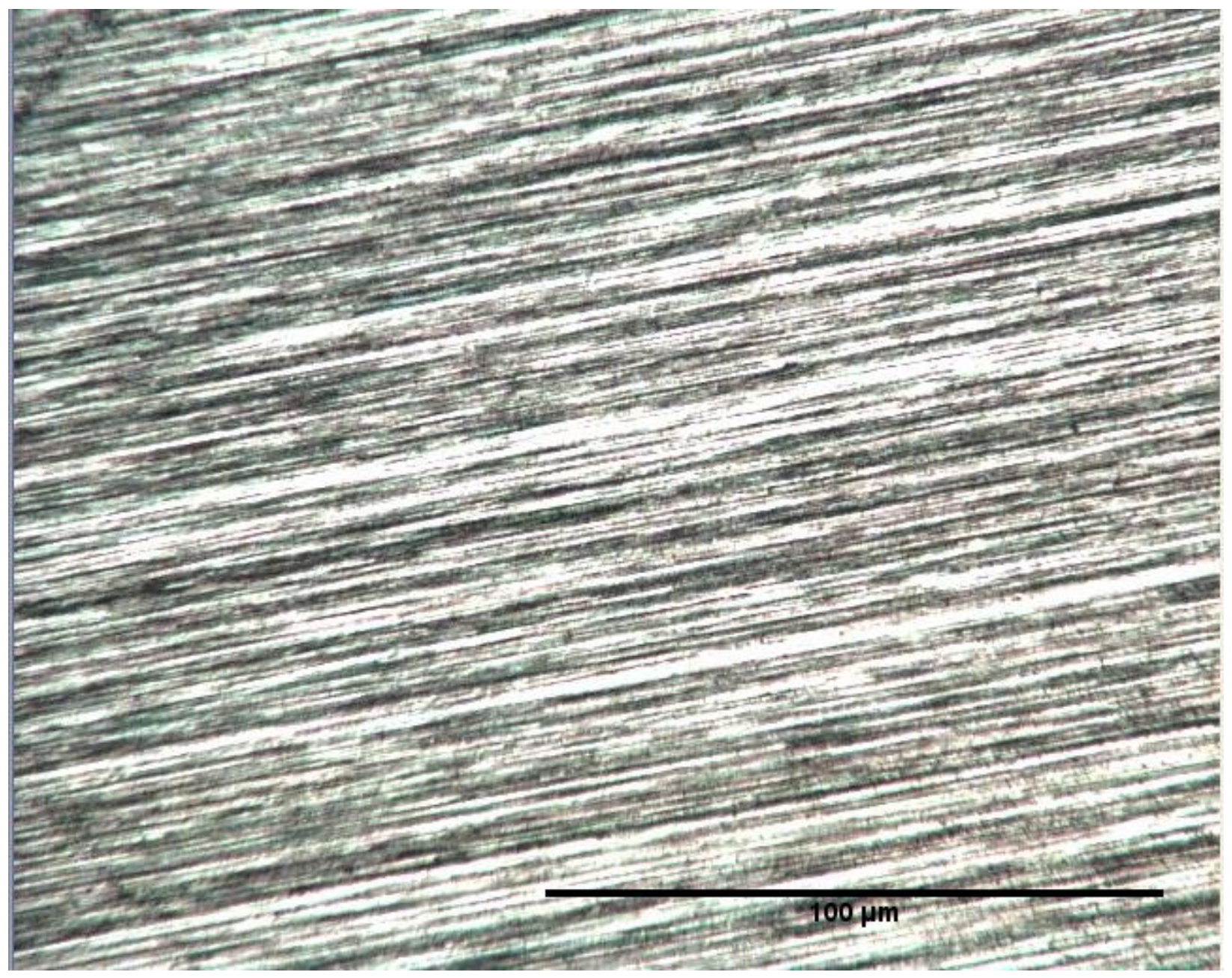

Figure 22 - 304 SS after 600 grit sanding (Originally captured at 500X). Note the surface lacks sulfide inclusions.

Figure 22 shows the surface of a sample of 304 SS ground through 600 grit sanding paper. The surface of this sample appears to be sulfide inclusion free, at least at the magnification used. 
The small lines observed in the image are again scratches left behind from sanding. As mentioned before, finer sand paper leaves behind smaller scratches.

2. Samples polished from $6 \mu \mathrm{m}$ to $1 \mu \mathrm{m}$ :

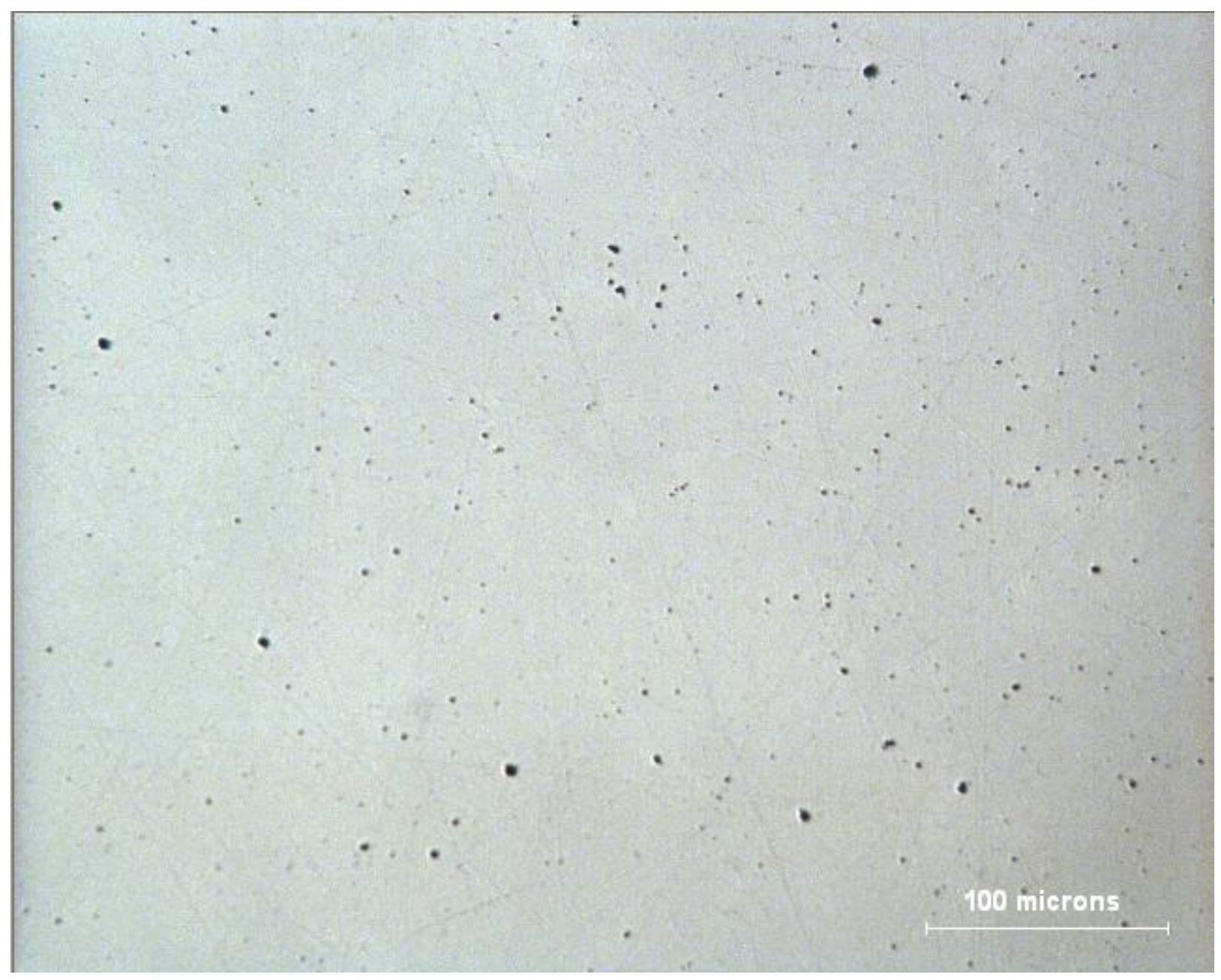

Figure 23 - 303 SS after $1 \mu \mathrm{m}$ diamond polishing (Originally captured at 200X).

Note the abundance of sulfide inclusions.

Figure 23 showed the surface of a sample of 303 SS. The sample's surface was diamond polished from $6 \mu \mathrm{m}$ through $1 \mu \mathrm{m}$. The lines in the image were scratches left on the surface after 
polishing. Surface features still remained on the surface even after being diamond polished. The black dots in the image are inclusions on the microstructure of the sample.

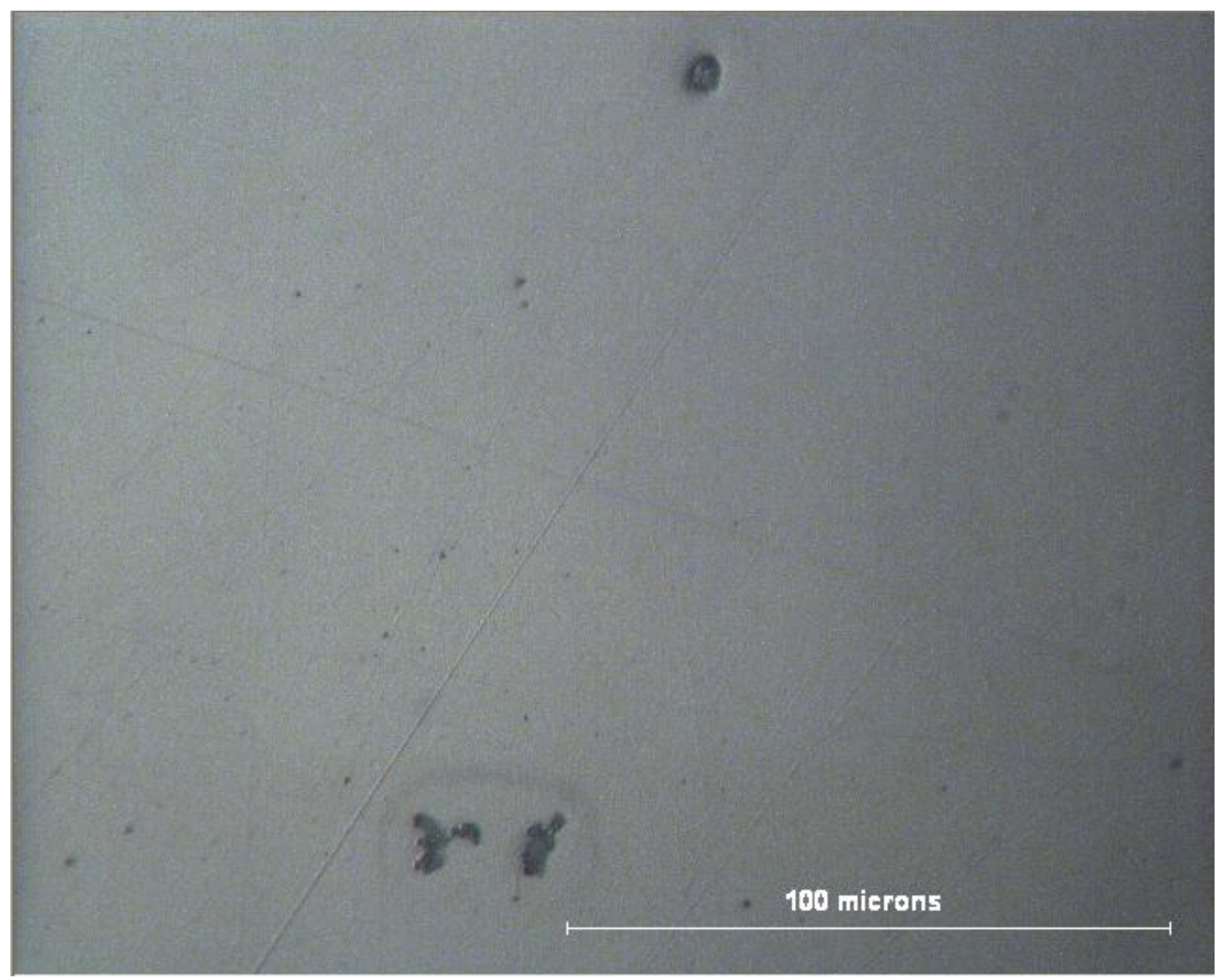

Figure 24 - Microstructure of 304 SS after $1 \mu \mathrm{m}$ diamond polishing (Originally captured at 500X). Note very few sulfide inclusions present.

Figure 24 showed the surface of a sample of 304 SS. The sample's surface was diamond polished from $6 \mu \mathrm{m}$ through $1 \mu \mathrm{m}$. The lines in the image were scratches left from the polishing process. The polishing produced a smooth surface that lacks surface features. The black spots in the top and bottom of the image are sulfide inclusions. 


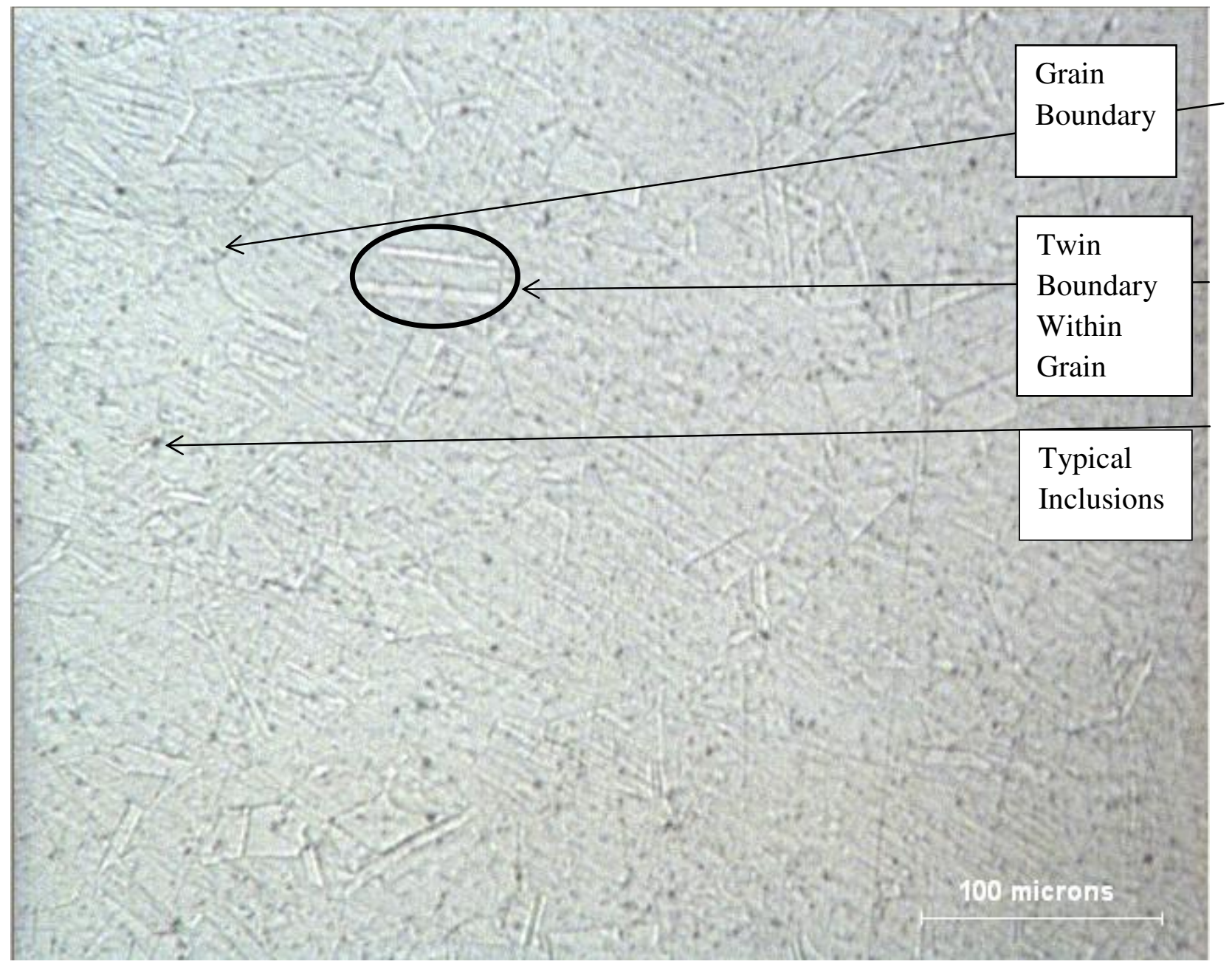

Figure 25 - Microstructure of 304 SS after $1 \mu \mathrm{m}$ diamond polishing (Originally captured at 200X, etched). Note the visible microstructure and grain boundaries.

Figure 25 showed the surface of a sample of 304 SS polished through $1 \mu \mathrm{m}$ diamond. The sample was electrochemically etched in $10 \%$ oxalic acid in order to show more details of the microstructure. The grain boundaries, as well as twin boundaries are clearly shown in the image. The etching process selectively corrodes interfaces at these locations in order to make them more evident. Although the etching process enhances the view of the grain boundaries, it also causes pitting (or pit corrosion). There were lots of black dots in this image. Although these black dots 
could be sulfide inclusions, given that this was 304 SS, they could also be pits formed during the etching process. The sample was re-polished to rid the surface of pitting prior to bacterial exposure.

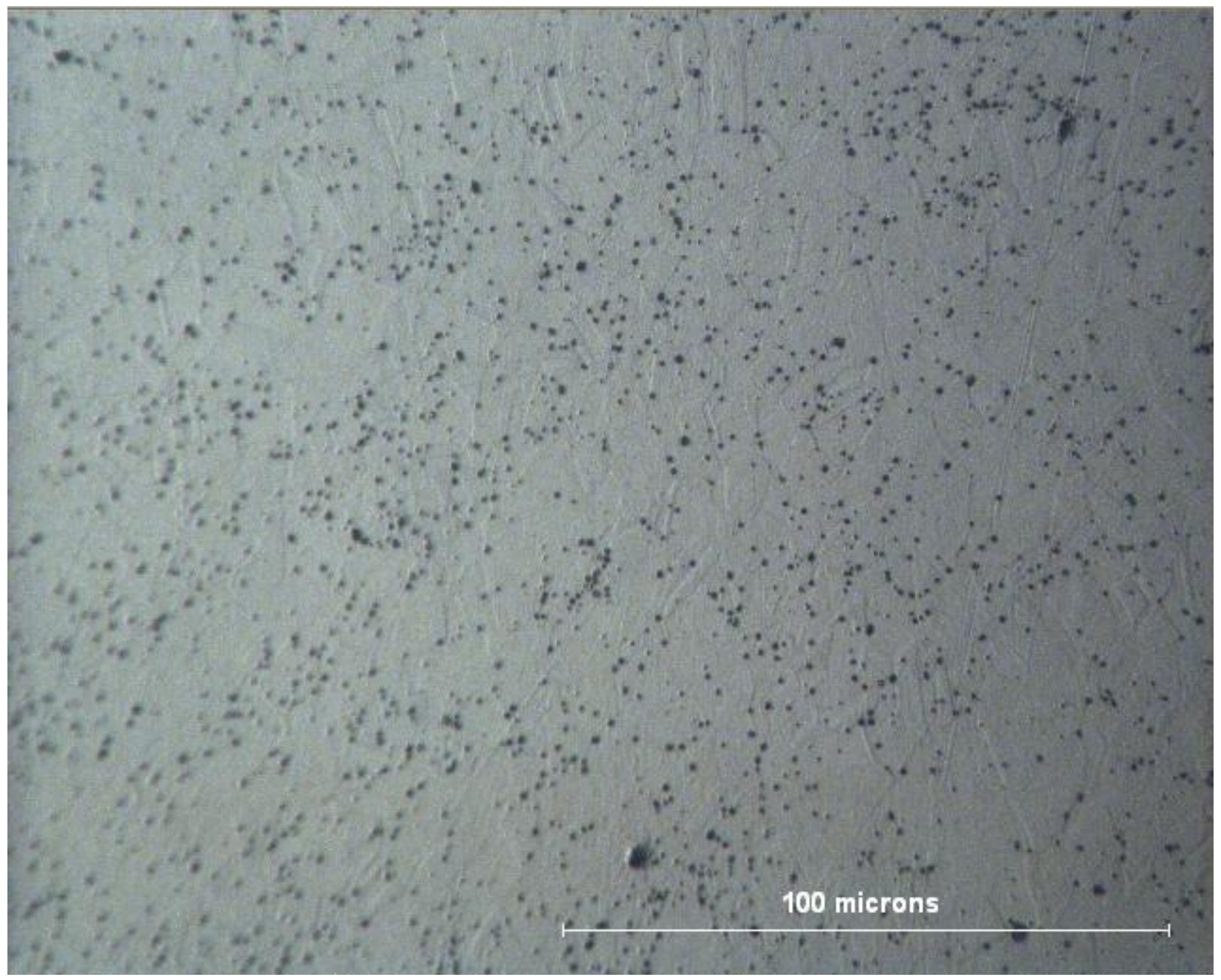

Figure 26 - Microstructure of 303 SS after $1 \mu \mathrm{m}$ diamond polishing (Originally captured at $500 \mathrm{X}$, etched). Note the visible microstructure and grain boundaries.

Figure 26 showed the surface of a sample of 303 SS polished through $1 \mu \mathrm{m}$ diamond. The sample was etched in $10 \%$ oxalic acid to show more details of the microstructure. As mentioned above, etching selectively attacks interfaces and can also cause pitting. The black 
dots in the image were pits and sulfide inclusions on the surface of the metal. The sample was re-polished to rid the surface of pitting before bacterial exposure.

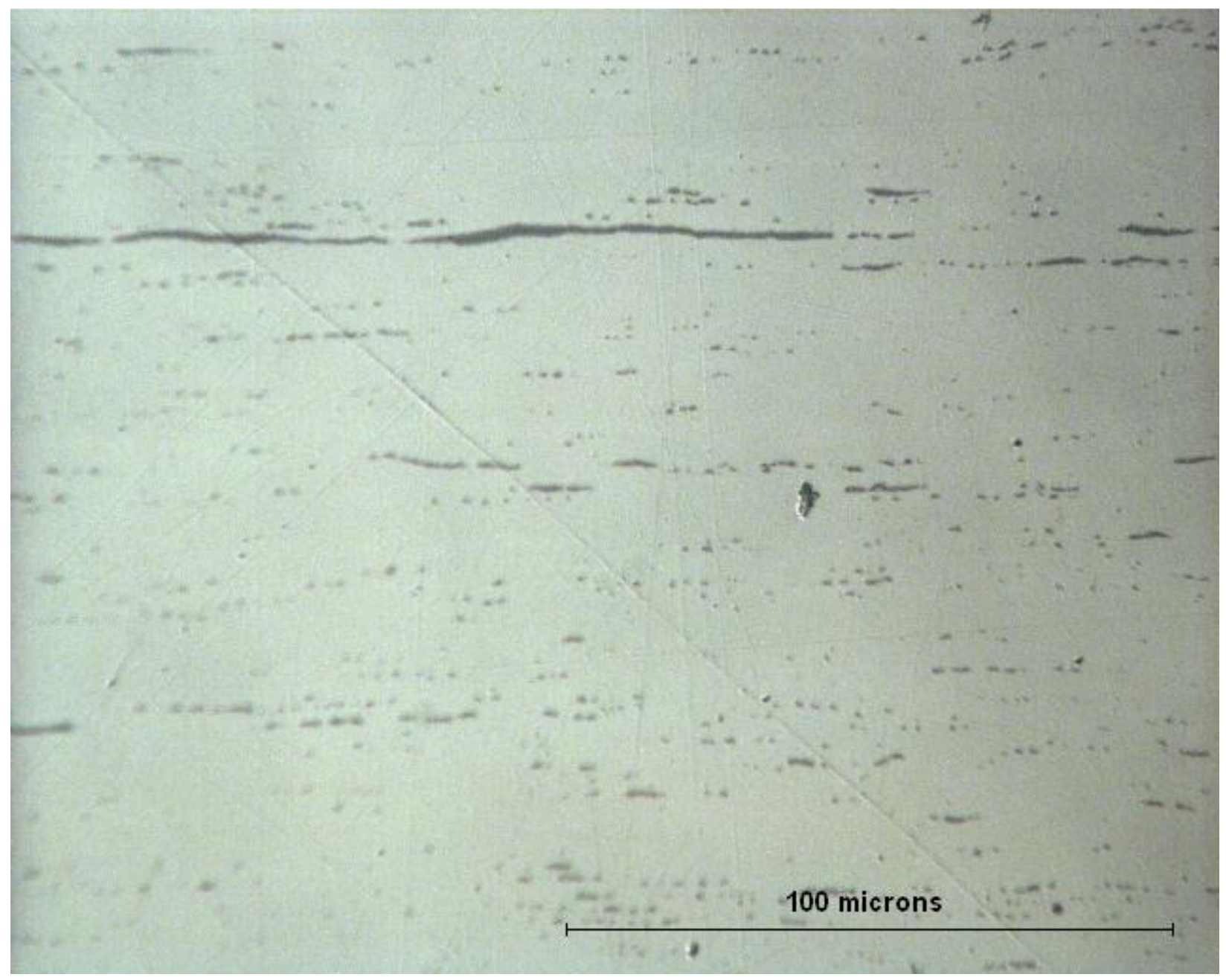

Figure 27 - Microstructure of 303 SS polished through $1 \mu \mathrm{m}$ diamond (Originally captured at 500X). The material was longitudinally mounted to show the microstructure parallel to the rolling direction. Note that the sulfide inclusions are preferentially elongated in the rolling direction and have very large aspect ratios which are not evident when the sample surface is transverse to the rolling direction. 
Figure 27 showed the surface of a sample of 303 SS mounted longitudinally in Bakelite and polished to produce a longitudinal view of the sulfide inclusions. This image gives a more comprehensive view of the sulfide inclusions. The sulfide inclusions in the matrix are extended, flattened cylinders rather than spheres.

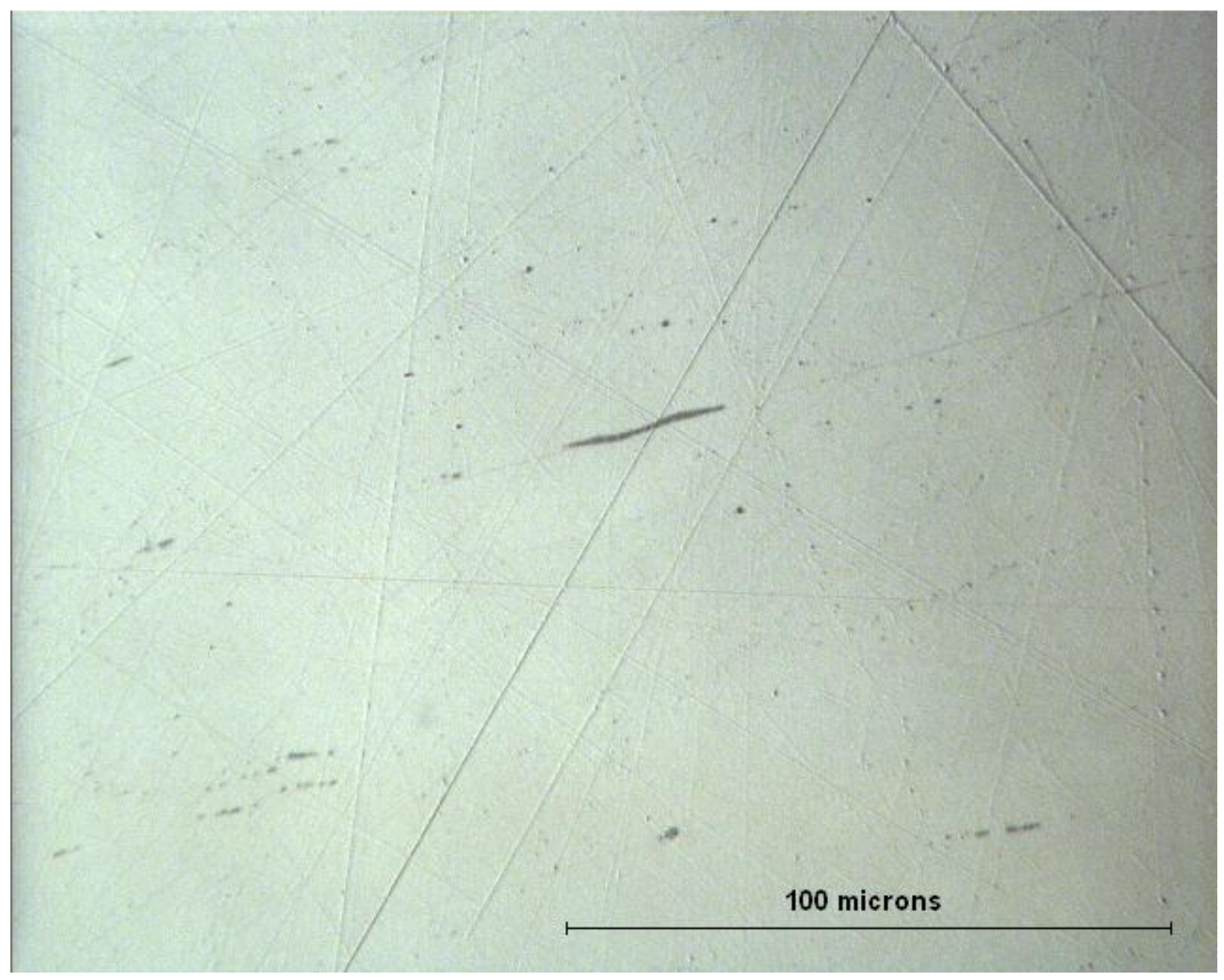

Figure 28 - Microstructure of 304 SS after $1 \mu \mathrm{m}$ diamond polishing (Originally captured at 500X, longitudinally mounted). Note the sulfide inclusions are preferentially elongated in the rolling direction. 
Figure 28 showed the surface of a sample of 304 SS mounted longitudinally in Bakelite and polished to produce a longitudinal view of the sulfide inclusion elongated in the rolling direction. This image provides a more comprehensive view of the sulfide inclusions. These elongated inclusions are rare in the 304 SS samples, thus this image is not typical of the majority of the sample surface, as 304 SS had a low sulfur content by design. The black dots in the image were most likely formed by aluminum oxide impurities and are a normal result of the deoxidizing process in the material. Aluminum oxides solidify at a much higher temperature than the sulfide inclusions during basic material processing. Thus at the temperature employed during hot rolling the sulfide inclusion soften or melt and are thus easily deformed into the high aspect ratio inclusions observed. The alumina inclusions, on the other hand, do not soften or melt but remain hard undeformable spheres. The temperature during hot rolling causes sulfide inclusions to melt into a long line while aluminum oxides remain spherical. 


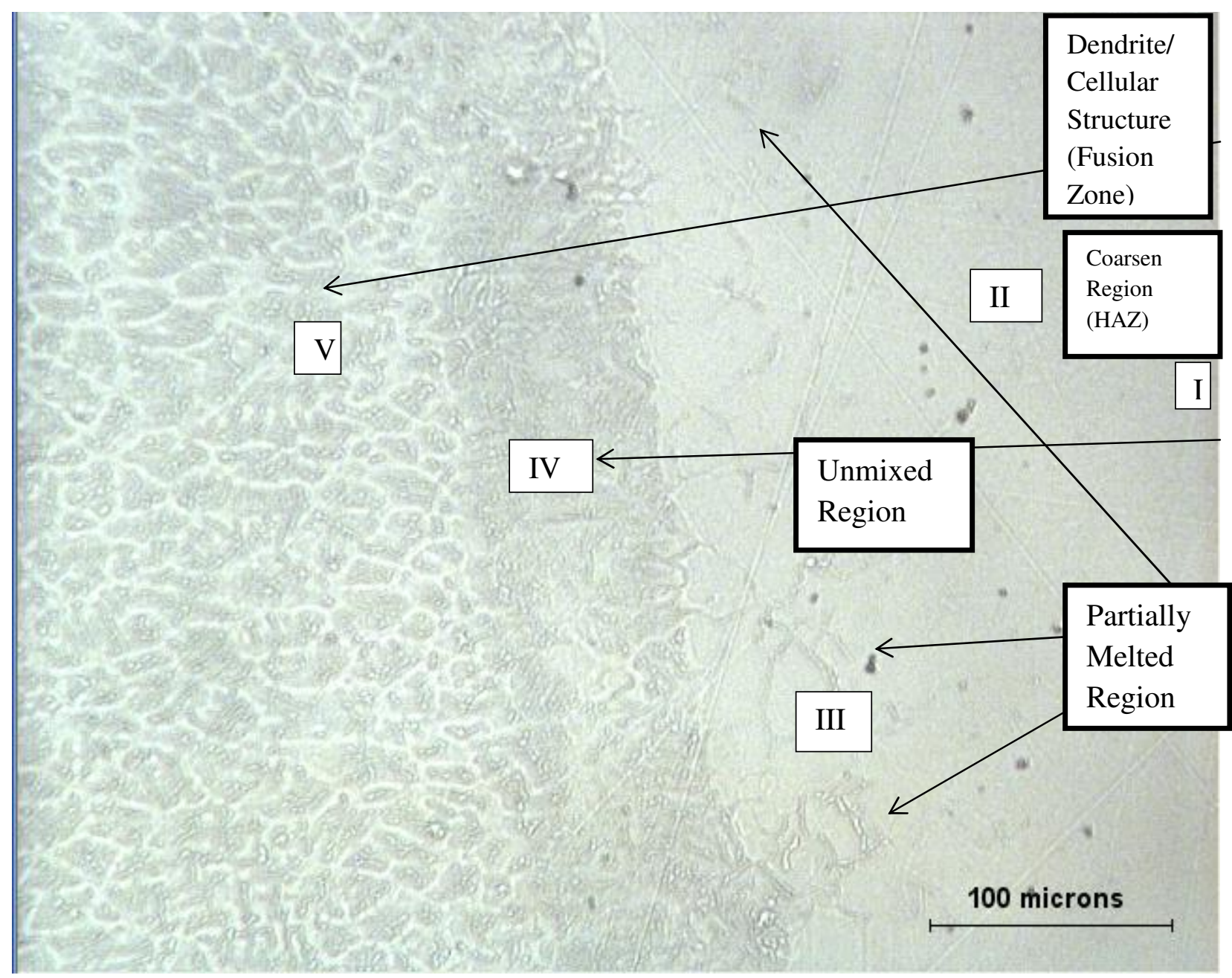

Figure 29 - Microstructure of weld interface region in 304 SS. Polished through $1 \mu \mathrm{m}$ diamond and etched (Originally captured at 200X). Note the varied microstructures in the different reviews. From left to right, the zones consist of the fusion zone, the partially melted zone (PMZ), the true heat affected zone (HAZ), and base material. At the grain boundaries, in the PMZ, evidence of a liquated region is visible.

Figure 29 showed the surface of a sample of 304 SS with a Gas Tungsten Arc Weld (GTAW). After the GTAW sample was polished and etched, the grain boundaries and other structures become evident in the image. The image showed the alteration of the microstructure in different zones caused by the thermal cycle associated with the different distances from the heat source. In zone I was the base material. In zone II was the heat affected zone (HAZ) and in zone III was the partially melted region. The next locale was the unmixed region (IV zone). The 
$\mathrm{V}$ zone was the fusion zone. The fusion zone was composed of composite zone (CZ) and unmixed zone (UZ). The unmixed zone was composed of a boundary layer of base metal that has melted and resolidified without mixing with the filler metal or flowing autogenous pool of welded w/o filler. After the 304 SS sample was welded, the fusion zone was no longer fully composed of austenite but also contained about $5 \%$ of ferrite. Ferrite dendrites were the first solids to form along with enriched chromium content at the core of the dendrite arms. During further cooling, ferrite transformed to austenite, except for the ferrite at the dendrite core which contained a high concentration of chromium. The high concentration of chromium in the dendrite core stabilizes about $5 \%$ of the ferrite.

The partial melting zone was formed by the peak temperature falling between the liquidus line and solidus line. The local melting temperature is depressed at grain boundaries, and in locations where the matrix reacts with inclusions. The larger grain size in the coarsened region was due to the coarsening effect driven by surface energy. The slower the cooling rate during solidification, the more time was available for the larger grains to grow at the expense of smaller grains. The black spots in the image are inclusions. The inclusions were presented in both the bulk material and in the heat affected zone (HAZ). In the PMZ, local melting occurred at the grain boundary in the base material. 


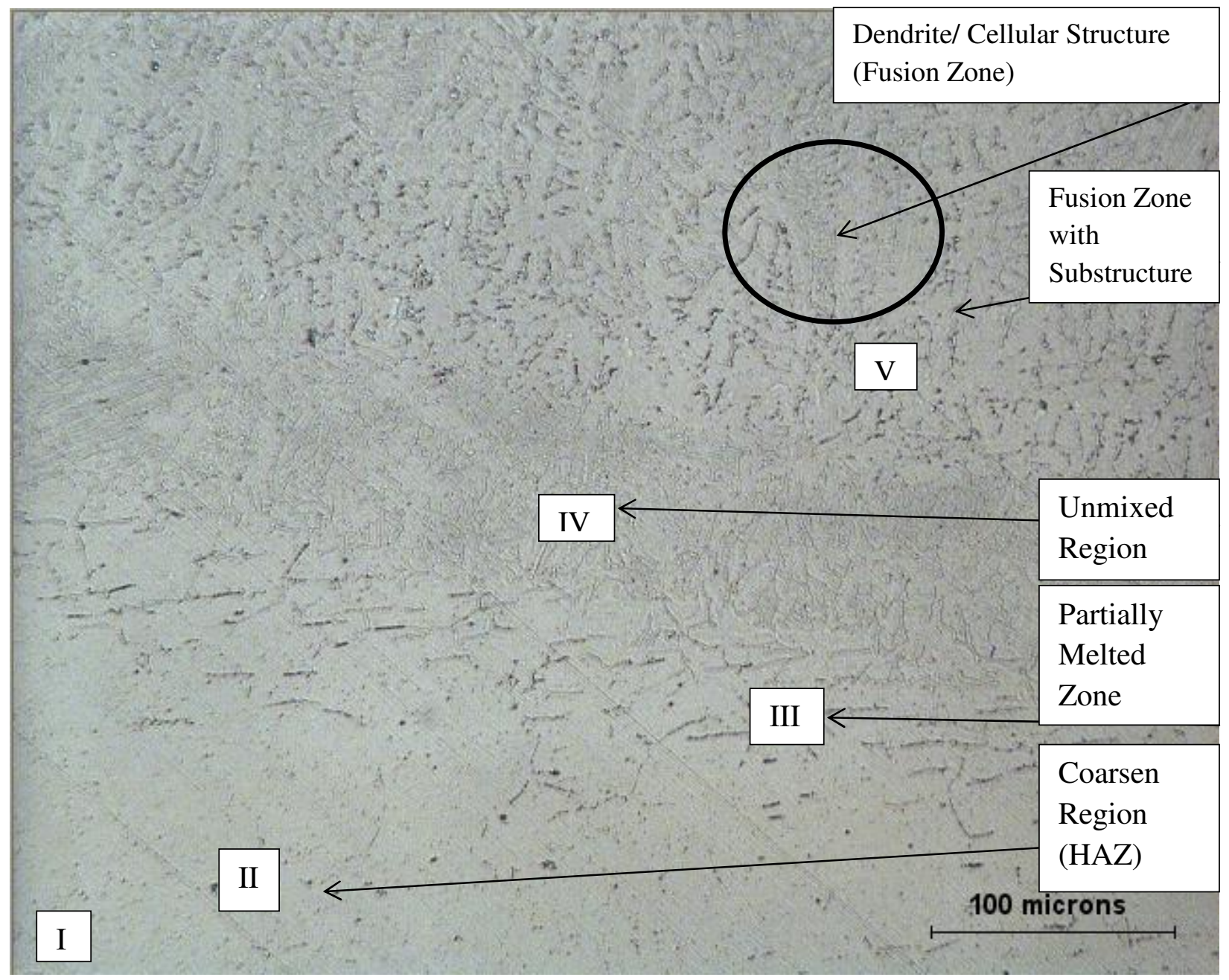

Figure 30 - Microstructure of 304 SS weldment polished through $1 \mu \mathrm{m}$ diamond and etched (Originally captured at 200X).

Not only does the heat transmission from welding alter the microstructure at the surface of the material, the material structure through thickness was also affected. Figure 30 shows the microstructure of $304 \mathrm{SS}$ with a weld in the longitudinal position. In zone V was the fusion zone. In zone IV was the unmixed region. In zone III was the partially melted zone (PMZ). In zone II was the true HAZ. In zone I was the base material. The fusion zone was composed partially of austenite, with some ferrite. Ferrite dendrites along with enriched chromium content were the first to solidify at the core of the dendrite arms. Further cooling causes most ferrite to transform 
to austenite. The dendrite core with the high concentration of chromium content stabilizes about $5 \%$ of the ferrite. The ratio of the temperature gradient in the weld pool to growth rate in the weld dictates the mode of solidification. As mentioned before, the partial melting zone (PMZ) was composed of localized melting along the grain boundary and in the grain interior. The peak temperature of the PMZ was between the liquidus line and solidus line. Again the coarsened region had a larger grain size due to the coarsening effect. During solidification in the coarsened region, there was a slower cooling rate and longer period of time for the larger grains to grow at the expense of smaller grains.

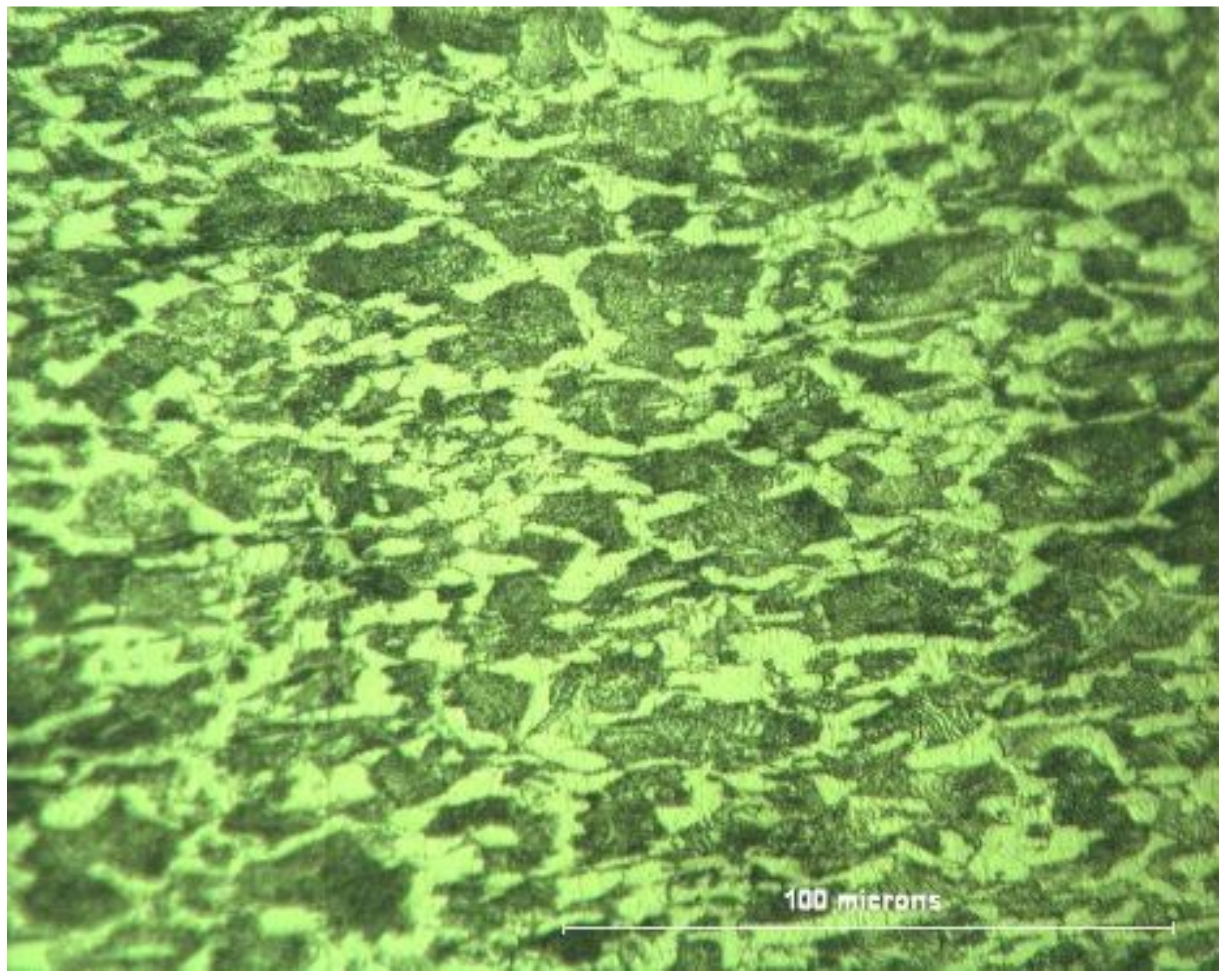

Figure 31 - Microstructure of AISI 1018 steel polished through $1 \mu \mathrm{m}$ diamond and etched (Originally captured at 500X and etched). Note the microstructure lacks orientation. 
An AISI 1018 steel sample was polished through $1 \mu \mathrm{m}$ diamond (Appendix D) and etched with 2\% Nital (Appendix E). Figure 31 shows the microstructure of the 1018 sample. The sample has been etched to provide a clearer view of its microstructure. The etching highlights interfaces to enhance their visibility. There were two distinct types of regions shown in this image. The light regions are ferrite grains. The dark regions are a more complex constituent, pearlite. Pearlite is actually two phases in intimate contact. Sequential layers of ferrite and $\mathrm{Fe}_{3} \mathrm{C}$ form from austenite to produce this constituent in the microstructure. This image indicates that the 1018 lacks an oriented direction. The sample will be re-polished to rid the surface of corrosion before exposing to bacteria.

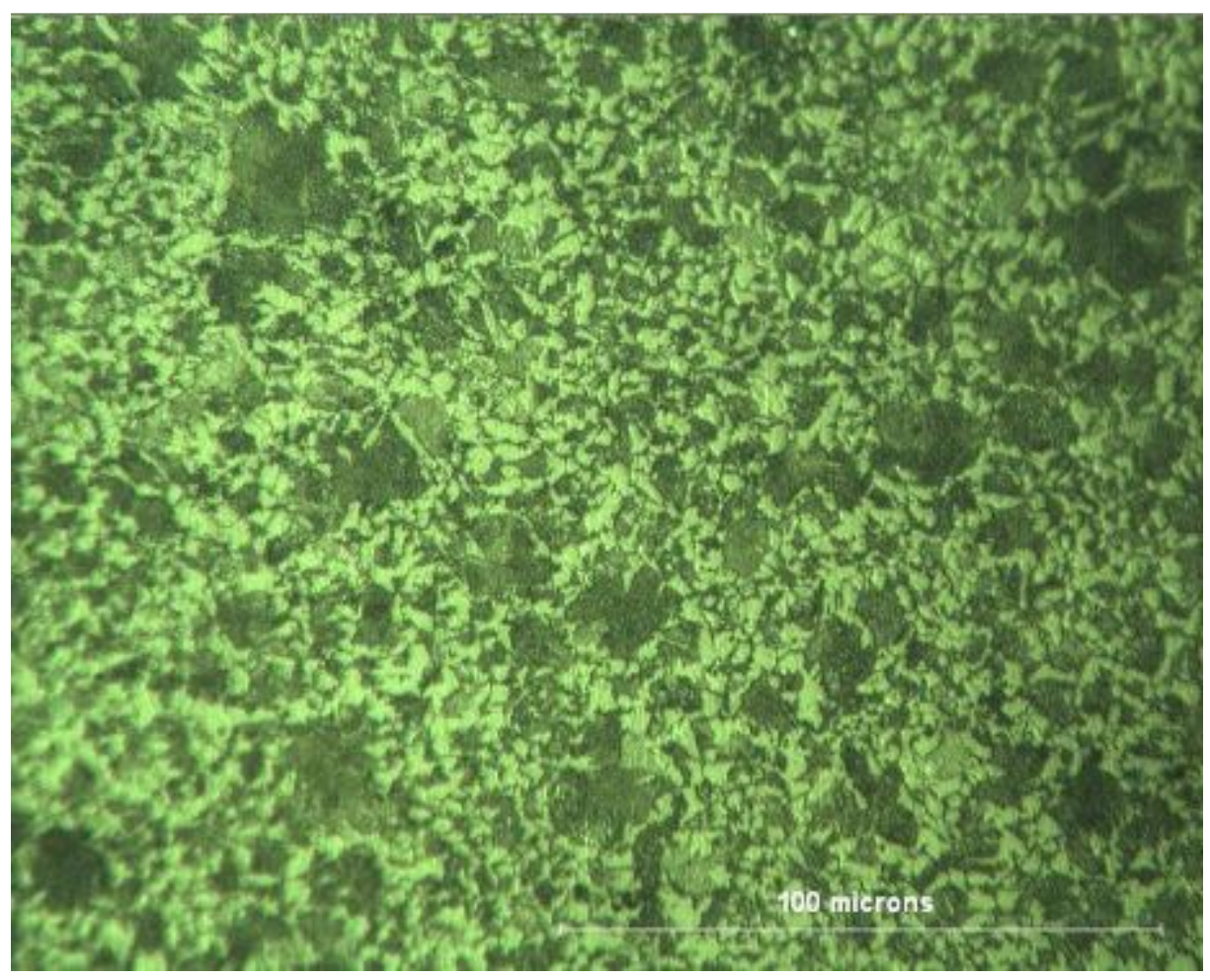

Figure 32 - Cross-section of AISI 1018 steel polished through $1 \mu \mathrm{m}$ diamond and etched (Originally captured at 500X and etched). 
A second sample of the 1018 material was prepared. The orientation was transview to the rolling direction in the first sample. Figure 32 showed the microstructure of the sample 1018. There were two distinct types of regions on the sample. The dark regions were a more complex constituent, pearlite. As mentioned before, pearlite was actually two phases in intimate contact. Sequential layers of ferrite and $\mathrm{Fe}_{3} \mathrm{C}$ form from austenite to produce this constituent in the microstructure. The light regions were ferrite grains. The boundaries of AISI 1018 steel lack an oriented direction as mentioned above. Before the sample was exposed to bacteria, it was polished to rid the surface of corrosion.

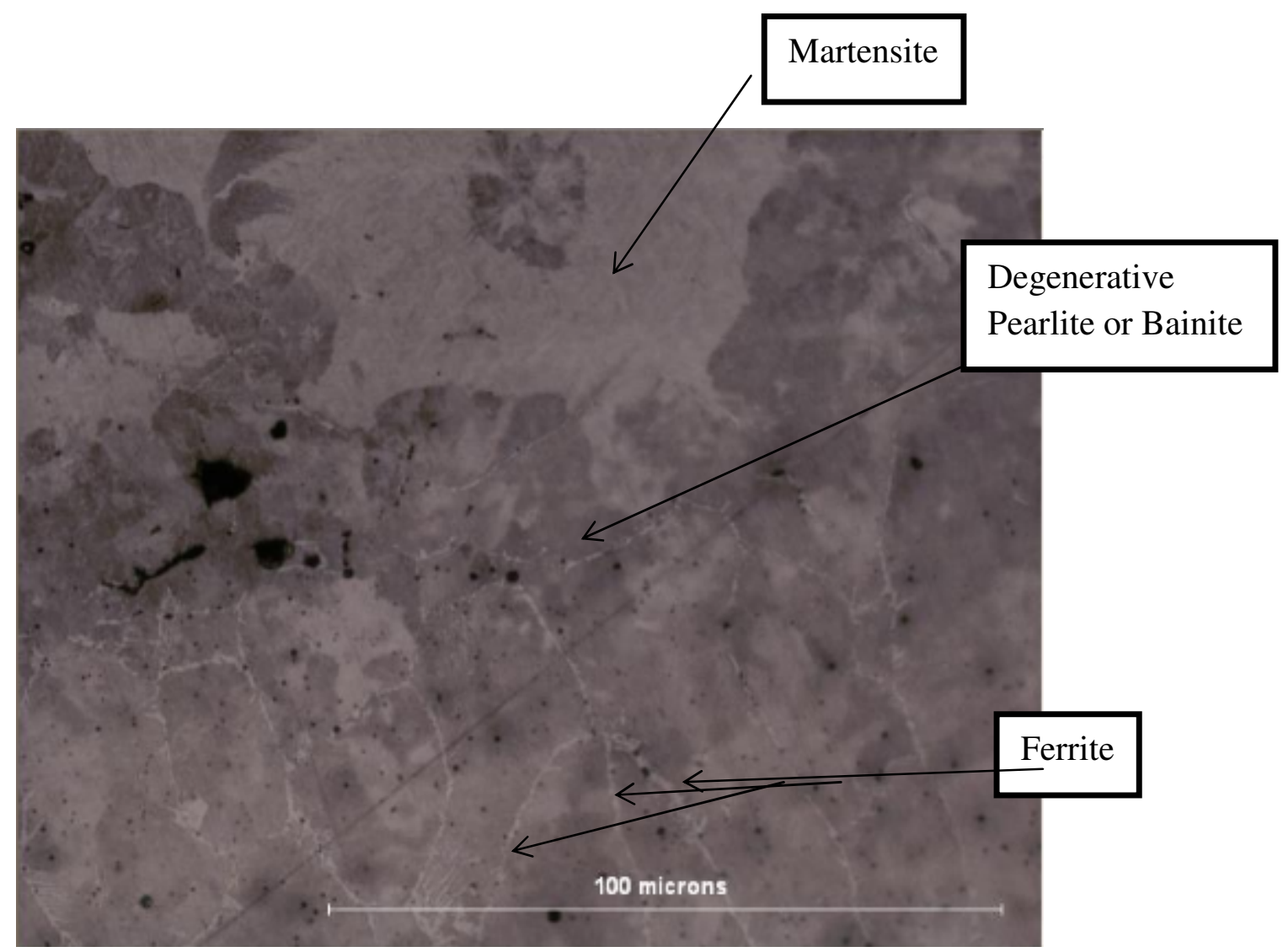

Figure 33 - Microstructure of AISI 1075 steel weldment polished through $1 \mu \mathrm{m}$ diamond. (Originally captured at 500X). Note the different boundaries (pearlite, martensite, and ferrite). 
Figure 33 showed the surface of a sample of AISI 1075 steel in the welded region. AISI 1075 steel sample contains $0.75 \%$ carbon. The dark regions are degenerative pearlite and martensite. The very light material which outlines the prior austenitic boundary in this region is ferrite.

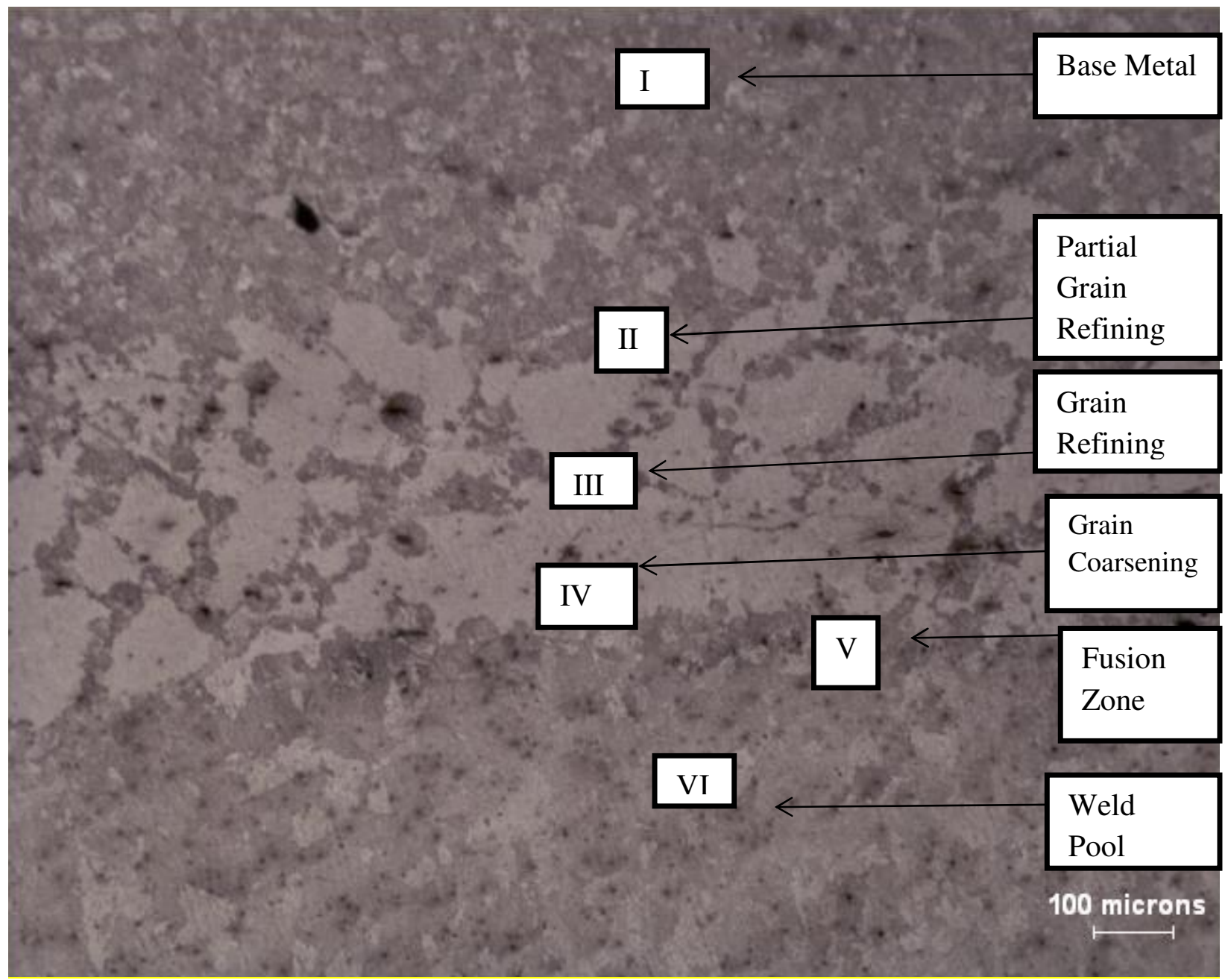

Figure 34 - Microstructure of AISI 1075 steel weldment polished through $1 \mu \mathrm{m}$ diamond (Originally captured at 500X). Note the alteration of the microstructure in different zones (Base Metal, Partial Grain Refining, Grain Refining, Grain Coarsening, Fusion Zone, and Weld Pool).

Figure 34 shows the grain boundaries of AISI 1075 steel at the heat affected zone (HAZ).

This image showed another perspective of the AISI 1075 steel's microstructure in the welded 
region. In zone I was the base metal. In zones II, III, IV was the heat affected zone (HAZ). The HAZ is comprised of regions that are evidence of grain coarsening, grain refining and partial grain refining zones. In zone $\mathrm{V}$ and zone $\mathrm{VI}$ were fusion zone and weld pool. The HAZ was mostly composed of martensite. The grain coarsened region was composed of mostly martensite with a relatively small amount of bainite and pearlite concentrated at the grain boundary. Both high cooling rate and large grain size of the grain coarsened region further contributes to the formation of martensite. The grain refined region was mostly composed of pearlite with a relatively small amount of ferrite and bainite at the grain boundary. Due to the low cooling rate and small grain size in the grain refined region, the formation of pearlite and ferrite were promoted.

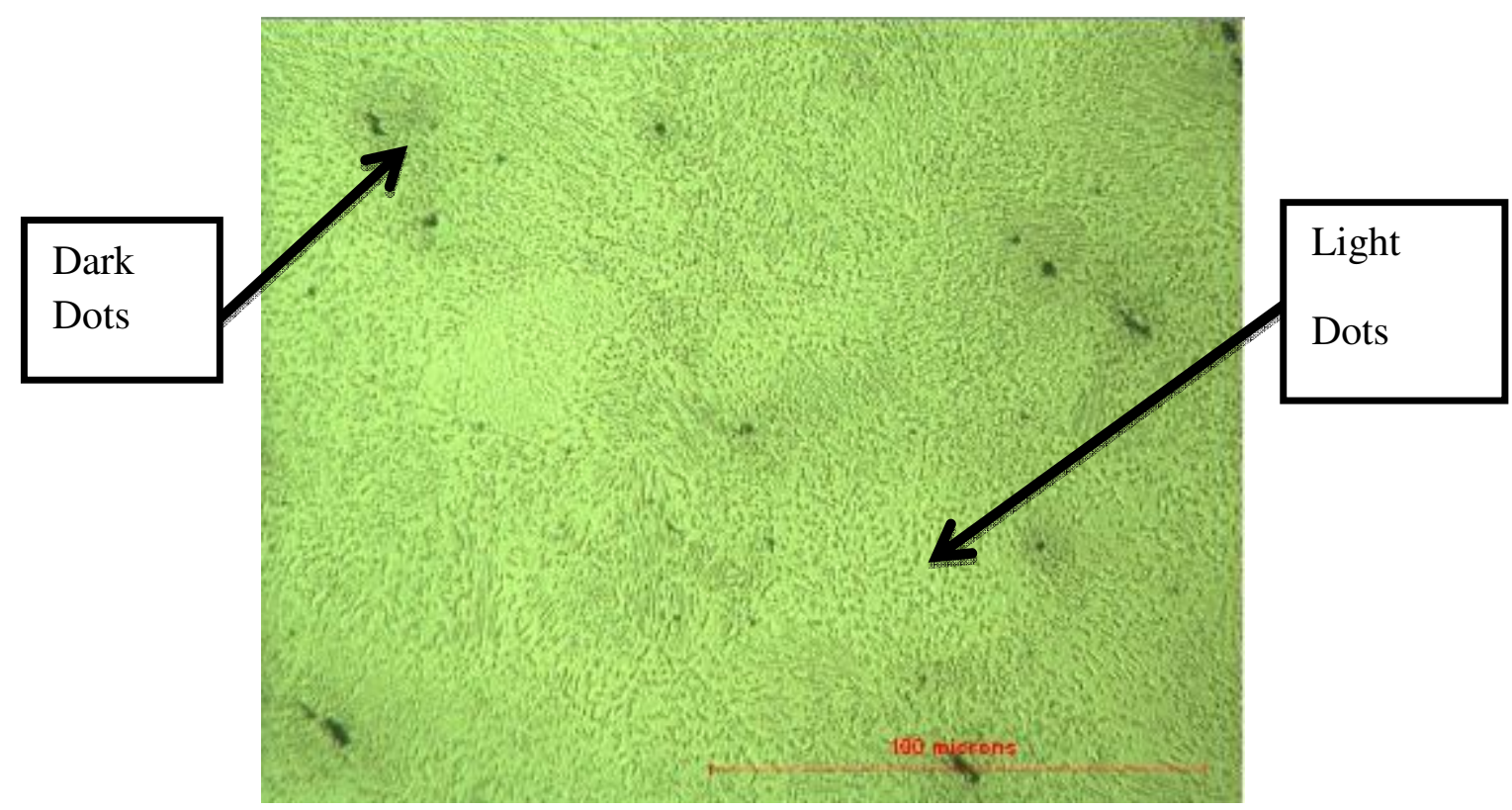

Figure 35 - Microstructure of AISI 1075 steel weldment polished through $1 \mu \mathrm{m}$ diamond and etched (Originally captured at 500X, longitudinal, welded and etched). Note the alteration of the grain boundaries. 
The AISI 1075 steel weldment was polished through $1 \mu \mathrm{m}$ diamond and etched $(2 \%$ Nital). Figure 35, showed the grain boundaries of AISI 1075 steel at the heat affected zone (HAZ). Etching selectively corrodes the surface in order to make the boundaries more visible. In this image, there were tiny dark and light dots forming a swirl. The region with the dots was in the location where the peak temperature approached but did not exceed the lower transition temperature so that the predominantly pearlitic microstructure spheroidized. The tiny dots were composed of ferrite and cementite. The combination of ferrite and cementite formed pearlite.

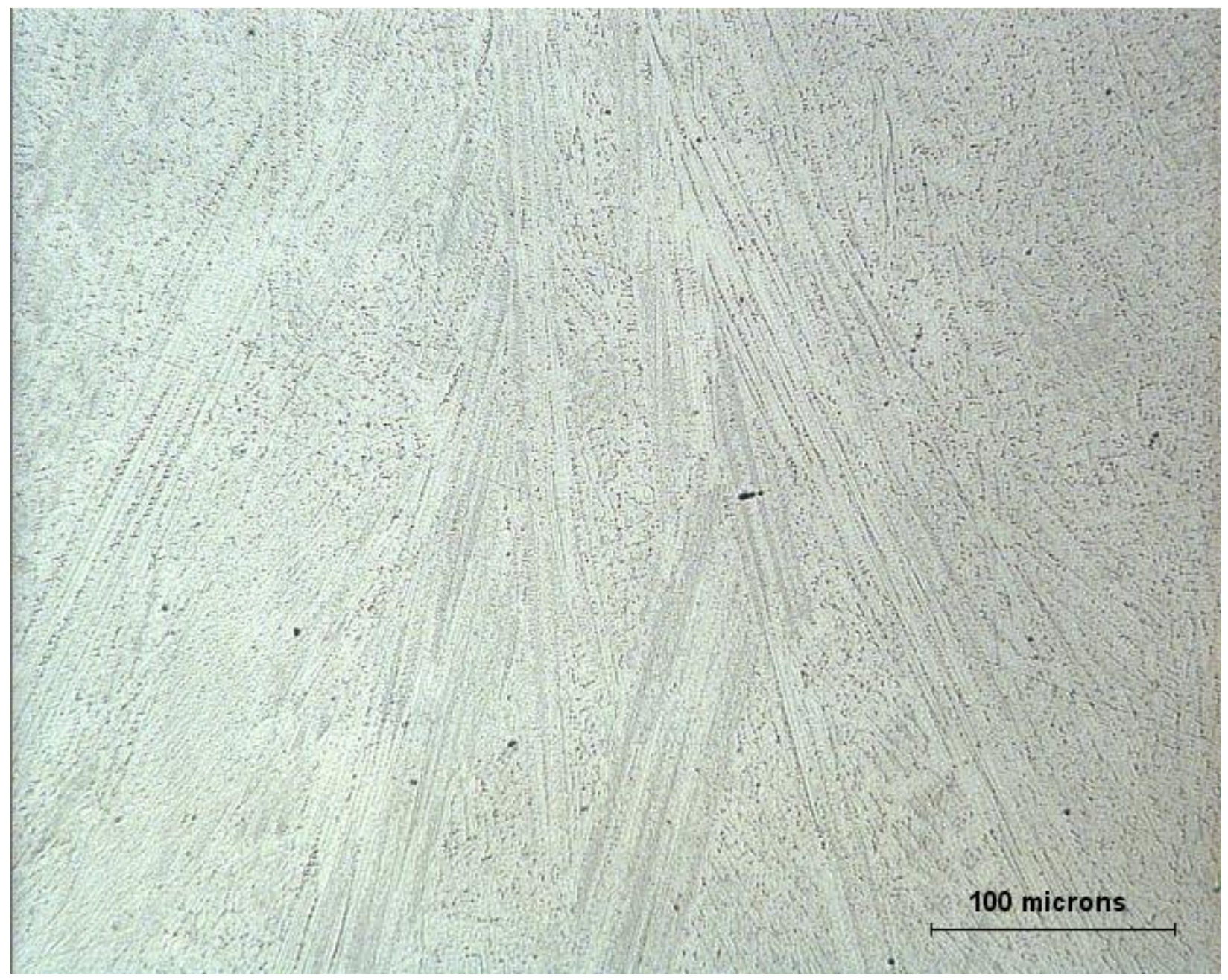

Figure 36 - Microstructure of steel 304 SS weldment polished through $1 \mu \mathrm{m}$ diamond and etched (10\% oxalic acid electroetch) (Originally captured at 200X, welded pool, etched). Note the sub-grains in this picture. 
Figure 36 showed the fusion zone of a weldment on 304 SS. The image was taken at a region where competitive growth is evident inside the fusion zone. The visible competitive grain growth had developed behind the weld pool as it solidifies. The grain growth starts to form by epitaxially arranging atoms from the liquid phase on the crystalline substrate at the weld pool boundary. It allows the grains favorably oriented with respect to the weld thermal gradient. The successful grains tend to grow perpendicular to the solid/liquid interface during solidification, as this leads to the maximum alignment with the temperature gradient in the pool. The microstructure consisted of sub-grain and the original grain boundaries.

II. Post Exposure Inspection - Scanning Electron Microscope (SEM) examination

1. Samples Polished to $1 \mu \mathrm{m}$ : 


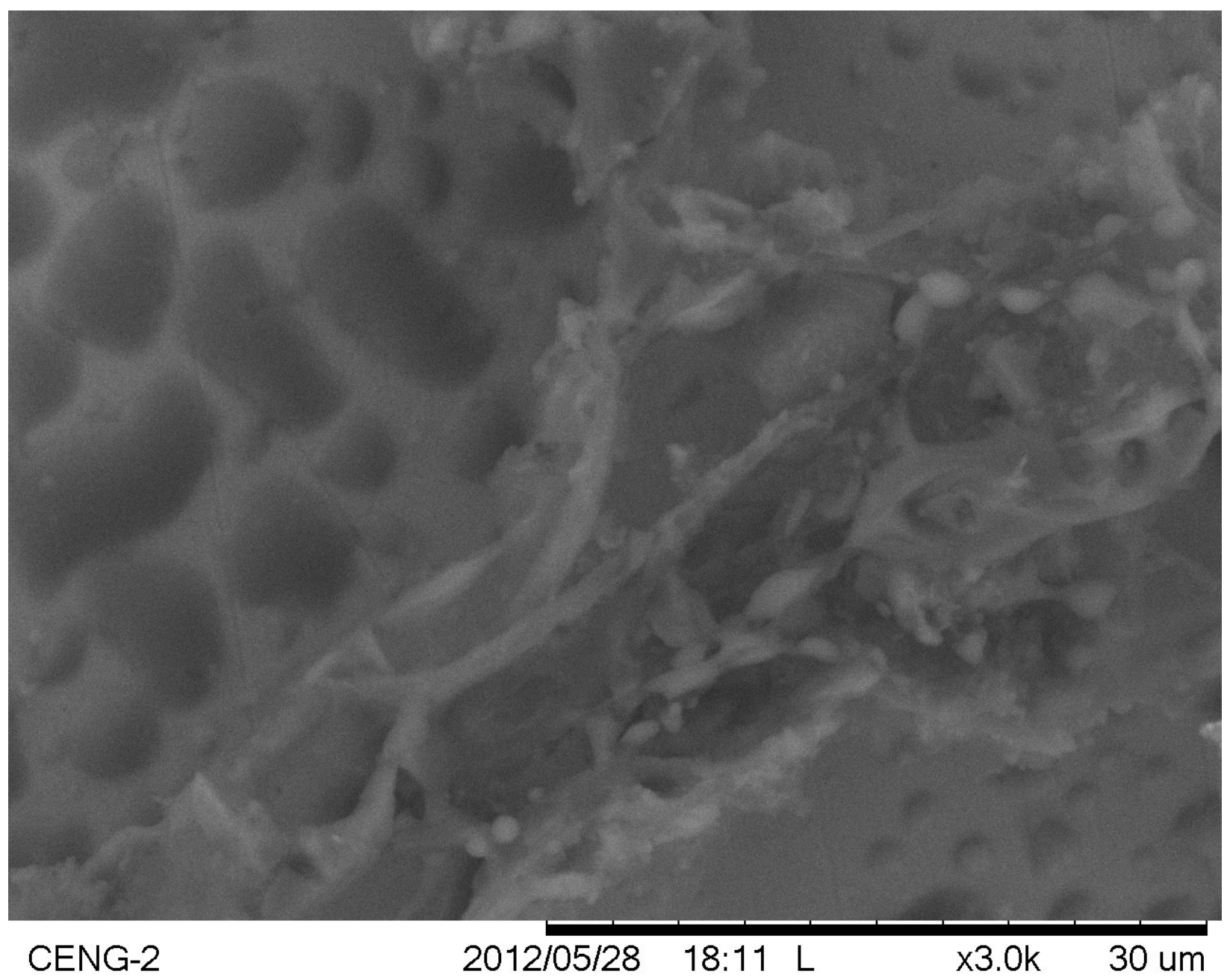

Figure 37 - 304 SS polished through $1 \mu \mathrm{m}$ diamond and longitudinally mounted (exposed for 24 hrs., originally captured at 3000X).

The sample of $304 \mathrm{SS}$ was longitudinally mounted, polished to $1 \mu \mathrm{m}$, cleaned and exposed to biologically active water. After exposure for $24 \mathrm{hrs}$., the sample was chemically treated to fix biofilm that had formed at the surface and subsequently looked at under the SEM. In Figure 37, the SEM image showed the sample 304 SS after bacterial exposure. The sample was coated with material that in some cases appeared to aggregate. In other locations, the material at the surface appeared to congeal, possibly as a result of the fixing procedure. In another location, bacteria were evident. Furthermore, some locations had larger organisms as 
well as material masses on them. Because this image was originally taken at $3000 \mathrm{X}$, the white dots appeared to be microbes. Around the artifact there appears to be EPS footprint. EPS footprints were caused by desiccated thin film layer. A thin film layer was developed during the $24 \mathrm{hr}$. period of exposure which covers the surface of the sample. The thin film layer was desiccated by the chemical's fixation process and caused the film to contract to smaller clumps.

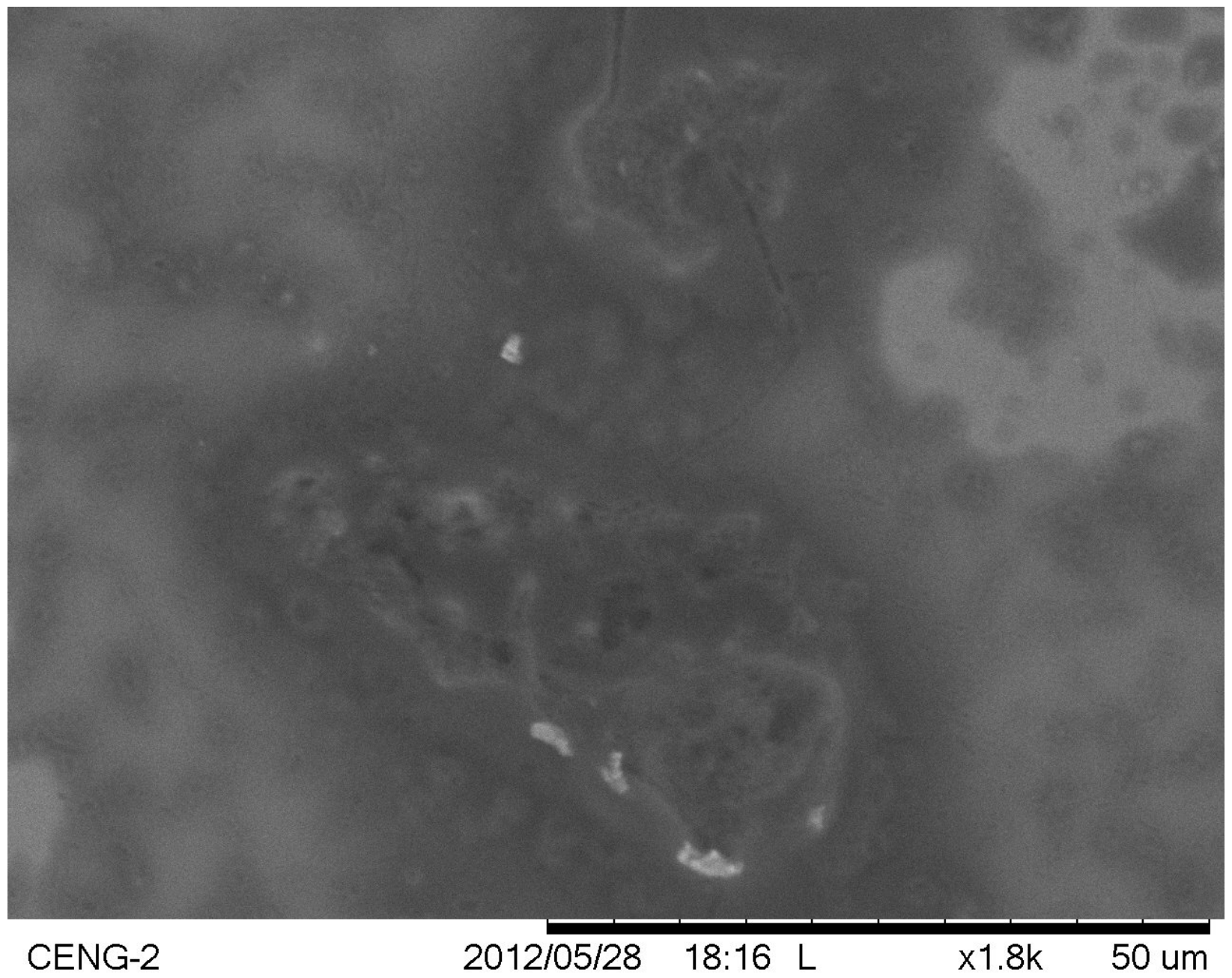

Figure 38 - 304 SS polished through $1 \mu \mathrm{m}$ diamond and longitudinally mounted (exposed for 24 hrs. and originally captured at 1800X). Note there are two dark regions on the surface that appear to indicate bacterial growth and also EPS footprints. 
The same sample of 304 SS was imaged at a different location. In Figure 38, the SEM image showed two dark regions. The dark regions were indicative of bacterial growth. There appeared to be communities of microbes forming in the dark regions. On the upper right corner there appeared to be EPS foot print.

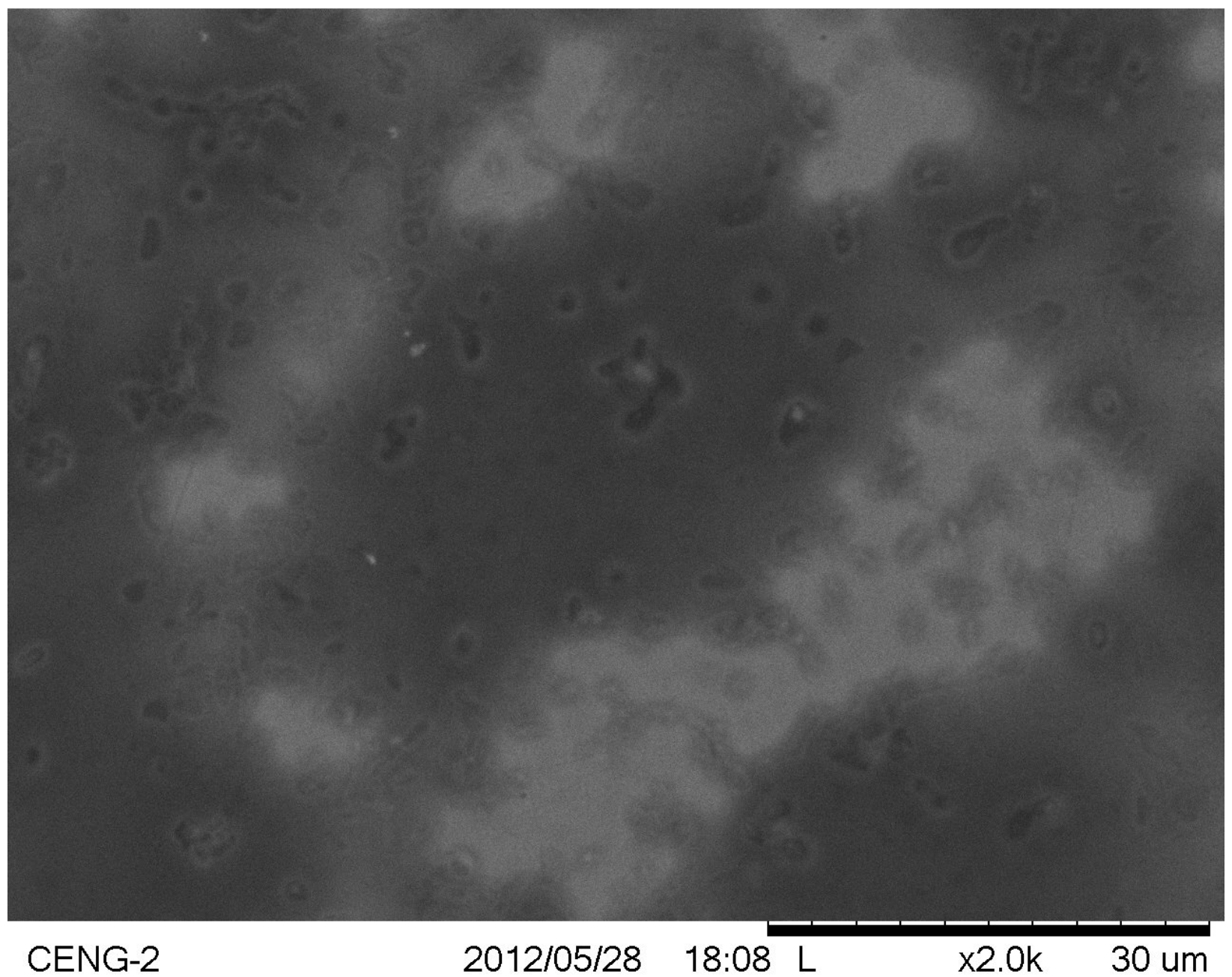

Figure 39 - 304 SS polished through $1 \mu \mathrm{m}$ diamond (exposed for $24 \mathrm{hrs}$. and originally captured at). Note the lack of dark regions and the decrease of EPS footprints.

Another location on the same 304 SS sample was imaged. In Figure 39, the SEM image showed less microbial growth on the surface of 304 SS. The small dark dots on the surface appear to be microbial attachments on the surface. Some of the microbes appeared to be in the 
process of forming a community. The dark region appeared to be a well-developed thick layer of EPS footprint covering the surface of 304 SS. The light region appeared to be composed of a thin layer of EPS footprints covering the surface. There wasn't enough exposure time for the light region to form a thicker layer of film on the surface. Compared to the location of Figure 38, this location has less microbial development on the surface.

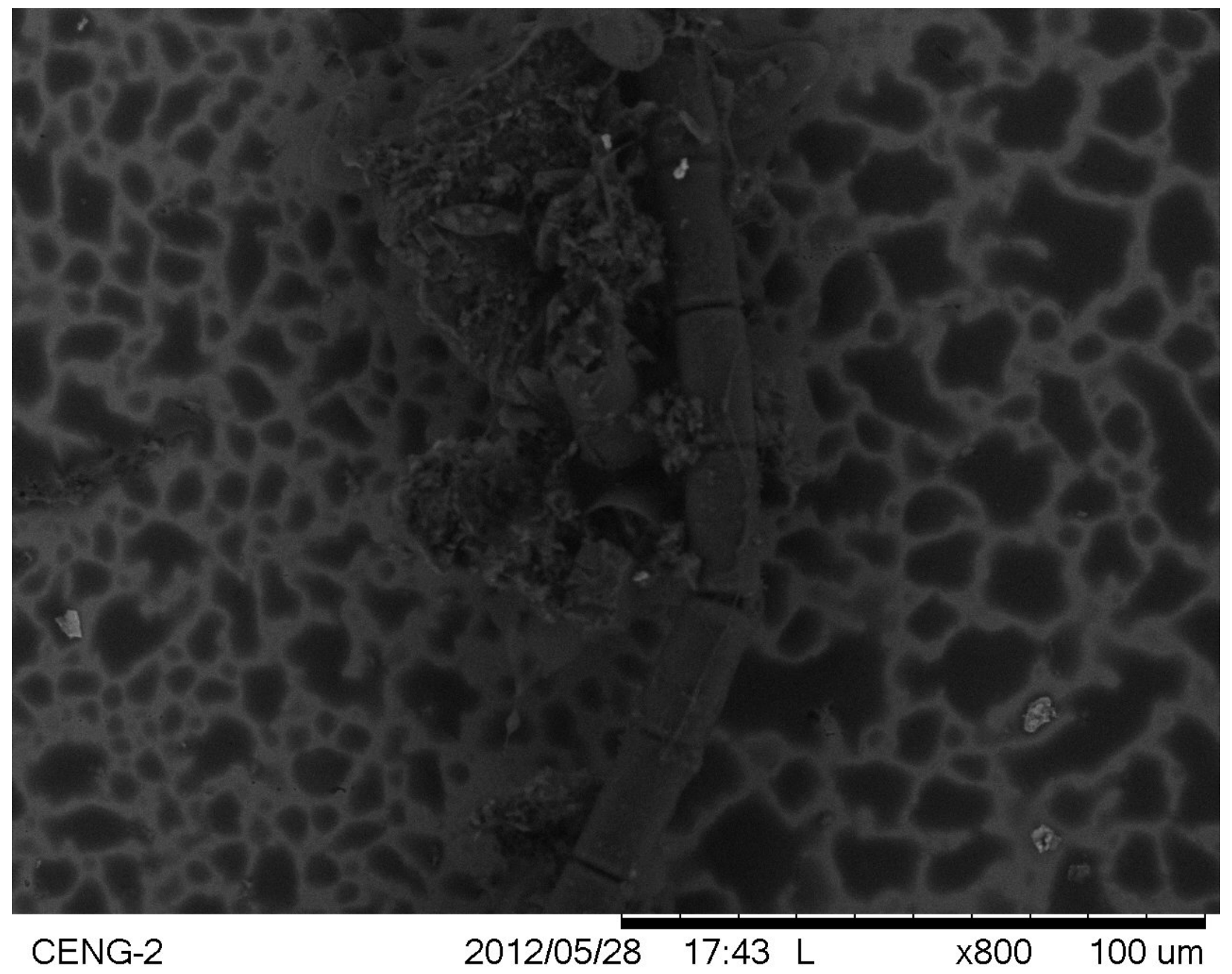

Figure 40 - 304 SS polished through $1 \mu \mathrm{m}$ diamond (welded, and exposed for 24 hrs.). Note there appears to be artifacts on the surface of the metal and EPS footprints. 
The sample $304 \mathrm{SS}$ with a weld was polished to $1 \mu \mathrm{m}$, cleaned and exposed to biologically active water for 24 hrs. After exposure for $24 \mathrm{hrs}$., the sample was chemically treated to fix biofilm that had formed at the surface and subsequently looked at under the SEM. In Figure 40, the SEM image showed the surface of 304 SS weldment mounted longitudinally after exposure to bacteria. The microstructure of the sample's surface could not be determined. The sample was coated with a material that appeared to cumulate in some locations. In other locations, the material appeared to coagulate, possible due to the fixing process. Bacteria were apparent in other locations. There were some locations with larger organisms, material matters and bacteria forming clusters. The appearance of the central region of this image was homogenous with the beginning of a tubercle. The dark spots on the surface appear to be thick layer of EPS footprints. The lighter region appeared to be a thin layer of EPS footprints. On the left of the image there appeared to be a community of microbial attachments. The purpose of this research was to prove that bacteria could grow on metal surfaces in a static bioreactor rather than correlating the microbial attachment with the underling microstructure of the metal. In future studies, tracking of microbial attachments to the underlying microstructures of the metal could be accomplished. 


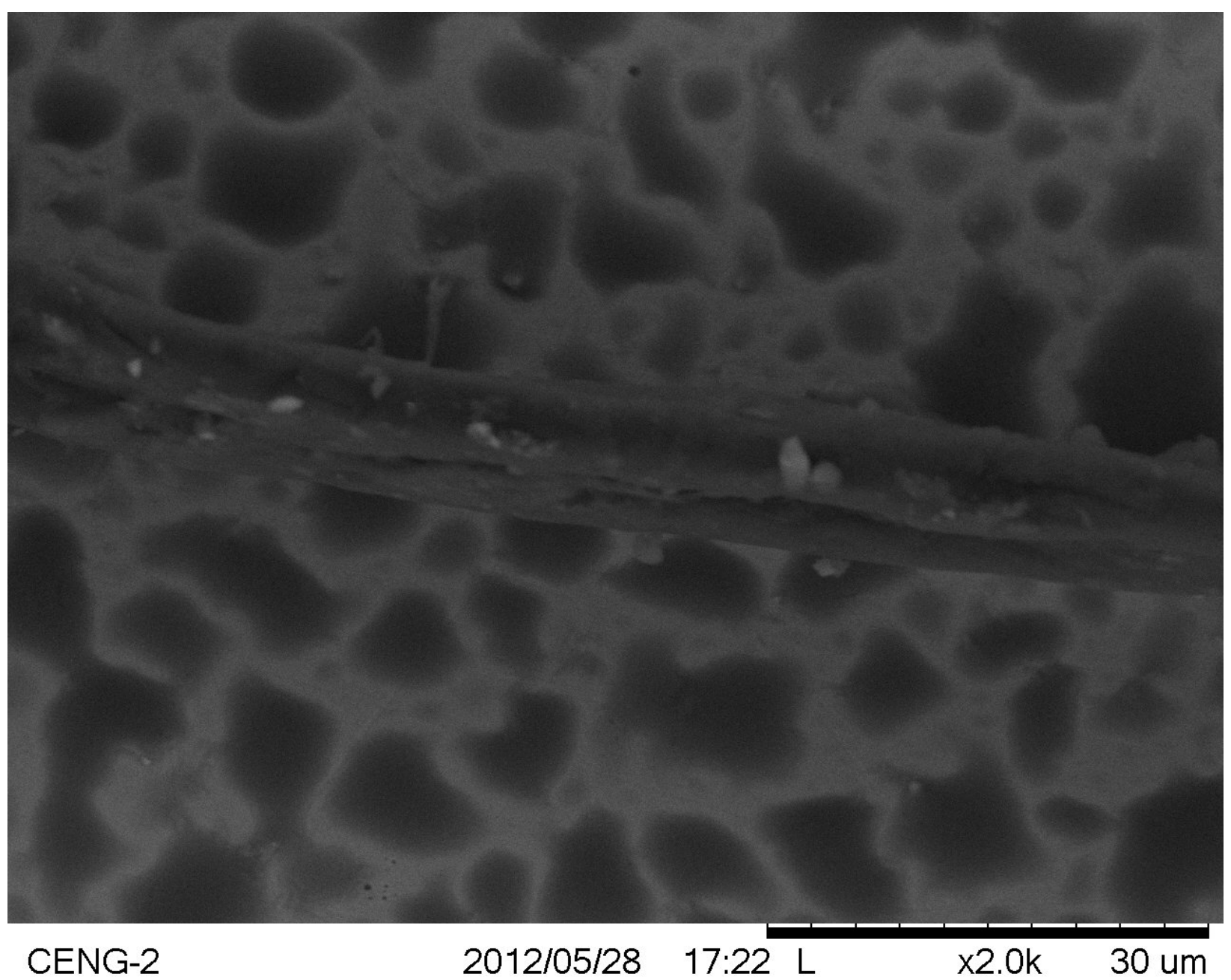

Figure 41 - 304 SS polished through $1 \mu \mathrm{m}$ diamond (welded, exposed for $24 \mathrm{hrs}$.).

Note there are large organisms on the surface and EPS footprints.

Another location of the same 304 SS sample was observed. In Figure 41, there appeared to be EPS footprints and a "stalk like" feature present on the surface. Originally observed at 3000X magnification, there was a "stalk like" feature on the surface running through the central region of the image. The sample was stained with a material that in some cases appeared to accumulate. In other locations, the material on the surface appeared to gelatinize. In other locations, bacteria were perceptible. There were other locations with larger organisms and material masses forming clumps on the surface. The dark regions were thick layers of EPS 
footprints. The light regions were thin layers of EPS footprints. The formation of EPS footprints were caused by the desiccation of the film layer during the fixing process. The diversity in the biofilm form by discrete microbes in the film had a similar scale as the microstructural diversity in the underlying material. Although the extent of this thesis didn't include mapping the distribution of microbial activity to the underlying microstructure, this investigation suggests that such an activity could be beneficial. The white dots appeared to be microbes attaching to the surface of the organisms. Again the objective of this thesis was to prove that bacteria could grow on metal surfaces in a static bioreactor. The scope of this effort did not include the correlation of attachment to underlying microstructure that was left for future efforts. 


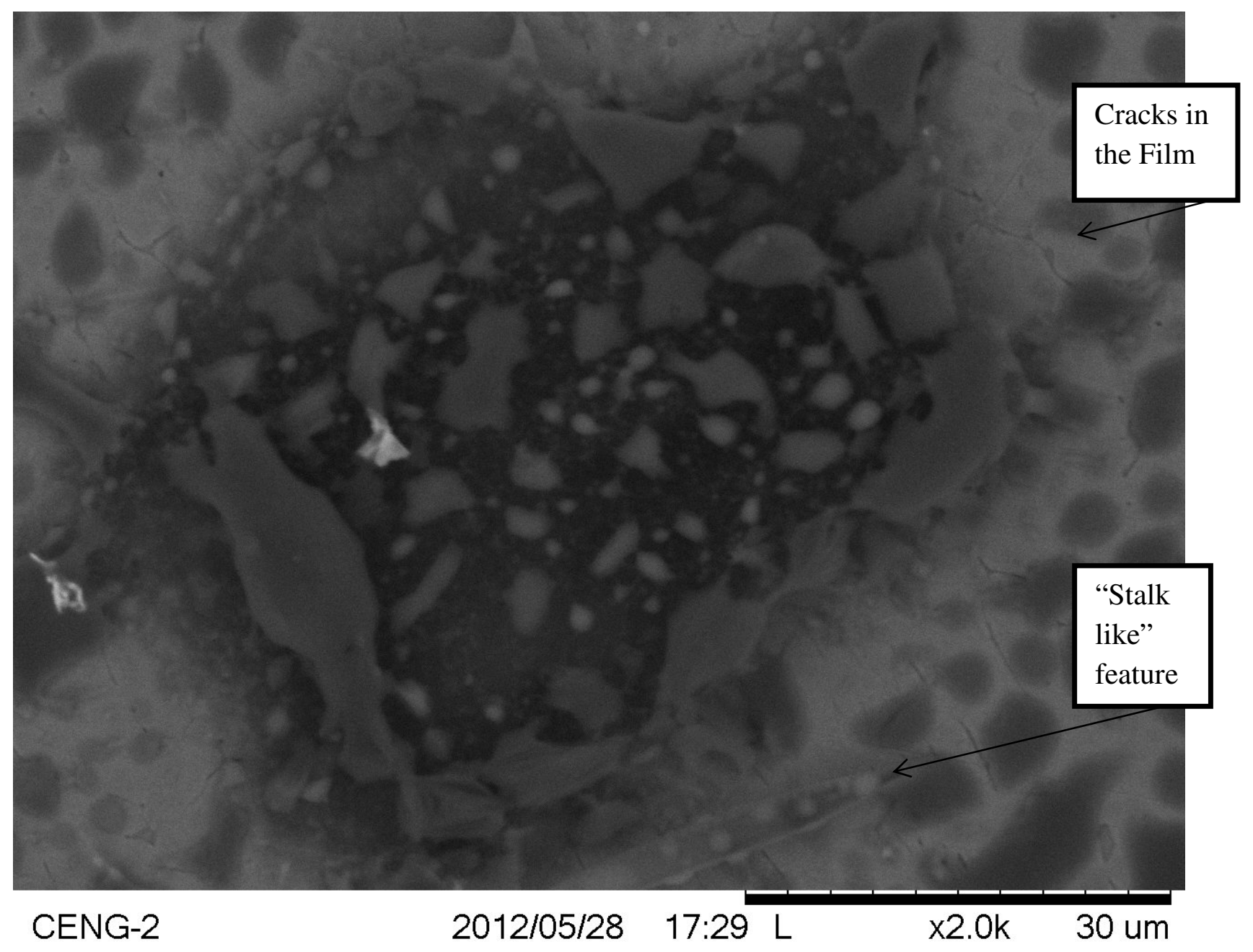

Figure 42 - 304 SS polished through $1 \mu \mathrm{m}$ diamond (welded, exposed for $24 \mathrm{hrs}$.). Note there appeared to be microbes growing in a pit and EPS footprints.

In the SEM image shown in Figure 42, communities of microbes appeared to be growing in a nascent pit. Similar to the previous images, the sample was covered by a material that appeared to gather on the surface. The thickness varies by locations. Bacteria had also manifest in other locations. There were also presence of larger organisms and material matter fusing into clumps on other locations. The dark circular region in the center of the image was a nascent pit. There appeared to be bacterial growth under the top layer of the pit. The appearance of this region is consistent with the beginnings of a tubercle. The dark clumps encircling the nascent pit 
appeared to be debris from a thicker layer of EPS that was associated with the early development of a tubercle. The light regions were possibly thin layers of EPS footprints. The cracks around the pit indicated that the EPS layer was thicker there. The fixing procedure caused the EPS layer to desiccate into smaller clumps of EPS footprints.

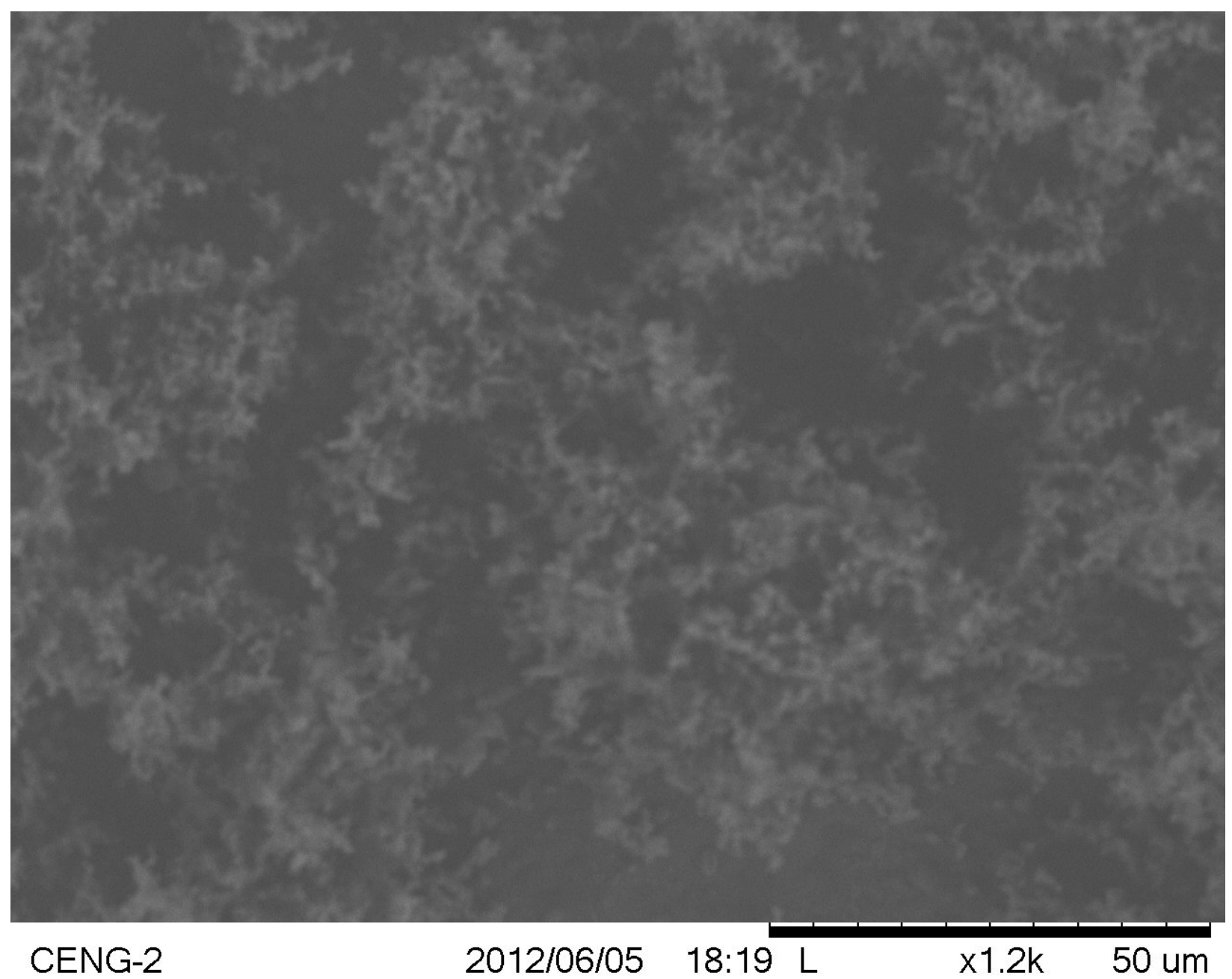

Figure 43 - AISI 1018 steel polished through $1 \mu \mathrm{m}$ diamond (Originally captured at 1200X, exposed for $24 \mathrm{hrs}$.). EPS debris and microbes that are consistent with residues left from the fixing of a biofilm. 
AISI 1018 steel sample was polished to $1 \mu \mathrm{m}$, cleaned and exposed to biologically active water for one day. In Figure 43, the SEM image showed bacterial growth on the surface of AISI 1018 steel. In this image the highly featured gray regions were communities of microbes. The dark regions appeared to lack bacterial growth. There could be thin EPS footprints developed on the surface of the dark regions. The communities of microbes that developed on the surface of the metal appeared to have formed biofilms. Typical mature biofilm is comprised of microcolonies of bacteria that form a "mushroom" forest structure (Figure 2). The microcolonies of bacteria are surrounded by an EPS matrix and fluid-filled channels. The fluid-filled channels allow the biofilm to increase water channel and aid in waste removal. The community of microbes in the highly featured gray region appeared to form biofilms in the same manner. The heterogeneity in the biofilm, that is, the varied density of the microbes in the films, had a scale that is similar to the scale of microstructural heterogeneity in the underlying material. Even though the scope of this work did not include mapping the distribution of microbial activity to the underlying microstructure, this observation suggests that such an activity could be very fruitful. 


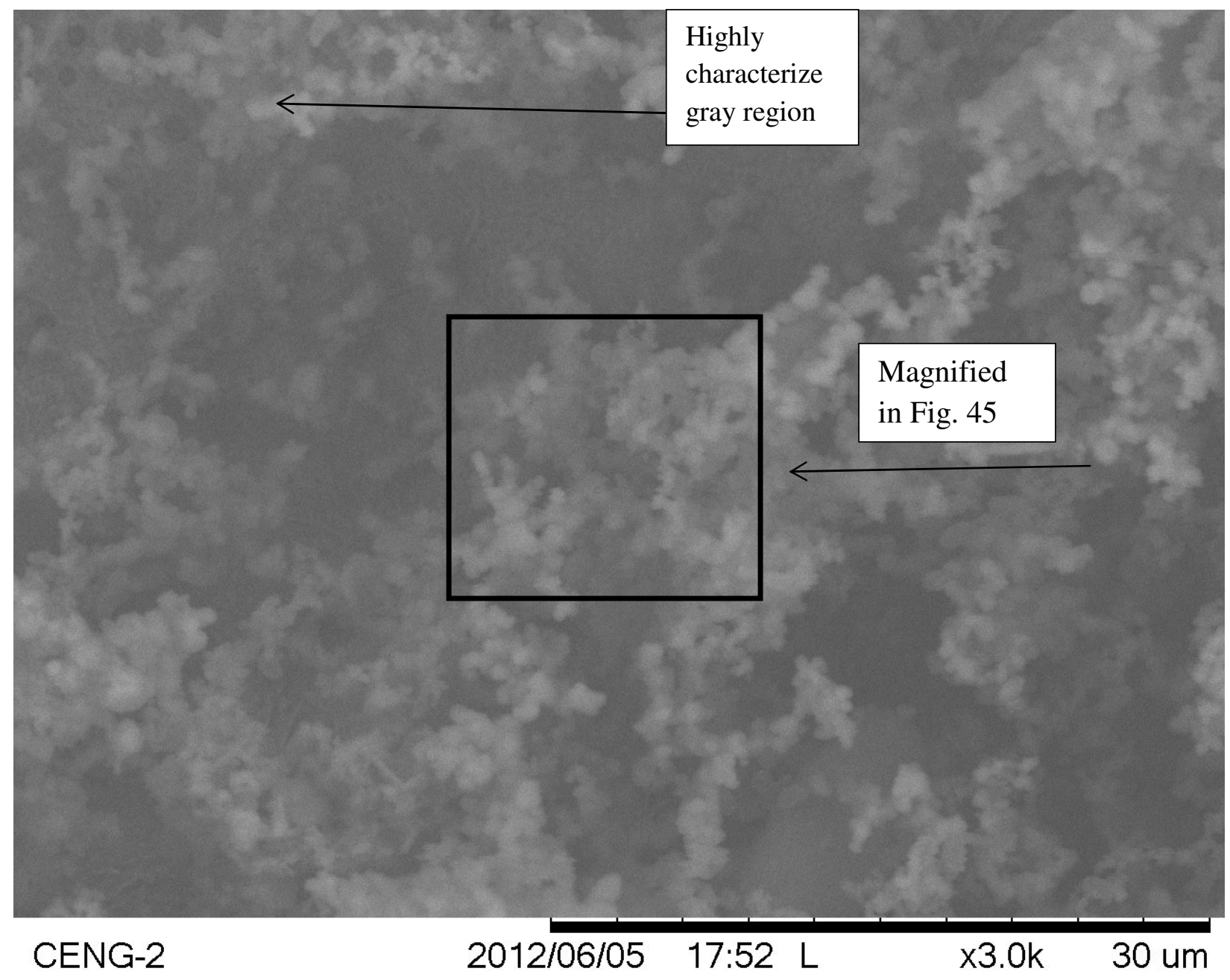

Figure 44 - AISI 1075 steel polished through $1 \mu \mathrm{m}$ diamond (Originally captured at $3000 \mathrm{X}$, exposed for $24 \mathrm{hrs}$.).

Similarly, AISI 1075 steel sample were welded, polished and exposed to biologically active water. In Figure 44, the SEM image showed bacterial growth on the surface of AISI 1075 steel. The steel was exposed for one day before the surface was chemically fixed. The highly detailed gray region in this image appeared to be communities of microbes. The dark regions were relatively free of bacterial attachments. In the highly detailed gray region there appeared to be microbial colonies and developing biofilms. Typically a relatively uniform seeding of the surface is due to microbes proliferating at particular locations and erupting into mushroom like 
structure or into tubercles. The microcolonies of bacteria are surrounded and protected by an EPS matrix. They are also separated by fluid filled channels. As the biofilm grows, the fluid filled channels expand to replenish nutrients and aid in waste removal. Mushroom like structure protects bacterial species from desiccation and selective pressures.

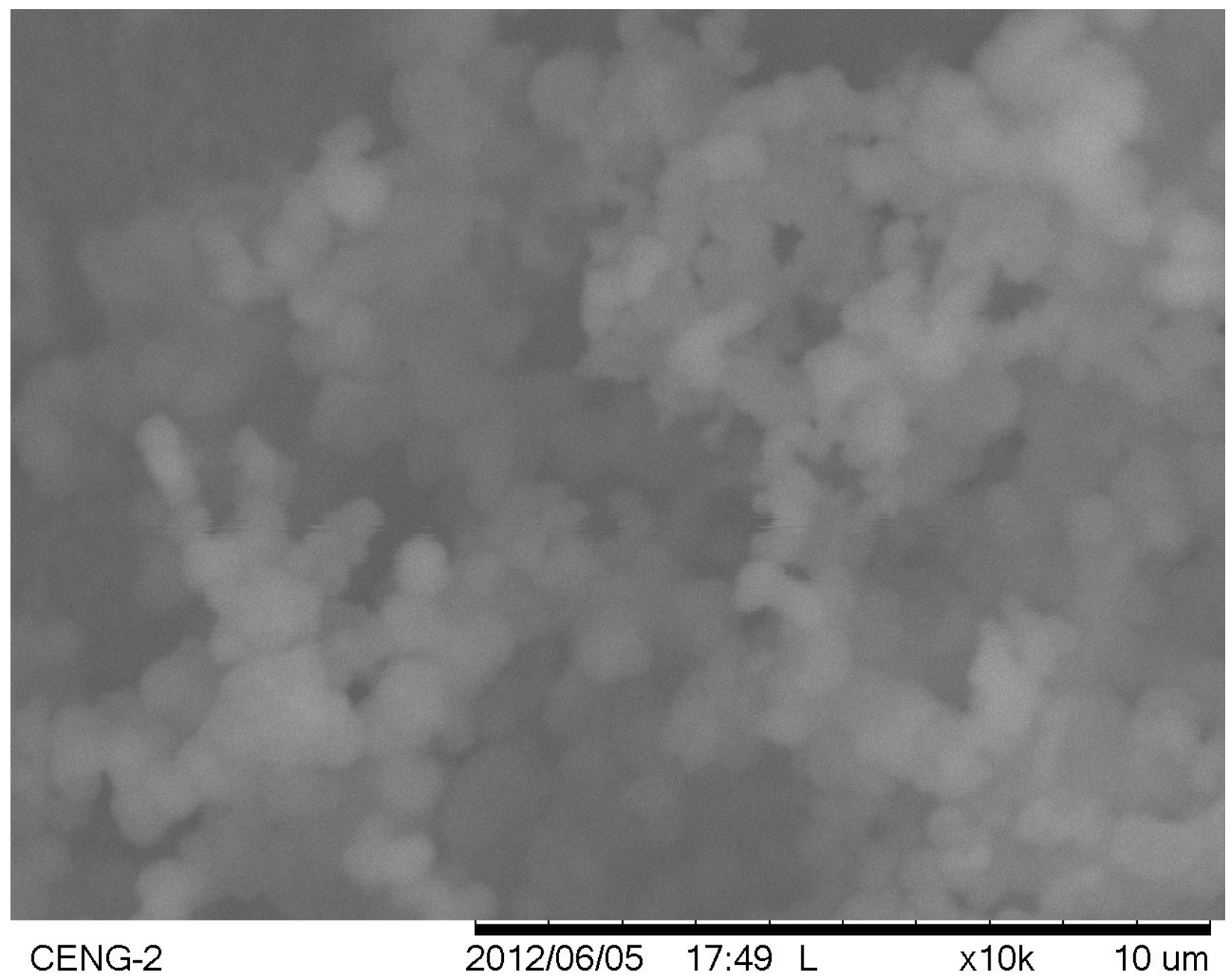

Figure 45 - AISI 1075 steel polished through $1 \mu \mathrm{m}$ diamond (Originally captured at 10,000X, exposed for $24 \mathrm{hrs}$.). Note this image was an enlargement of a region in Figure 44 where a typical mature biofilm had formed a mushroom like structure.

A part of the AISI 1075 steel originally observed at 10,000 magnification was taken for a clearer perspective on bacterial attachment on the surface. In Figure 45, the SEM image 
appeared to show a close up of a group of microbes in association. Typically microbes attach and grow on a surface with abundant nutrients. Biofilm development usually initiates with planktonic cells responding to a specific environmental cue (nutrient availability) from a surface. With the specific environmental cues, planktonic cells will become sessile cells and proliferate on the surface. The sessile bacteria are composed of mixed and integrated species which optimize the metabolism and efficiency of the community. The bacterial community is surrounded and protected by an EPS matrix. Biofilm development will reach the mature state as long as nutrients are abundant on the surface. Usually a relatively uniformed seeding on the surface is formed by microbes proliferating at specific locations and extravasate into mushroom like structure or into tubercles. They are also surrounded by fluid filled channels. The fluid filled channels extend as the biofilm grow to replenish nutrients and aid in waste removal.

The highly detailed gray region appeared to have communities of microbes developing into mature biofilms. Even though the sample's surface was only exposed for 24 hours, the biofilm was still able to develop into the mature state. The growth could be fostered and accelerated by the pitting on the surface. When the sample was retrieved from the exposure, there was rust which indicated corrosion. Multispecies biofilm in a metabolically integrated consortium usually forms an anode when settled in a deeper anaerobic zone (pitting). With respect to this anode in the pit, an associated microcolony of bacteria forms a biofilm with metabolic activities and metal-binding activities that augment the efficiency of the cathode. A corrosion potential will form between the anode and the cathode which becomes a corrosive cell. The anode will donate electrons to the cathode. The rust could have been developed in the same manner as biofilms forming corrosive cells on the surface of the metal. The corrosion was another indication of bacterial attachment and growth. 


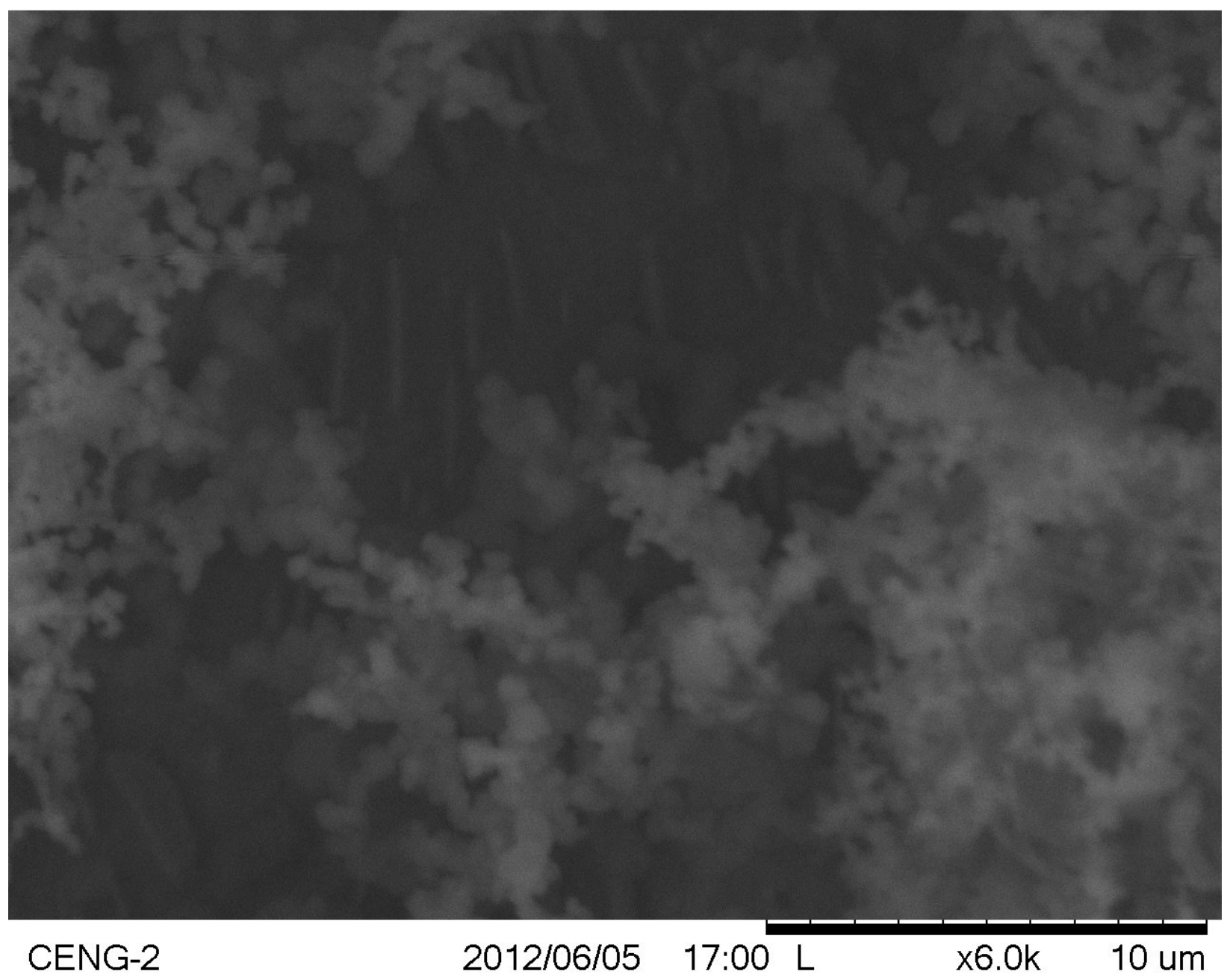

Figure 46 - AISI 1075 steel polished through $1 \mu \mathrm{m}$ diamond and longitudinally mounted

(Originally captured at 6000X, base metal of weld, exposed for $24 \mathrm{hrs}$.).

Another location on the exposed surface of the AISI 1075 steel sample was examined. In Figure 46, an SEM image of this region showed the base metal after biologically active water exposure. Although the sample was exposed for only 24 hours, there were bacterial attachment and biofilm development on the surface. Bacteria (planktonic cells) usually search for a surface with abundant nutrients to colonize on. Planktonic cells change to sessile cells once they find a surface to colonize on. The sessile cells develop into mixed and integrated microcolonies. The microcolonies' purpose is to optimize metabolism and increase efficiency of the community. An 
EPS matrix is produce by the microcolonies for structure and protection purpose. After the biofilm is formed, abundant nutrients from the surface will allow the biofilm to reach its mature state. The microcolonies will erupt from the substratum and form a mushroom like structure or a tubercle. The EPS matrix and the fluid filled channels will expand to compensate for the growth of the microcolonies. The fluid filled channels replenish the nutrients and remove waste from the microcolonies. The highly detailed gray region appeared to have mushroom like structure developed from the mature biofilms on the surface. The dark region appeared to have biofilm development.

Typical biofilms decrease in size and release planktonic cells when nutrients on the surface are depleted. Planktonic cells are released to search for a new surface with abundant nutrients. The planktonic cells will settle on a surface and become sessile once a nutrient abundant surface is found. They will then begin to establish biofilms. The detailed white lines in the dark regions appeared to be biofilms beginning to form mushroom like structures. Around the communities of microbes in the dark regions could also be EPS footprints. The top region in the image was near the HAZ. 


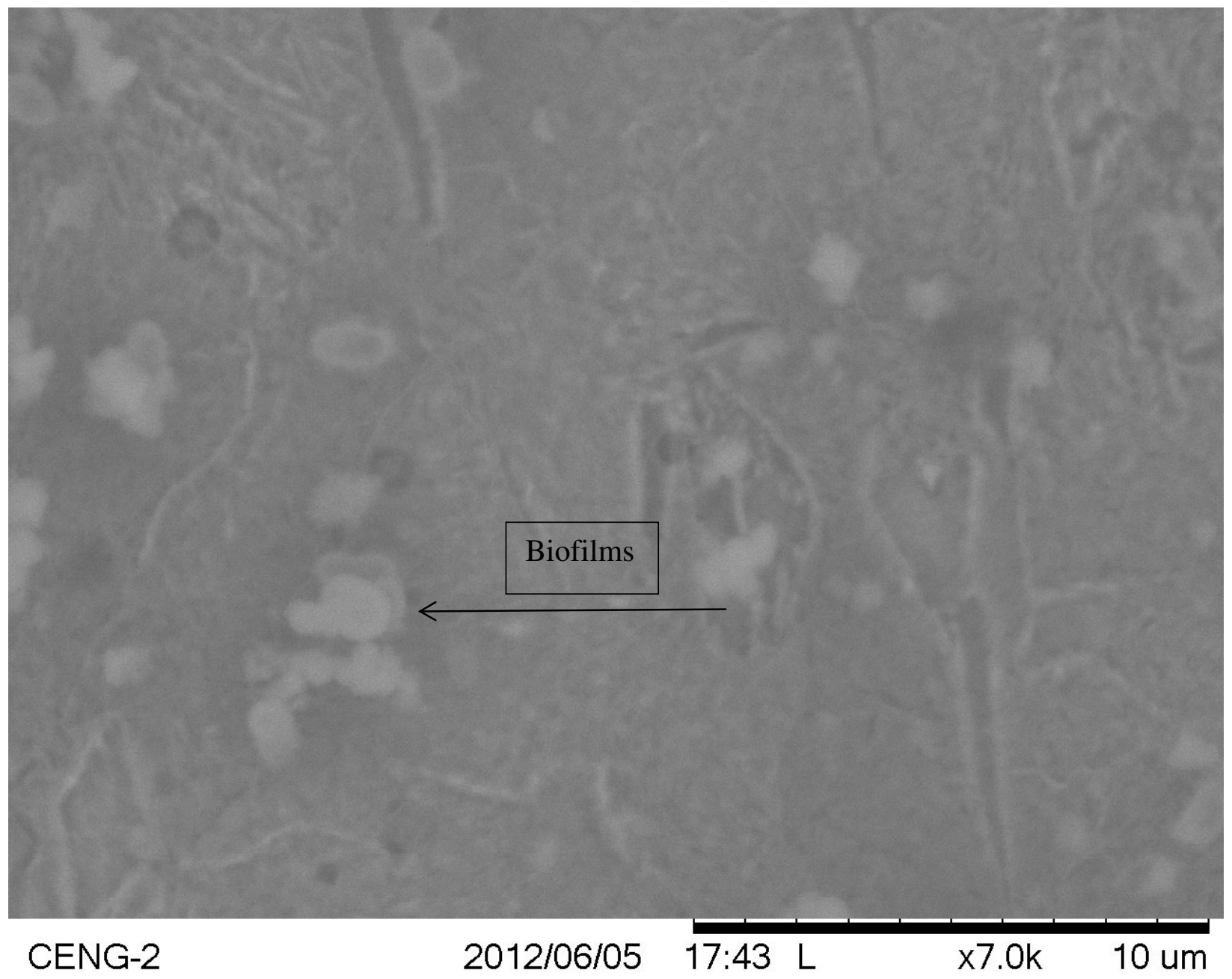

Figure 47 - AISI 1075 steel polished through $1 \mu \mathrm{m}$ diamond (Originally captured at 7000X, HAZ, exposed for 24 hrs.). Note a great reduction of microbial growth.

The HAZ on the exposed surface of the AISI 1075 steel sample was examined. In Figure 47, the SEM image showed a reduction of microbial growth on some locations on the surface. There are other locations where microbes flourished. The number of microbes on the surface is much lower than other location on AISI 1075 steel. Typically biofilm development initiates from planktonic cells searching for a surface with abundant nutrients. Once a suitable surface is found, planktonic cells become sessile cells and colonize on the surface. An EPS matrix is formed to surround and protect the community of microspecies from the outside environment. If 
there are still nutrients available on the surface after biofilm development, the biofilm will continue to proliferate to its mature state. It appeared that the surface of the HAZ region had a subsequent growth of microbes and a uniform film layer covering the surface. The dark regions on the surface could be EPS footprints. The highly feature white regions appeared to be biofilm growth. The biofilms were proliferating on the surface to reach its mature form.

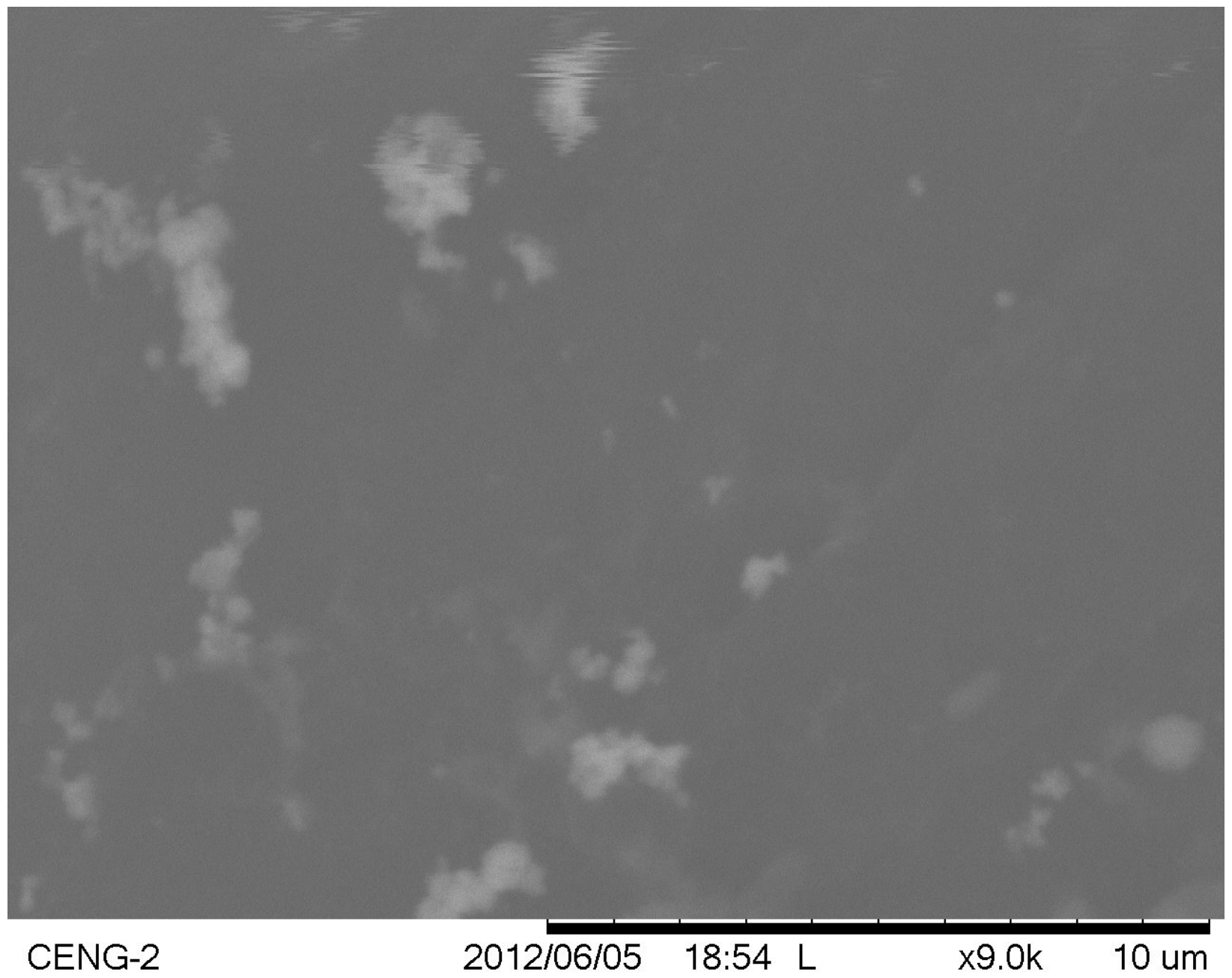

Figure 48 - Polystyrene exposed to bacteria for 9 days (Originally captured at 9000X). 
Polystyrene sample was cleaned and exposed to bacteria for 9 days. In Figure 48, the SEM image showed the surface of polystyrene that was originally magnified at $9000 \mathrm{X}$. The surface appeared to have some microbial attachment and growth. Typically biofilm development initiates from the spread of planktonic cells. Planktonic cells are released to colonize on a nutrient rich surface. Once the surface is found, the cells become sessile and form microcolonies. The microcolonies tend to be mixed and integrated in order to optimize metabolism and increase the efficiency of the community. An EPS matrix is formed to surround the microcolonies and protect them from the outside environment. The EPS matrix serves as a gate way for diffusion of particles. After the biofilm develops, if nutrients are still abundant on the surface the biofilm will increase in size until it reaches the mature state. The dark regions appeared to have microcolonies of bacteria attached on the surface. The microcolonies of bacteria could have formed a thin film layer that cover the surface as a typical biofilm does. The highly detailed white regions appeared to be biofilm growth. The surface of the highly detailed white regions could have abundant nutrients that allowed the biofilm to continue to grow.

Usually biofilm will decrease in size and release free floating cells (planktonic cells) when the surface is depleted of nutrients. The planktonic cells search for new locations with abundant nutrients to colonize on. The dark regions appeared to be in the same state as mention above. The nutrients on the dark surface could only be enough to support the planktonic cells to form biofilms on the surface without reaching the mature state. After forming biofilms, new planktonic cells were released again to colonize a new surface with abundant nutrients. The dark regions could have EPS footprints on them. 


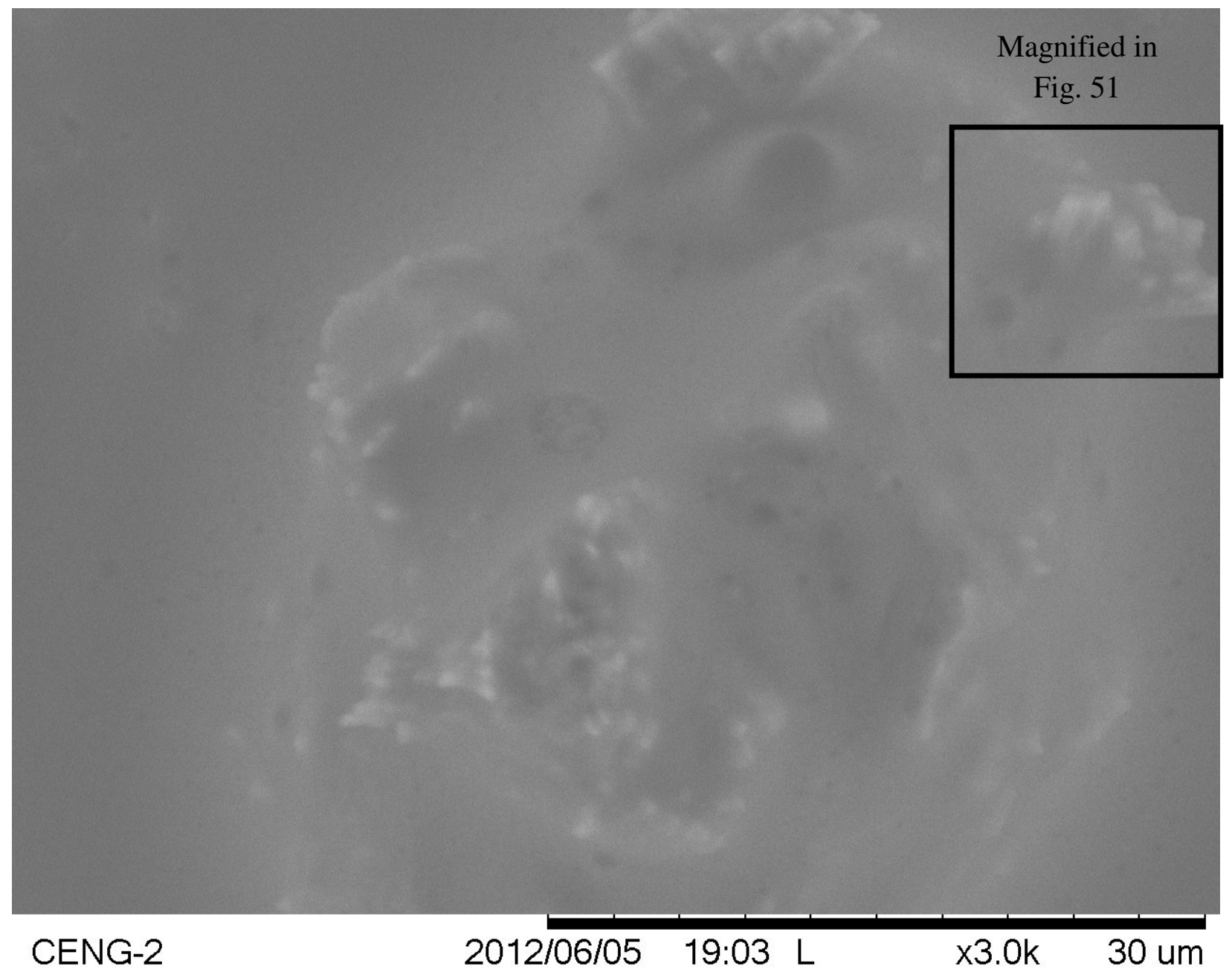

Figure 49 - Polystyrene exposed to bacteria for 9 days (Originally captured at 3000X). Note the cloudiness was indicative of microbial growth.

In Figure 49, the SEM image showed another location of the bacteria exposed to the polystyrene sample. The highly featured light gray region appeared to be a community of microbes. Typically biofilm development imitates from planktonic cells searching for a nutrient abundant surface to colonize on. The sessile cells settle on the surface and form microcolonies. The microcolonies are usually mixed and integrated to optimize the metabolism and the efficiency of the community. EPS matrix is formed to serve as structure and protection for the microcolonies. The biofilm continues to grow as the nutrients are still present on the surface. 
The biofilm will continue to grow and form a mushroom structure. The microcolonies of bacteria will continue to expand and push off from the substratum with the presence of nutrients. The EPS matrix and fluid filled channels inside the mushroom structure will continue to expand in order to compensate for the growth. The fluid filled channels expand to replenish nutrients and aid in waste removal. The highly featured light gray region appeared to be a mushroom structure from a mature biofilm. This location of the polystyrene could have more nutrients present on surface which allowed the biofilm to develop into mature state. The dark regions appeared to have community of microbes forming biofilms on the surface. 


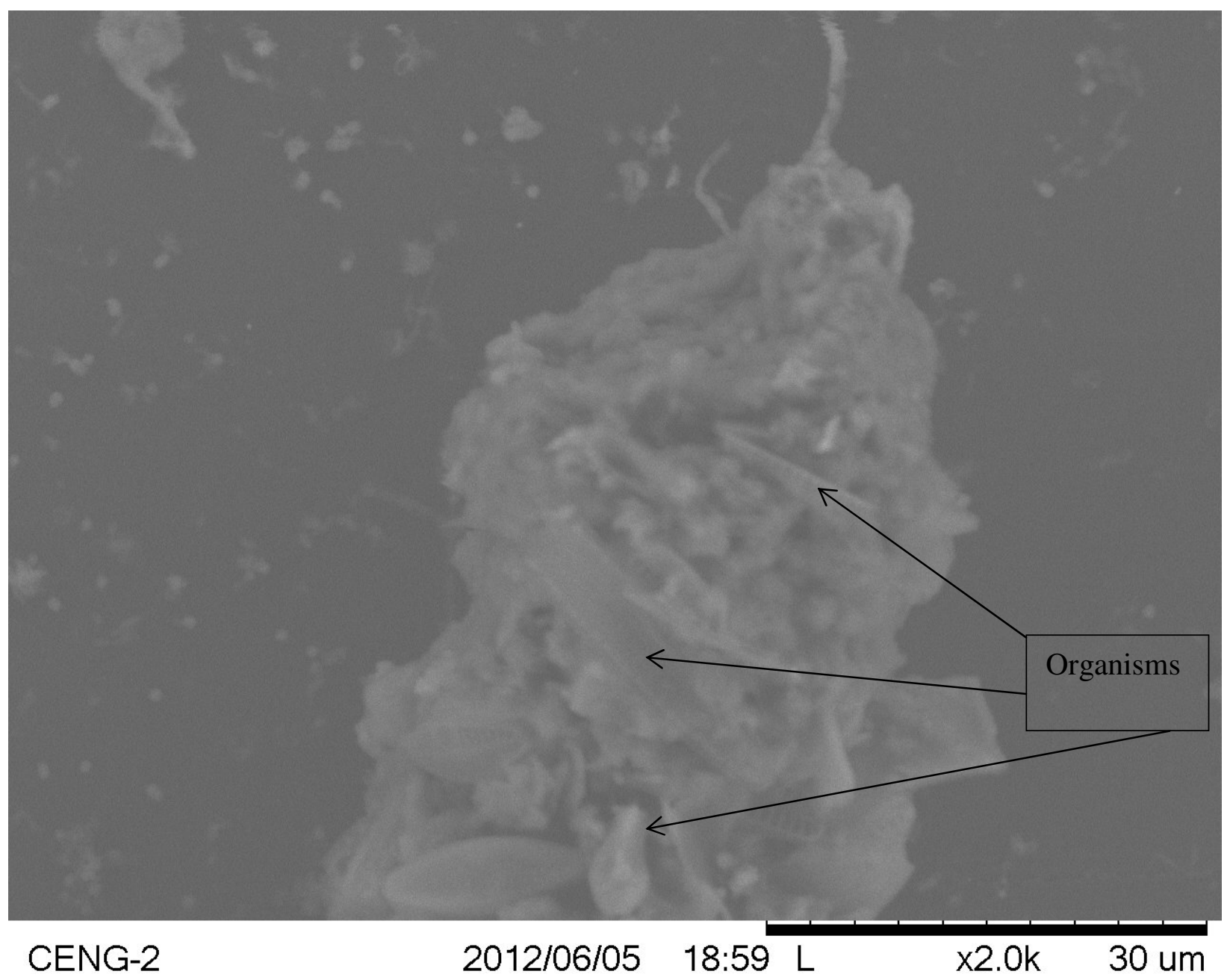

Figure 50 - Polystyrene exposed to bacteria for 9 days (Originally captured at 2000X). Note microbes are attaching to the surface of larger organisms.

Another location on the exposed surface of the polystyrene sample was examined. In Figure 50, the SEM image showed microbes attaching on the surface of organisms. The sample appeared to be covered by material fragments. In some locations the material appeared to accumulate in clumps. In other locations, the material appeared to form clots due to the fixing process. There were also organisms and bacteria evident on the surface. In the center of the image appeared to be a clot formed by a mixture of bacteria, organisms and material masses. 
The microbes appeared to be attached to the clot in the center of the image instead of the substratum of the surface. The dark region could be covered by a thin layer of film.

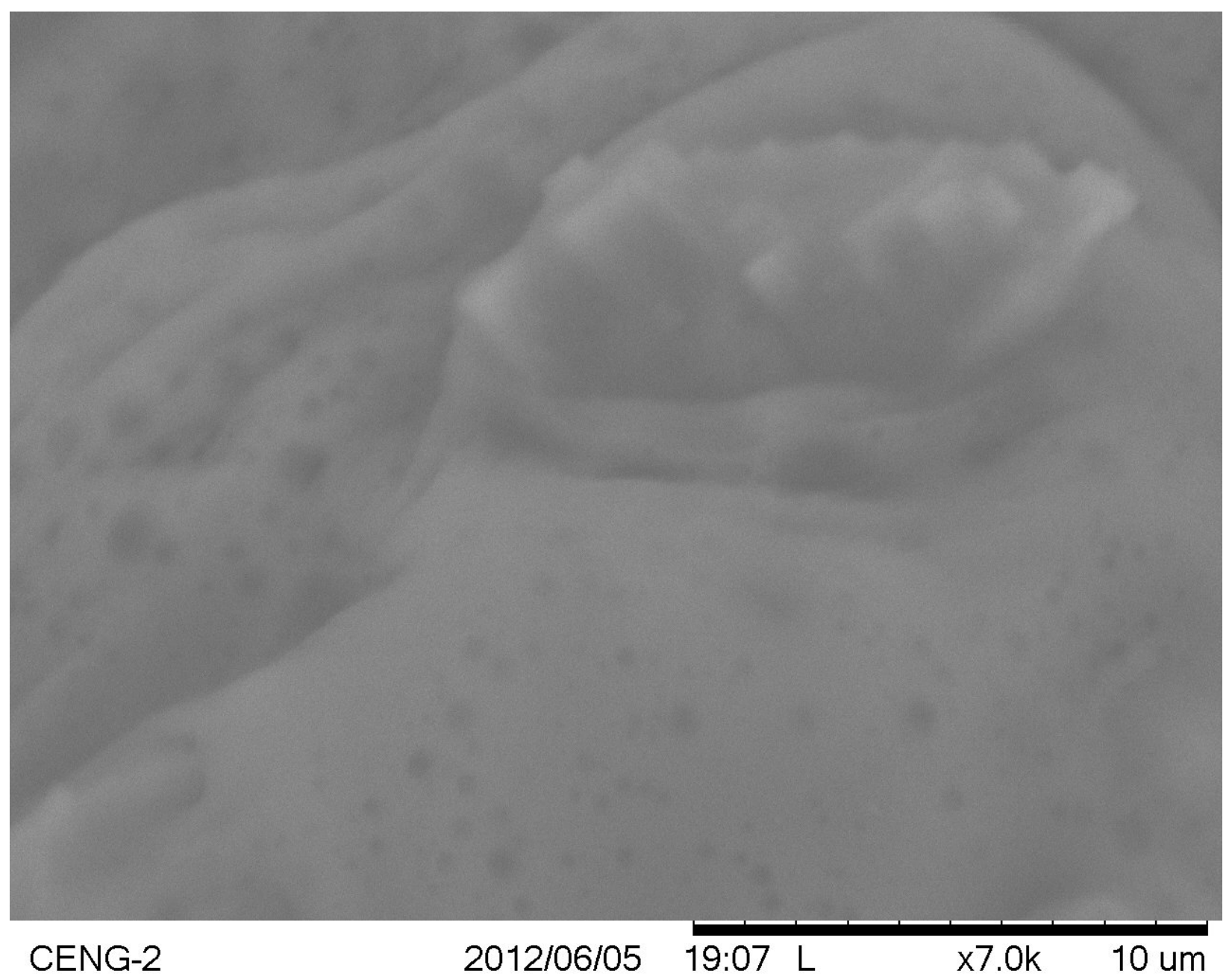

Figure 51 - Polystyrene exposed to bacteria for 9 days (Originally captured at 7000X).

Note this is an image of Figure 49 at a higher magnification that showed a typical mature biofilm that formed a mushroom like structure.

Figure 51 was a closed up image of Figure 41 that showed a clearer perspective of a typical mature biofilm development. Typically a mature biofilm is comprised of microcolonies of bacteria that form a mushroom like structure. The microcolonies are mixed and integrated in order to optimize metabolism and increase the cooperative efficiency of the community. As the 
mushroom like structure expands, the EPS matrix expands along with it. The EPS matrix not only serves as a structure purpose, it also protects and filters diffusing particles for the microcolonies. The fluid filled channels will extend in the mushroom structure to replenish the nutrients and aid in waste removal in order to keep up with the growth of the microcolonies. The highly featured gray region appeared to be a typical biofilm in its mature state. The mushroom like structure appeared to be well developed since it was exposed for 9 days. 


\section{CHAPTER FIVE}

\section{Conclusion}

The following conclusions can be made based on this study.

1. The bioreactor system was capable of supporting observable biofilm formation on exposed sample surfaces

2. The Scanning Electron Microscope (SEM) is a suitable system to image samples before and after exposure to biologically active fluids.

3. A static bioreactor system can be used to observe the effect of mechanically treated surfaces on bacterial attachment and growth, as well as thermomechanical treatments on bacterial attachment and growth.

4. Initial bacterial attachment at the surfaces appeared to be random. Not all locations developed at the same rate.

5. Microbial attachments varied on different surfaces. For the exposure periods studied, the steel samples were more heavily populated by microbes than the stainless steel samples. The polystyrene samples were the least populated surfaces.

6. The observed biofilms were not uniform, but varied as a function of location on the sample's surface. In each sample, particular locations were more populated than others.

7. The scale variation in the biofilm was similar to the scale of variations in the sample's microstructure.

8. The fixing procedure caused the EPS layers in the biofilm to contract. Regions of varied thickness were evident. In several cases, development of tubercles was evident. 
9. Film development on polystyrene surfaces appeared to be much slower than development on metallic surfaces.

10. Microbial growths were able to form a uniform layer of film to cover the surface of HAZ in steel 1075. 


\section{CHAPTER SIX}

\section{Future Work}

Based on the results of this study, the following efforts would produce valuable results.

1. Developing the ability to map and store the locations of individual microstructural features at the sample's surface.

2. Developing the ability to map and store locations of microbial activity in the growing and fully evolved biofilm.

3. Correlating bacteria attachment to the underlying microstructure on a feature by feature basis.

4. Developing a statistically based characterization of the sample's surface prior to exposure.

5. Developing a statistically based characterization of the populated surface after exposure to biologically active solutions.

6. Correlating bacterial attachment to the underlying microstructure on a wholistic statistical basis.

7. Systematically vary surface characteristics and correlate this to microbial growth.

8. Systematically vary thermomechanical treatments and correlate this to microbial growth.

9. Systematically vary material chemistry, particularly at the surface, and correlate this to microbial growth.

10. Correlate various stages in film development.

11. Determine the effects of bacterial development on rates and locations of corrosion.

12. Examine the effect of different exposure time on bacterial growth. 
13. Develop a procedure to observe bacterial growth at different exposure times on an individual sample, rather than fixing similar samples that are held at different exposure times.

14. Develop a new dynamic bioreactor system that is more capable of simulating natural systems. (See Chapter Seven). 


\section{CHAPTER SEVEN}

\section{Future Directions}

The next step is to understand the growth status of biofilm formation on the surface of different materials. Although a static bioreactor promotes bacterial attachments on the surface of materials, a dynamic bioreactor system will increase the exposure rate of bacteria which may enhance bacterial attachments on different materials' surface. The current static bioreactor could be modified to a dynamic bioreactor system by adding a closed loop. The dynamic bioreactor (Figure 52) will be composed of a glass jar that has the shape of a cylinder. The lid has two through holes that allow the attachment of an inflow and out flow tube of the closed loop system. Bakelite mounted samples are attached to the lid of the jar by a Mylar string (fishing line). The Mylar string keeps the Bakelite mounted sample from touching other surfaces. The lid is sealed off with parafilms to maintain an anaerobic environment in the bioreactor system (Figure 52). A magnetic stir bar is added in the jar to maintain a turbulent flow. A magnetic hot plate is used to control the speed of the magnetic stir bar and the temperature in the jar. The medium is held in one carboy container (capacity of 4 liter). A T - connector is used to connect the outflow with the medium which allows the pump to send the fluid into the jar. Because this bioreactor system is a closed loop, there is no need to collect waste water. Valves will be installed near the upstream and downstream of the jar to allow easy detachments of the tubes from the bioreactor. This bioreactor system increases the exposure of bacteria to the samples. By increasing the bacteria exposure rate, there's a higher chance for bacterial attachments to occur on the surface of the samples (Figure 52). 


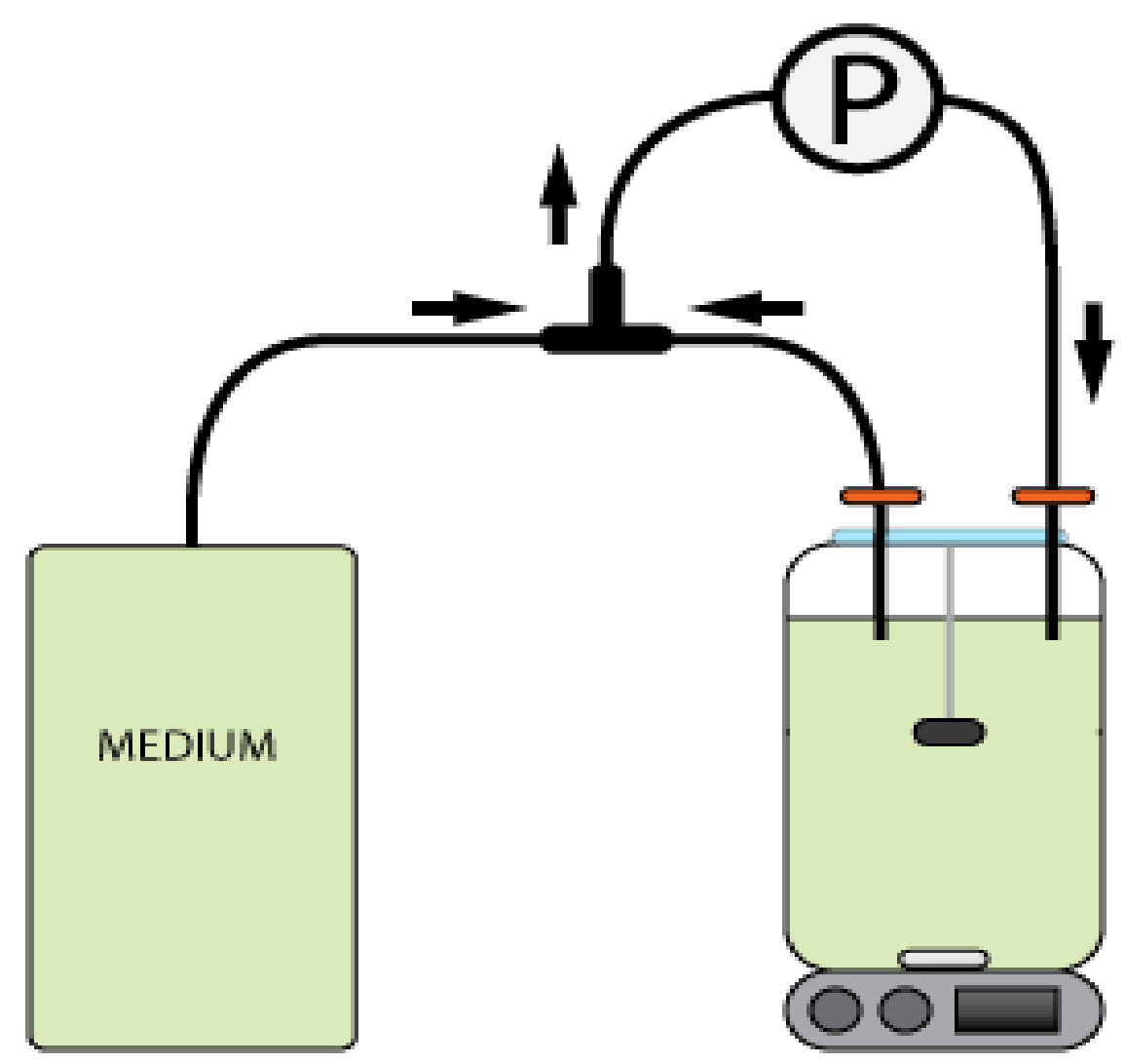

Figure 52 - Close loop bioreactor.

In the future, biofilm attachment on a surface could be observed in greater detail with a bioreactor that doesn't require fixation. The capillary biofilm system used by Werner and her colleagues, allows the viewing of live bacteria attachment on surfaces of materials (Figure 53) (Werner et al., 2004). In this capillary bioreactor system, the glass capillaries allow the observation of bacterial growth under a microscope without fixation. The biofilm can be kept in a live state as it is developing. 


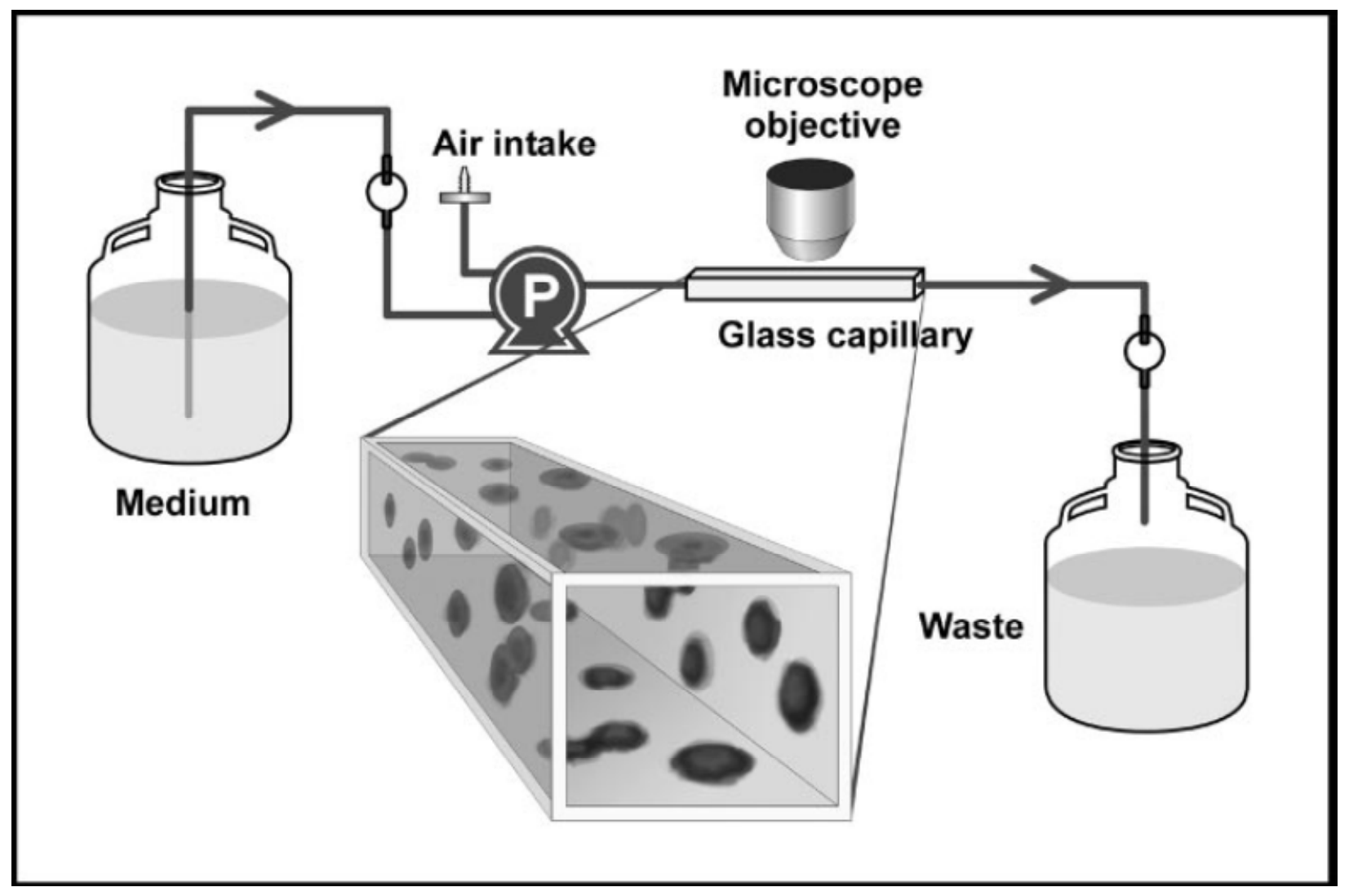

Figure 53 - Continuous flow bioreactor (Werner et al., 2004).

The biofilms in Werner's research were grown in a glass capillary tube under a continuous condition. The capillary tubes have square cross-sections which allowed biofilms to grow on the flat tube walls (Werner et al., 2004). The flat tube walls allowed direct microscope observation on biofilm formation. A flow cell holder was needed to protect the fragile capillary tubes.

The bioreactor system was composed of two medium carboys (capacity of 4 liters), a flow break valve, a filtered air entry unit, a peristaltic pump, a flow cell holder, capillary tubes, and an inoculation port. Only the carboy that holds the medium was vented (Werner et al., 2004). The bioreactor system was connected by plastic tubing. The T-connector upstream of the capillary tube allowed the mixture of air and the medium. The medium was pumped through the capillary tube by a peristaltic pump (Werner et al., 2004). 
This bioreactor system simulates a partially aerobic environment for bacterial growth in a capillary tube. Consortia biofilm consisted of multiple species living in one niche. The aerobic species on the upper layer of the slime consumed the oxygen while the anaerobic species on the bottom layer were shielded from the oxygen (Werner et al., 2004). This bioreactor system also allowed easy access in changing capillary tubes which decreases the time needed to view multiple biofilms by skipping extra steps in preparing bacteria for fixation. The downstream and upstream capillary tubes have to be clamped in order to examine the biofilm growth (Werner et al., 2004). Before clamping, the capillary tube was fully filled with media which supplied the biofilm with nutrient. This bioreactor system was autoclave for sterilization (Werner et al., 2004).

Although this system allowed direct microscope view in a timely fashion, the bioreactor can be modified further to analyze the attachment of bacteria to different surfaces. The system can remain as a continuous flow system since the capillary tube is in micrometers (Werner et al., 2004). Because a carboy can hold about one gallon of liquid of media, it is enough for the biofilms to grow significantly in the capillary tube (Werner et al., 2004).

The bioreactor system can be further simplified to incorporate metal pieces as part of the bioreactor. Because the capillary tube is measured in micrometers, it is too small to place sample metal coupons inside the tube (Werner et al., 2004). The new modified capillary tube can be composed of the sample material and a cover slip. A channel would be created through etching on the surface of the material. The surface of the channel could be altered through different polishing techniques. The capillary tube would be sealed off with a cover slip (Werner et al., 2004). A flow cell holder is no longer needed because the new capillary tube has a higher resistance to breakage. The bioreactor system would have tubes attaching to both ends to receive 
the medium and release waste (Werner et al., 2004). Valves would be installed on both ends of the capillary tube to allow easy disassembly and to control the media flow through the bioreactor (Werner et al., 2004).

This bioreactor could be easily dissembled for sterilization. The capillary tube, silicone tubes, and medium could be sterilized by autoclave (Werner et al., 2004). The pulsatile pump could be replaced by a single direction flow pump. Instead of only allowing air though the port, the port would be open for gas intake instead. This modified bioreactor would allow live view of bacterial growth on the surface of materials (Werner et al., 2004). The live bacterial growth could be observed under direct microscope without fixing the biofilm on the material. The bacteria exposure time could be taken at any time without disturbing the biofilm growth. This bioreactor system also minimizes the chances of contamination (Werner et al., 2004). 


\section{REFERENCES}

Abarzua, S., \& Jakubowski, S. (1995). Biotechnological investigation for the prevention of biofouling 1. Biological and biochemical principles for the prevention of biofouling. Mar Ecol Prog Ser, 123, 301-312.

Adams Jr., V. A., C. S., Parvizi, J., Davidson, H. M., Composto, R. J., Freeman, T. A., \& Hickok, N. J. (2008). The inhibition of staphylococcus epidermidis biofilm formation by Vancomycin-modified titanium alloy and implications for the treatment of periprosthetic infection. Biomaterials, 29.35, 4684-4690.

An, Y. H., \& Friedman, R. J. (1998). Concise review of mechanisms of bacterial adhesion to biomaterial surfaces. J Biomed Mater Res, 43, 338-348.

Andrews, J. (2012, December 12, 2012). Kansas City Star finishes probing series on U.S. beef industry discusses tenderization risks, antibiotics in livestock. Food Safety News.

Baier, R. E., Shafrin, E. G., \& Zisman, W. A. (1968). Adhesion: Mechanisms that assist or impede it. Science, 162, 1360-1368.

Bayles, K. W., Wesson, C. A., Liou, L. E., Fox, L. K., Bohach, G. A., \& Trumble, W. R. (1998). Intracellular staphylococcus aureus escapes the endosome and induces apoptosis in epithelial cells. Infect Immun, 66(1), 336-342.

Berntsson, K. M. (2001). Larval behaviour of the barnacle Balanus improvisus with implications for recruitment and biofouling control. PhD thesis, Dept. Marine Ecology, Göteborg University.

Berntsson, K. M., \& Jonsson, P. R. (2003). Temporal and spatial patterns in recruitment and succession of a temperate marine fouling assemblage: A comparison of static panels and boat hulls during the boating season. Biofouling, 19, 187-195.

Berntsson, K. M., Jonsson, P. R., Lejhall, M., \& Gatenholm, P. (2000). Analysis of behavioural rejection of micro-textured surfaces and implications for recruitment by the barnacle Balanus improvisus. J Exp Mar Biol Ecol, 251, 59-83. 
Bers, A. V., \& Wahl, M. (2004). The influence of natural surface micro topographies on fouling. Biofouling, 20(1), 43-51.

Blecua, P., Lipowsky, R., \& Kierfeld, J. (2006). Line tension effects for liquid droplets on circular surface domains. Langmuir, 22(26), 18. doi: 10.1021/la0609773

Bohringer, K. F. (2003). Surface modification and modulation in microstructures: Controlling protein adsorption, monolayer desorption and micro-self-assembly. J Microtech Microeng, 13, S1-S10.

Bottemiller, H. (2012, May 3, 2012). USDA to trace beef contaminated with E. Coli back to source. Food Safety News.

Brady, R. F. (2003). Antifouling coatings without organotin. J Protect Coat Linings, 20(1), 33-37.

Brennan, A. B., Baney, R. H., Carman, M. L., Estes, T. G., Feinberg, A. W., Wilson, L. H., \& Schumacher, J. F. (2005). Surface topography for non-toxic bioadhesion control. USA Patent 20060219143.

Callow, M. E., Callow, J. A., Pickett-Heaps, J. D., \& Wetherbee, R. (1997). Primary adhesion of Enteromorpha propagules: Quantitative settlement studies in video microscopy. J Phycol, 33, 938-947.

Callow, M. E., \& Fletcher, R. L. (1994). The influence of low surface energy materials on bioadhesion: A review. Int Biodeterior Biodegradation, 34, 333-343.

Callow, M. E., Jennings, A. R., Brennan, A. B., Seegert, C. E., Gibson, A., Wilson, L., \&. Callow, J. A. (2002). Micro topographic cues for settlement of zoospores of the green fouling alga Enteromorpha. Biofouling, 18, 229-236.

Carman, M. L., Estes, T. G., Feinberg, A. W., Schumacher, J. F., Wilkerson, W., Wilson, L. H., \& Brennan, A. B. (2006). Engineered antifouling microtopographies - correlating wettability with cell attachment. Biofouling, 22: 11-21.

Clegg, S., \& Gerlach, G. F. (1987). Enterobacterial fimbriae. J Bacteriol, 169, 934-938. 
Costerton, J. W. (2007). The biofilm primer. Berlin: Springer.

Daifuku, R., \& Stamm, W. E. (1986). Bacterial adherence to bladder uroepithelial cells in catheterassociated urinary tract infection. N Engl J Med, 314, 1208-1213.

Dobretsov, S. (2008). Inhibition and induction of marine biofouling by biofilms. Springer Series on Biofilms, 1-21.

Garibaldi, R. A., Burke, J. P., Britt, M. R., Miller, W. A., \& Smith, C. B. (1980). Meatal colonization and catheter-associated bacteriuria. $N$ Engl J Med, 303, 316-318.

Gerbig, Y. B., Phani, A. R., \& Haefke, H. (2005). Influence of nanoscale topography on the hydrophobicity of fluoro-based polymer thin films. Appl Surf Sci, 242, 251-255.

Griesser, H. J., Hartley, P. G., McArthur, S. L., McLean, K. M., Meagher, L., \& Thissen, H. (2002). Interfacial properties and protein resistance of nano-scale polysaccharide coatings. Smart Mater Struct, 11, 652-661.

Hartstein, A. I., Garber, S. B., Ward, T. T., Jones, S. R., \& Morthland, V. H. (1981). Nosocomial urinary tract infection: A prospective evaluation of 108 catheterized patients. Infect Control, 2, 380-386.

Hashmi, S., Kelly, E., Rogers, S. O., \& Gates, J. (2003). Urinary tract infection in surgical patients. Am J Surg, 186, 53-56.

Hoipkemeier-Wilson, L., Schumacher, J. F., Carman, M. L., Feinberg, A. W., Callow, M. E., Finlay, J. A., \& Gibson, A. L. (2004). Antifouling potential of lubricious, microengineered, PDMS elastomers against zoospores of the green fouling alga ulva (Enteromorpha). Biofouling, 20(1), 53-63.

Jones, B. V., Young, R., Mahenthiralingam, E., \& Stickler, D. J. (2004). Ultrastructure of Proteus mirabilis swarmer cell rafts and role of swarming in catheter-associated urinary tract infection. Infect Immun, 72, 3941-3950.

Kean, T., \& Thanou, M. (2010). Biodegradation, biodistribution and toxicity of chitosan. Advanced Drug Delivery Reviews, 62.1, 3-11. 
Kovalak, W. P., Longton, G. D., \& Smithee, R. D. (1990). Infestation of power plant water systems by the zebra mussel (Dreissena polymorph). Proceedings of the American Power Conference, 52, 998-1000.

Kumar, M. N. V. R. (2000). A review of chitin and chitosan applications. Elsevier Science, $46,27$.

Leranoz, S., Orus, P., Berlanga, M., Dalet, F., \& Vinas, M. (1997). New fimbrial adhesins of Serratia marcescens isolated from urinary tract infections: Description properties. $J$ Urol, 157, 694-698.

Lewandowski, Z., \& Beyenal, H. (2008). Mechanisms of microbially influenced corrosion. Springer Series on Biofilms, 1-30.

Li, X., Johnson, D. E., \& Mobley, H. L. T. (1999). Requirement of MrpH for mannoseresistant Proteus-like fimbria-mediated hemagglutination by Proteus mirabilis. Infect Immun, 67, 2822-2833.

Martinez, L. R., Mihu, M. R., Han, G., Frases, S., Cordero, R. J. B., Casadevall, A., \& Nosanchuk, J. D. (2009). The use of chitosan to damage cryptococcus neoformans biofilms. Biomaterials, 31.8, 669-679.

Moody, L. F., \& Princeton, N. J. (1944). Friction factors for pipe flow. Transactions of the A.S.M.E., 66(8), 13.

Morra, M., \& Cassinelli, C. (1997). Bacterial adhesion to polymer surfaces: A critical review of surface thermodynamic approaches. J Biomat Sci Polymer Ed, 9, 55-74.

Murthy, P. S., \& Venkatesan, R. (2008). Industrial Biofilms and their control. Springer Series on Biofilms 1-37.

Nedved, B. T., \& Hadfield, M. G. (2009). Hydroides elegans (Annelida: Polychaeta): A model for biofouling research. Springer Ser Biofilms. Marine and Industrial Biofouling. doi: 10.1007/7142_2008_15

O’May, G. A., Jacobsen, S. M., Stickler, D. J., Mobley, H. L. T., \& Shirtliff, M. E. (2008).

Complicated urinary tract infections due to catheters. Springer Series on Biofilms, 1-43. 
O’Toole, G., Kaplan, H. B., \& Kolter, R. (2000). Biofilm formation as microbial development. Annual Reviews, 54, 49-79. doi: 0066-4227/00/1001-0049\$14.00

Old, D. C., Adegbola, R., \& Scott, S. S. (1983). Multiple fimbrial haemagglutinins in Serratia species. Med Microbiol Immunol, 173, 107-115.

Orgaz, B., Lobete, M. M., Puga, C. H., \& Jose, C. S. (2011). Effectiveness of chitosan against mature biofilms formed by food related bacteria. International Journal of Molecular Sciences, 12, 817-828.

Peng, Z.-X., Tu, B., Shen, Y., Du, L., Wang, L., Guo, S.-R., \& Tang, T.-T. (2011). Quaternized chitosan inhibits IcaA transcription and biofilm formation by staphylococcus on a titanium surface. Antimicrobial Agents and Chemotherapy, 55.2, 860-866.

Poulsen, L. V. (1999). Microbial biofilm in food processing. Lebensmittel-Wissenschaft undTechnologie, 32(6), 321-326.

Romeo, T. (2010). Bacterial Biofilms. Berlin: Springer.

Saint, S. (2000). Clinical and economic consequences of nosocomial catheter-related bacteriuria. Am J Infect Control, 28, 68-75.

Satran, J. (2012, December 12, 2012). Beef investigation by Kansas City star uncovers serious risks, including fecal contamination. The Huffington Post.

Scardino, A., Nys, R. D., Ison, O., O'Connor, W., \& Steinberg, P. (2003). Microtopography and antifouling properties on the shell surface of the bivalve mollusks. Mytilus galloprovincialis and Pictada imbriticata. Biofouling, 19, 221-230.

Schembri, M. A., Blom, J., Krogfelt, K. A., \& Klemm, P. (2005). Capsule and fimbria interaction in Klebsiella pneumoniae. Infect Immun, 73, 4626-4633.

Stamm, W. E. (1991). Catheter-associated urinary tract infections: Epidemiology, pathogenesis, and prevention. Am J Med, 91, 65S-71S. 
Stamm, W. E., \& Hooton, T. M. (1993). Management of urinary tract infections in adults. $N$ Engl J Med, 329, 1328-1334.

Stickler, D., Morris, N., Moreno, M.-C., \& Sabbuba, N. (1998a). Studies on the formation of crystalline bacterial biofilms on urethral catheters. Eur J Clin Microbiol Infect Dis, 17, 649-652.

Stickler, D. J., Morris, N. S., Mclean, R. J. C., \& Fuqua, C. (1998b). Biofilms on indwelling urethral catheters produce quorum-sensing signal molecules in situ and in vitro. Appl Environ Microbiol, 64, 3486-3490.

Tambyah, P. A., \& Maki., D. G. (2000). Catheter-associated urinary tract infection is rarely symptomatic: A prospective study of 1,497 catheterized patients. Arch Intern Med, 160, 678-682.

Tan, Y., Han, F., Ma, S., \& Yu, W. (2011). Carboxymethyl chitosan prevents formation of broad-spectrum biofilm. Carbohydrate Polymers, 84.4, 1365-1370.

Tang, H., Zhang, P., Kieft, T. L., Ryan, S. J., Baker, S. M., Wiesmann, W. P., \& Rogelj, S. (2010). Antibacterial action of a novel functionalized chitosan-arginine against gramnegative bacteria. Acta Biomaterialia, 6, 2562-2571.

Temenoff, J. S., \& Mikos, A. G. (2008). Biomaterials: The intersection of biology and materials science. Upper Saddle River, NJ: Pearson/Prentice Hall.

vanLoosdrecht, M. C. M., Norde, W., Lyklema, J., \& Zehnder, A. J. B. (1990). Hydrophobic and electrostatic parameters in bacterial adhesion. Aquat Sci, 52, 103-113.

Venkatesan, R., \& Murthy, P. S. (2008). Macrofouling control in power plants. Springer Series on Biofilms, 1-27.

Vladkova, T. (2008). Surface modification approach to control biofouling. Springer Series on Biofilms, 1-29. doi: 10.1007/7142_2008_22

Warren, J. W. (1997). Catheter-associated urinary tract infections. Infect Dis Clin North Am, $11,609-622$. 
Werner, E., Roe, F., Bugnicourt, A., Franklin, M. J., Heydorn, A., Molin, S., \& Stewart, P. S. (2004). Stratified growth in pseudomonas aeruginosa biofilms. Applied and Environmental Microbiology, 70(10), 6188-6196. doi: 10.1128/AEM.70.10.61886196.2004

Wilson, M., \& Devine, D. (2003). Medical implications of biofilms. Cambridge, UK: Cambridge UP.

Yamamoto, T., Ariyoshi, A., \& Amako, K. (1985). Fimbria-mediated adherence of Serratia marcescens strain US5 to human urinary bladder surface. Microbiol Immunol, 29(677681). 


\section{APPENDIX A}

\section{List of Materials Used}

Table 4 - List of Materials Used In This Thesis

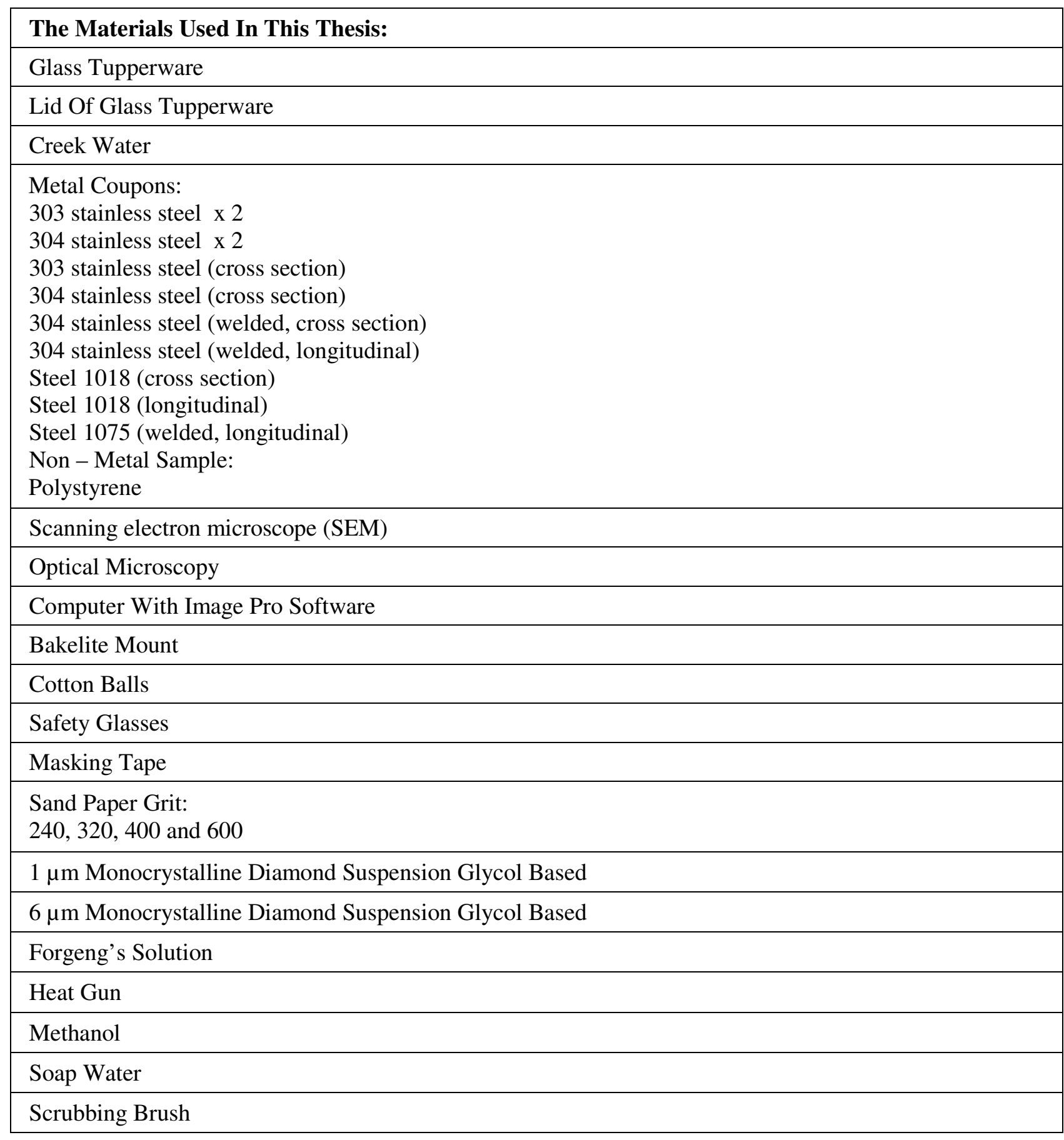

\section{APPENDIX B}




\section{Fixing Microbe Procedure}

Proper ventilation is needed during the fixation process.

1. Only pure solutions are used in the fixation procedure and are contained in disinfected glassware.

The solutions used in this lab are:
I. Glutaraldehyde
$200 \mathrm{~mL}$
II. Pure Ethanol
$200 \mathrm{~mL}$
III. Pure TF Freon Solvent $200 \mathrm{~mL}$

2. Tongs are used to carefully remove the metal coupons from the beaker. The materials are carefully gripped from the side to avoid touching the bacterial attached surface. In the procedure, only one sample is submerged at a time in each solution.

3. The sample is submerged in glutaraldehyde for about 3 minutes

4. The sample is removed from glutaraldehyde and submerged in pure ethanol for about 3 minutes

5. The sample is removed from formaldehyde and submerged in pure TF Freon solvent for about 1:30 minutes

6. The sample is removed from the pure TF Freon Solvent and placed on a clean covered surface to avoid contamination.

The next procedure is to analyze the sample under the scanning electron microscopy. For storage, the samples are placed in separate containers to keep them from touching and covered to prevent detachment of bacteria. 


\section{APPENDIX C \\ Scanning Electron Microscope (SEM) Procedures}

1. Secure the sample with double sided tape on the stage

2. Center the sample in the machine with the adjuster on the left of the stage

3. Ensure the sample is $1 \mathrm{~mm}$ below from the top of the machine's opening

4. Close the door

5. Power on the SEM

6. Turn on the program call "Hitachi TM 1000" in the computer

7. Turn on the exchange button to create vacuum in the SEM

8. Ensure the machine's light switches from air to ready

9. Click "start" on the program

10. There are two knobs that shift the stage:

A. The knob on the left shifts the stage right and left

B. The knob on the right shifts the stage up and down

11. The program is exited

12. Turn off the exchange button

13. Turn off the machine's power

14. Open the chamber door

15. Take out the sample from the stage

16. Cover the sample with cotton and wrap masking tape to preserve it. 


\section{APPENDIX D \\ Protocols and Experimental Procedures}

\section{Bakelite Mount Procedures:}

1. Ensure Buehler Simplimet II is working properly

2. Turn on heater and place on mold top

3. Set timer for 15 to 20 minutes

4. Ensure the pressure valve is closed by turning the knob clockwise

5. Unscrew mold top

6. Raise ramp to the top of the cavity mold

a. Raise the ramp by pumping the right handle

7. Place one sample at a time in the center of mounting stage

8. Open pressure to lower the mounting stage 3 inches down and close the pressure valve

9. Add one level scoop of black Buehler powder into the mold cavity

10. Screw mold top back on

11. The temperature is held at $4200 \mathrm{psi}$ and held for a minute

12. The pressure valve is slightly open and closed

13. The top assembly is tapped by a rubber mallet

14. The temperature is held at 4200 psi for 8 minutes

15. Removed heater and replace with cooling cylinder for 2 minutes

16. The cooling cylinder is then replaced with the heater

17. The pressure valve is slowly opened to release pressure and closed again

18. Unscrew the top mold with glove

19. Eject sample by pumping ramp

20. Tap the intersection of Bakelite and stage with mallet

21. Tap the Bakelite mount gently to rid the surface of flakes

22. Etch the name of the sample on the back of the Bakelite mount 


\section{Characterizing Metals Procedure:}

1. Turn on Kalamazoo belt grinder

2. Sand down the edges of the Bakelite mount

a. Slightly rotate the Bakelite mount in a circular motion

3. Sand the sample from a low to high grit sand paper $(240,320,400$ and 600)
a. Turn on water while sanding
b. Sand top surface of sample in a one way direction
c. Repeat the sand on the same grit from 10 to 50 times
d. Rinse sample with water
e. The procedure from a to $\mathrm{d}$ is repeated for every different grit paper

\section{Polishing Procedure:}

\section{Cleaning}

1. Add soap water to sample

2. Clean sample with brush

3. Add ethanol to the sample

4. Dry the sample with a dryer 


\section{Microns Polish}

1. Clean the sample

2. Add a diamond drop of $6 \mu \mathrm{m}$ monocrystalline diamond suspension glycol based in the cloth wheel

3. Rotate the sample counterclockwise on the wheel

4. Hold the sample on the wheel for a count of 5

5. Clean the sample

6. Look at the sample with the naked eye for scratches or smudges

7. If scratches or smudges exist, repeat step 1 to 6 until the sample looks smooth

8. The sample is ready to move on to 1 micron polishing

\section{$\underline{1 \text { Micron Polish }}$}

1. Clean the sample

2. Add a diamond drop of $1 \mu \mathrm{m}$ monocrystalline diamond suspension glycol based in the cloth wheel

3. Rotate the sample counterclockwise on the wheel

4. Hold the sample on the wheel for a count of 5

5. Clean the sample

6. Look at the sample with the naked eye for scratches or smudges

7. If scratches or smudges exist, repeat step 1 to 6 until the sample looks smooth

8. The sample is ready to view under a microscope 


\section{Optical Microscope procedure:}

\section{Mounting Press}

1. Ensure that a flat steel sheet is clean on both sides

2. Place clay on one side of the metal plate

3. Place sample on the clay

4. Place the sample in the mounting press

5. Push the button on the mounting press to set the sample flat on metal plate

\section{Examining Through Microscope}

1. Open image pro

2. Click acquire

3. Click video digital capture

4. Click evolution

5. Click preview

6. Adjust the fine course knob

7. Adjust control stage knobs

8. Make sure the lens is not contacting the sample

* Note: always adjust the lens from low to high power to ensure the lens and the sample does not make contact.

9. Click snap to take a picture

10. Click wrench icon to add measurement bar

11. Click active spatial calibrate

12. Select scope

13. Select marker white color

14. Click the disk image to save the image 


\section{APPENDIX E}

\section{Etching Procedures}

\section{Etching Procedure for Stainless Steel}

1. Fill a beaker with $10 \%$ oxalic acid

2. Place beaker under the stand of the clamp

3. Lower the metal stick from clamp until it contacts the sample

4. Put sample on metal holder

5. Lower the metal holder with the sample into the beaker

6. Connect the positive charge to the metal stick

7. Connect the negative charge to metal holder

8. Turn on the BUEHLER Electromet III

9. Set the etching knob to 16

10. Set power source to 5

11. Let the sample bubble for 60 seconds

12. Take the sample out for cleaning

\section{Etching Procedure for Steel}

1. Fill a petri dish halfway with the solution ( $2 \mathrm{~mL}$ of $\mathrm{NHO}_{3}$ and $98 \mathrm{~mL}$ of Methanol )

2. Dip cotton in petri dish

3. Lightly wipe the cotton over the metal sample

4. Clean the sample 


\section{APPENDIX F}

\section{Mounting Directions}

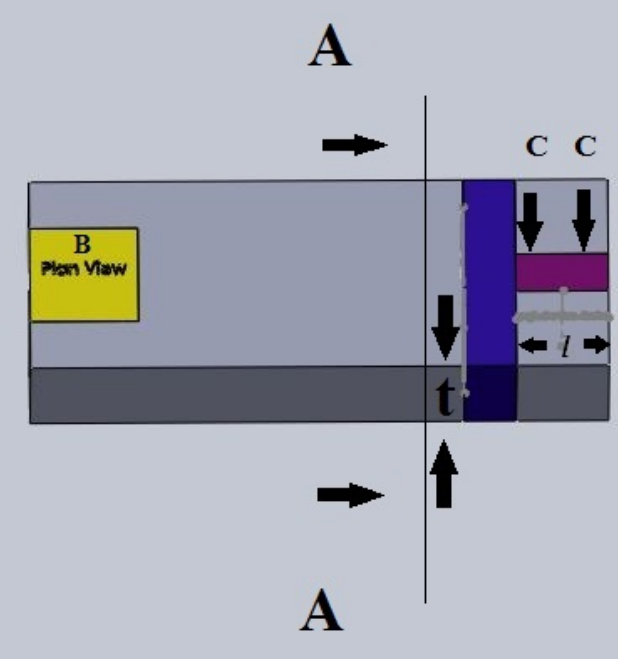

$$
\begin{array}{r}
\text { B - Plan View } \\
\text { ( || to roll ) }
\end{array}
$$

AA - Transverse Cross-Section ( $\perp$ to roll)

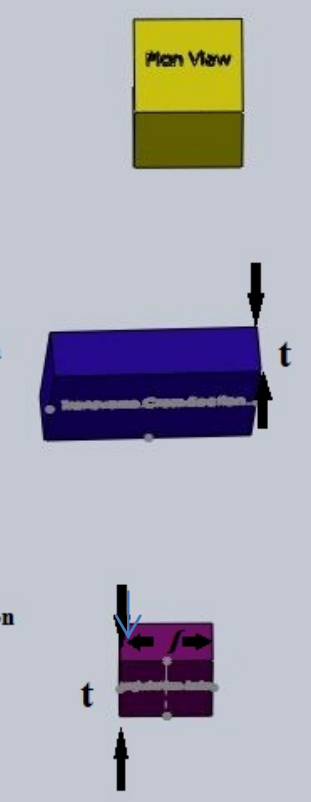

Figure 54 - Diagram of Sample Mounting Directions. 